\title{
Improved velocity data in circular jets using an avalanche photodiode-based 2-component point Doppler velocimeter
}

\author{
Thomas Trent Scarberry \\ West Virginia University
}

Follow this and additional works at: https://researchrepository.wvu.edu/etd

\section{Recommended Citation}

Scarberry, Thomas Trent, "Improved velocity data in circular jets using an avalanche photodiode-based 2-component point Doppler velocimeter" (2001). Graduate Theses, Dissertations, and Problem Reports. 1205.

https://researchrepository.wvu.edu/etd/1205

This Thesis is protected by copyright and/or related rights. It has been brought to you by the The Research Repository @ WVU with permission from the rights-holder(s). You are free to use this Thesis in any way that is permitted by the copyright and related rights legislation that applies to your use. For other uses you must obtain permission from the rights-holder(s) directly, unless additional rights are indicated by a Creative Commons license in the record and/ or on the work itself. This Thesis has been accepted for inclusion in WVU Graduate Theses, Dissertations, and Problem Reports collection by an authorized administrator of The Research Repository @ WVU. For more information, please contact researchrepository@mail.wvu.edu. 


\title{
Improved Velocity Data in Circular Jets Using an Avalanche Photodiode-Based 2-Component Point Doppler Velocimeter
}

\author{
By \\ Thomas T. Scarberry \\ THESIS \\ Submitted to the College of Engineering and Mineral Resources \\ at \\ West Virginia University
}

In Partial Fulfillment of the requirements for the degree of

Master of Science

in

Aerospace Engineering

John M. Kuhlman, Ph.D., Chair

Gary J. Morris, Ph.D.

Wade Huebsch, Ph.D.

Department of Mechanical and Aerospace Engineering

Morgantown, WV

2001

Keywords: Velocity Instrumentation, Point Doppler Velocimetry, Avalanche Photodiode 


\begin{abstract}
Improved Velocity Data in Circular Jets Using an Avalanche Photodiode-Based 2Component Point Doppler Velocimeter
\end{abstract}

Thomas T. Scarberry

An existing Point Doppler Velocimeter (pDv) has been modified in an effort to improve the RMS velocity results. Improvements have been made by reducing the probe volume size by focusing the incident laser beam, thereby reducing the effects of spatial averaging on the mean and RMS velocity measurements.

In particular, the PIN photodetectors used previously, were tested using the reduced probe volume, and were then replaced by high-gain, high signal-to-noise ratio large area avalanche photodetectors (APD's). The purpose of using the APD's was to increase the signal-to-noise ratio by increasing the signal output per photon of incident laser light, while it was hoped that the system noise remained the same. Also, the effect of the $A / D$ board noise was reduced through the use of a new higher resolution $A / D$ board.

In order to document the improvements to the system, measurements were made on a 1-inch diameter standard circular jet. This flow was selected for measurement because it has been used in previous pDv research, it is well documented, and could be made more complex through the addition of a swirler or an annular nozzle.

Comparisons have been made between the data acquired and hot wire data obtained on the same jet flow, as well as data obtained in previous pDv research and two theoretical profiles. Good agreement was found with the mean and RMS velocity hot wire results at the exit of the jet, and the RMS velocities downstream have been improved as well. Mean velocities generally agreed with hot wire results to within 3-5\% of the exit velocity, while the RMS velocities agreed with hot wire measurements to within approximately $11 \%$ for the focused APD results. Normalized mean exit velocities for a combined PIN/APD run agreed with the Görtler theory to within 23-25\% for $4<\mathrm{x} / \mathrm{D}<$ 12 , and to within $+/-5-6 \%$ for a Gaussian profile for $\mathrm{x} / \mathrm{D} \geq 4$. 


\section{Acknowledgements}

As I was preparing this thesis, I realized that several people deserve my deepest thanks. First, I would like to thank God for giving me the ability and the means to pursue a profession that I love.

I would like to thank several individuals in the Mechanical and Aerospace Engineering Department. First, I thank Dr. Loth for the guidance and knowledge he has bestowed on me since early in my career at WVU. Dr. Loth convinced me to pursue an advanced degree and, as such, I owe him a debt which can never be repaid. Next, I would like to thank Chuck Coleman, Anthony Rossetti, and Andy Golden for all their assistance in getting this project started. The people in the MAE shop rarely receive the credit they deserve in supporting graduate research projects. I would especially like to thank Dr. Kuhlman for giving this average student a chance to work for him. I will always be grateful for the knowledge I gained, and the fun we had while working together. I would also like to thank Dr. Morris and Dr. Huebsch for serving on my committee.

Thank you to Gerald Angle and Michael Plyler for the help they provided during the summers. Thanks to David Webb for the data reduction software, which made life much easier. Thanks also to Pat Collins for all the groundwork he laid for this project and for all the other help he has provided. Thanks to Rich Schwartz, Gary Flemming, Jim Meyers and Joe Lee at Nasa-Langley Research Center for all the assistance they provided on this project and for allowing us to visit their facilities. I would also like to thank Kevin Ford for his friendship and for his tremendous effort on projects we have worked on together. 
I want to thank my mother, Helen, and my sisters, Lisa and Marsha, for all their love, hard work and support, both financial and otherwise, throughout my life. Finally, I would like to thank my wonderful wife, Stacie and my stepson, Nicholas for all their love and support and for keeping me motivated to complete this work. They have endured long weeks without me at home so that I could finish this degree. I love you and I dedicate this thesis to both of you. 


\section{Table of Contents}

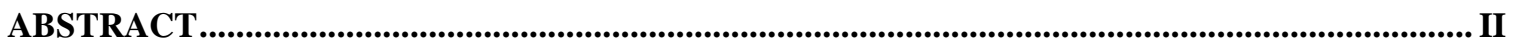

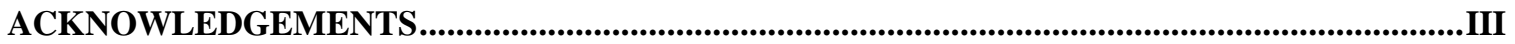

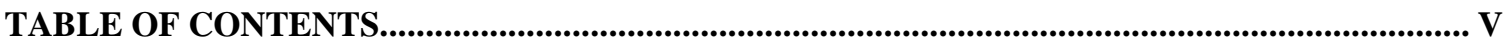

LIST OF TABLES........................................................................................................................................... VII

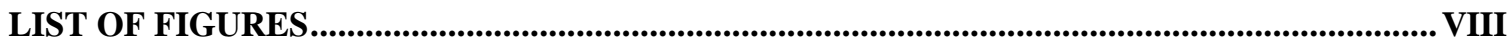

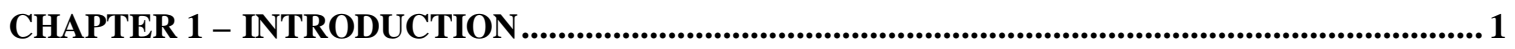

CHAPTER 2 - LITERATURE REVIEW ......................................................................................5

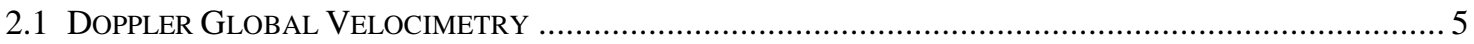

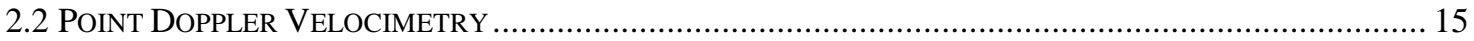

CHAPTER 3 - APPARATUS AND EXPERIMENTAL CONFIGURATION ..................................... 19

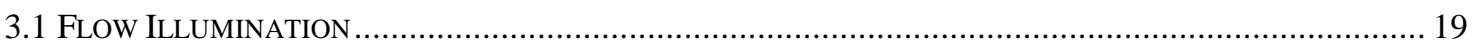

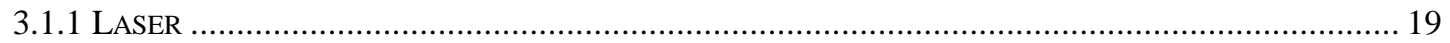

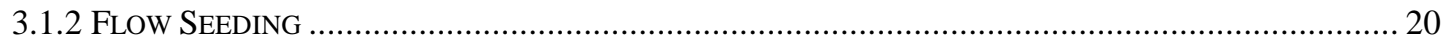

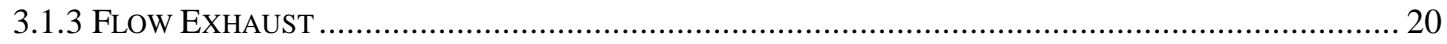

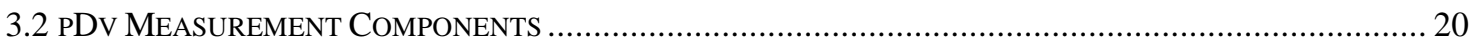

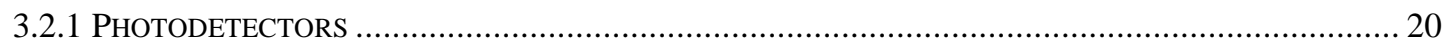

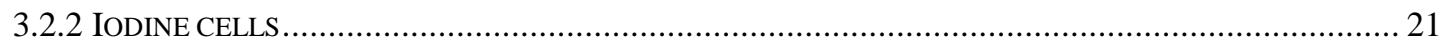

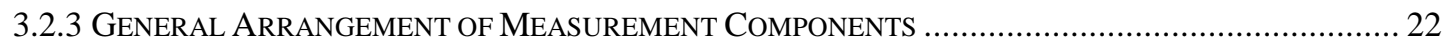

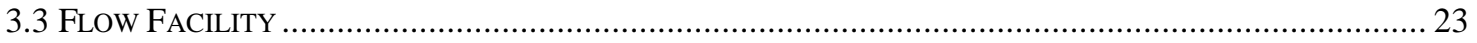

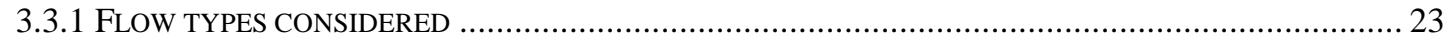

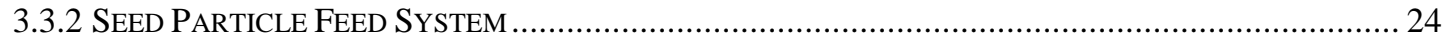

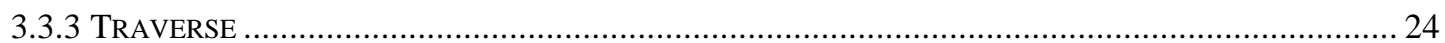

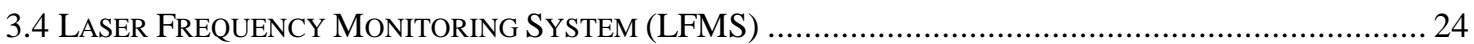

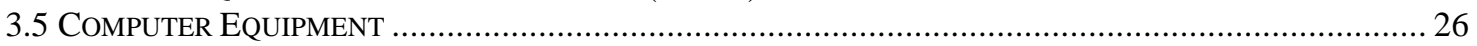

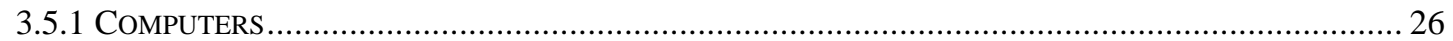

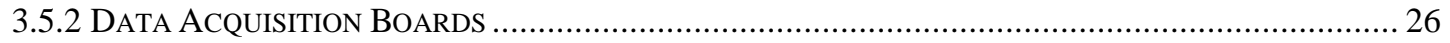

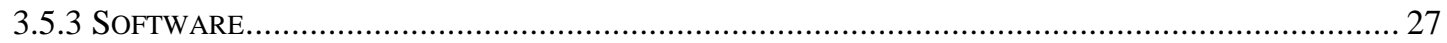

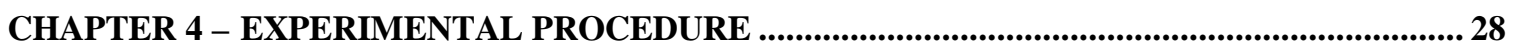

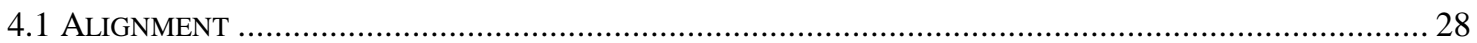

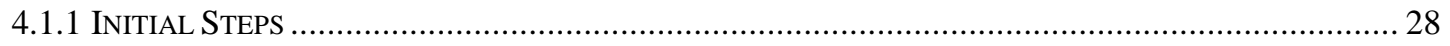

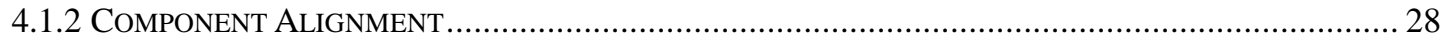

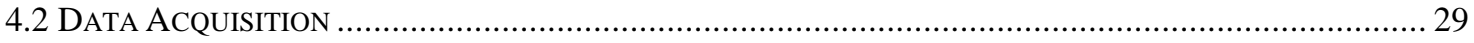

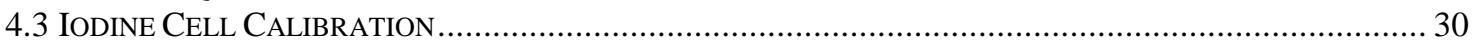

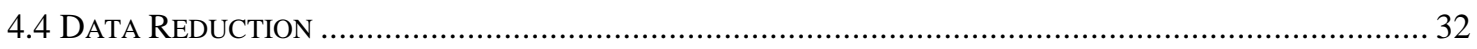

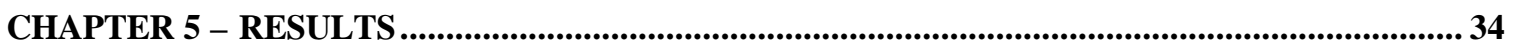

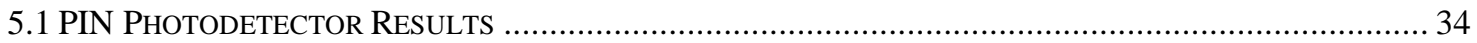

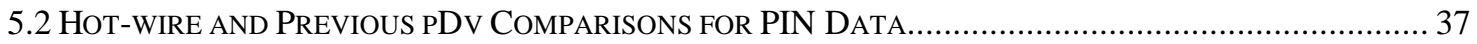

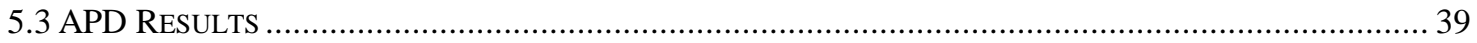

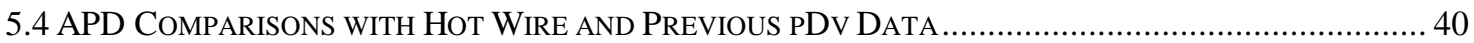

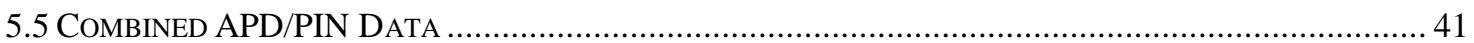

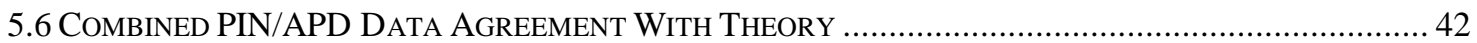

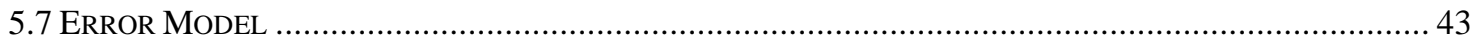


CHAPTER 6 - CONCLUSIONS AND RECOMMENDATIONS...................................................... 44

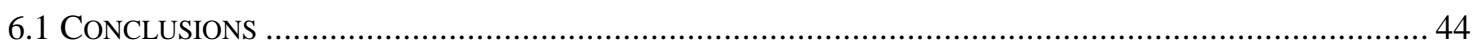

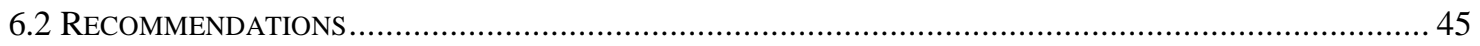

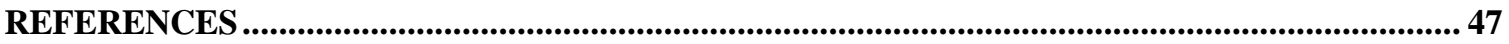




\section{List of Tables}

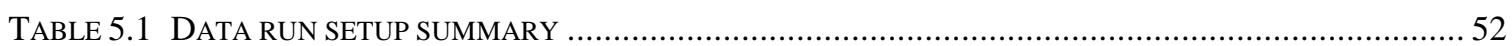

TABLE 5.2 ERROR MODEL PREDICTING RESOLUTION FOR SLOW CENTERLINE EXIT DATA ............................. 53 


\section{List of Figures}

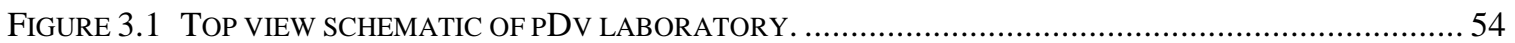

FigURE 3.2 AVALANCHE PHOTODETECTOR MODULE WITH HEAT SINK ATTACHED ...................................... 54

FIGURE 3.3 IODINE CELL WRAPPED IN HEATER TAPE AND METAL FOIL.................................................. 55

FIGURE 3.4 TYPICAL POINT DOPPLER VELOCIMETRY MEASUREMENT COMPONENT SETUP …...................... 55

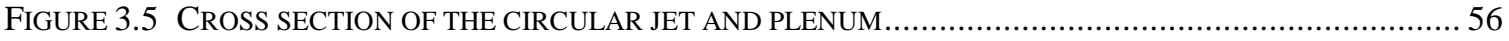

FIGURE 3.6 SCHEMATIC OF BLOWER/DIFFUSER/PLENUM/NOZZLE COMBINATION ....................................... 56

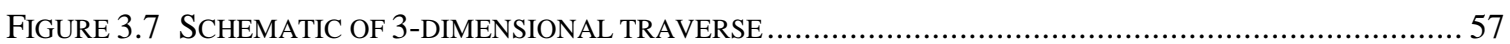

FIGURE 3.8 SCHEMATIC OF LASER FREQUENCY MONITORING SYSTEM (LFMS) ....................................... 57

FIGURE 4.1 POINTER USED FOR PDV COMPONENT ALIGNMENT INSTALLED ON NOZZLE …......................... 58

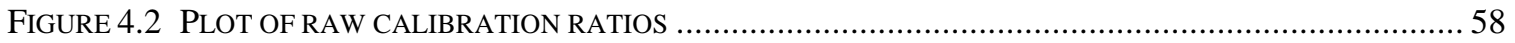

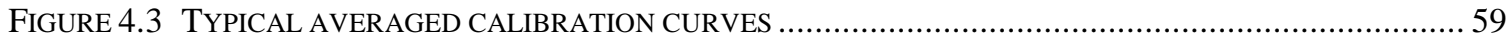

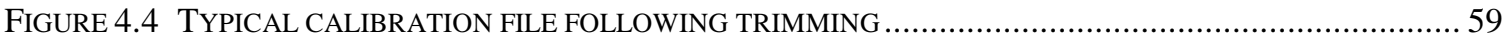

FIGURE 4.5 TYPICAL FINAL CALIBRATION SHOWING BOLTZMANN FITTING FUNCTION CURVE FITS............... 60

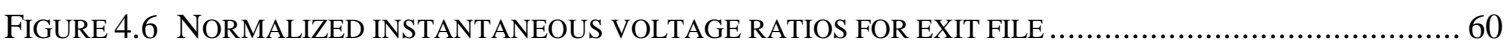

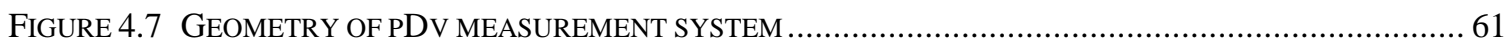

FIGURE 5.1 AXIAL VELOCITY RESULTS FOR RUN 1 (PIN DETECTORS, FOCUSING) .................................... 62

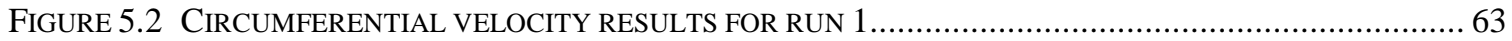

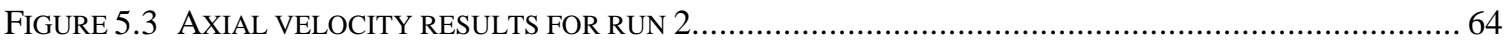

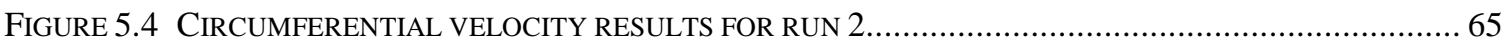

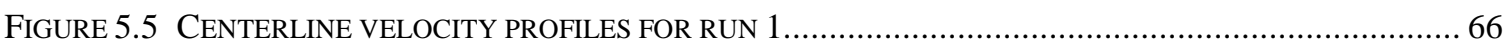

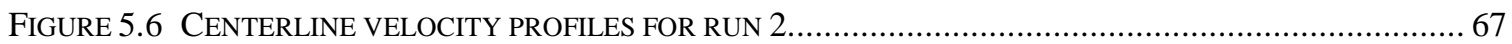

FIGURE 5.7 EXIT COMPARISONS OF BOTH RUNS WITH COLLINS AND HOT WIRE RESULTS ............................ 68

FIGURE $5.8 \mathrm{x} / \mathrm{D}=4$ COMPARISONS OF BOTH RUNS WITH COLLINS AND HOT WIRE RESULTS .......................... 69

FIGURE $5.9 \mathrm{x} / \mathrm{D}=6$ COMPARISONS OF BOTH RUNS WITH COLLINS AND HOT WIRE RESULTS ….................... 70

FIGURE $5.10 \mathrm{x} / \mathrm{D}=8$ COMPARISONS OF BOTH RUNS WITH COLLINS AND HOT WIRE RESULTS........................ 71

FIGURE 5.11 CENTERLINE COMPARISONS OF BOTH RUNS WITH COLLINS AND HOT WIRE RESULTS................ 72

FIGURE 5.12 CENTERLINE VELOCITY PROFILES FOR UNFOCUSED APD DATA RUN.................................... 73

FIGURE 5.13 CENTERLINE VELOCITY PROFILES FOR FOCUSED APD RUN …........................................... 74

FIGURE 5.14 CENTERLINE COMPARISONS OF AXIAL VELOCITY RESULTS FOR BOTH APD RUNS WITH COLLINS

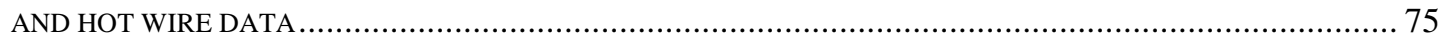

FIGURE 5.15 AXIAL VELOCITY RESULTS FOR COMBINED APD/PIN DETECTOR DATA RUN ……................... 76

FIGURE 5.16 CIRCUMFERENTIAL VELOCITY RESULTS FOR COMBINED APD/PIN DETECTOR DATA ............... 77

FIGURE 5.17 CENTERLINE VELOCITY RESULTS FOR COMBINED APD/PIN DETECTOR DATA RUN .................. 78

FIGURE 5.18 AXIAL VELOCITY COMPARISON TO GÖRTLER THEORY FROM WHITE (1991)........................... 79

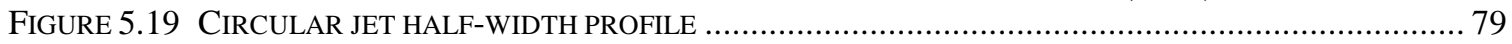

FigURE 5.20 AXIAL VELOCITY COMPARISON TO GAUSSIAN PROFILE FROM KUHLMAN (1986)..................... 80 


\section{Chapter 1 - Introduction}

When studying the behavior of a flow, the aerodynamicist has two basic means of measuring the velocity experimentally - intrusive measurements and non-intrusive measurements. An intrusive measurement is made when a probe of some sort is inserted into the flow. These types of probes include Pitot probes and hot-wires. The advantage of using intrusive measurements is that they are relatively easy to set up and do not require much effort to align. Although hot-wires are capable of measuring fast-response velocity fluctuations (turbulent flows), they cannot distinguish flow direction, unless a multiprobe is used (Barlow, Rae, Pope 1999). Also, they are susceptible to flow temperature changes, and require careful calibration. Pitot probes are limited to mean velocity measurements, due to the delay time following a flow change. Because both methods introduce a certain amount of error by disturbing the flow, it became necessary to develop non-intrusive instruments.

Non-intrusive measurement techniques include Laser Doppler Velocimetry (LDV), Doppler Global Velocimetry (DGV) and Point Doppler Velocimetry (pDv). Laser Doppler Velocimetry involves using optics to separate a laser beam into two beams that are focused to intersect at a point in the flow where the measurement is desired. A fringe pattern of light and dark "planes" is formed at that probe volume due to alternating levels of constructive and destructive interference between the two coherent beams. A photodetector is used to collect light scattered off seed particles passing through the bright regions. Since the laser frequency and the spacing between the fringes are known, along with the time a particle spends between each fringe, the velocity of the particles passing through the measurement volume can be 
determined. Both mean and instantaneous velocities can be measured, allowing for the acquisition of turbulence data. Using LDV, accurate non-intrusive velocity measurements can be made. Multi-dimensional measurements can be made by adding additional optics for extra sets of split beams and photodetectors. A major drawback of LDV is, however, the painstaking optical alignment that is necessary for operation. Also, measurements must be made at single points, requiring a severe time penalty for a whole-field survey.

A relatively new whole-field velocity imaging technique patented by Komine (1990) is Doppler Global Velocimetry. DGV utilizes the principle of a Doppler shift in light frequency scattered off small seed particles moving with the flow. A laser beam is spread into a light sheet, which intersects the seeded flow in the plane where the velocity information is desired. The scattered light is then collected by a set of components which are comprised of various optics and an Iodine cell. The Iodine cell is used as a frequency discriminating filter, which transforms the frequency shift in the laser light into light intensity variations, which are then recorded using a pair of CCD cameras, one looking through the Iodine cell and one not looking through the cell (to normalize the filtered image to account for light intensity variations and seed particle density variations across the field of view). A calibration is performed to predict the Iodine cell response to Doppler shifts in the scattered light. The ability of DGV to measure an entire plane of velocity in a single "picture" significantly reduces the time required to map out a flow field. When used in conjunction with a pulsed laser and high-speed cameras, DGV is capable of measuring turbulence data in a 
plane; however, this is associated with an increase in the cost of the system, as well as an increase in the complexity of the software required for data acquisition.

Another new non-intrusive point technique related to DGV is Point Doppler Velocimetry (pDv). In pDv, the laser beam is not spread into a sheet of light and the CCD cameras are replaced with either PIN photodiodes, avalanche photodiodes, or photo-multiplier tubes (PMT's). Avalanche photodiodes have a significantly higher signal-to-noise ratio than standard PIN detectors, thereby reducing the effect of the system noise on the velocity measurements. Since light is collected from a single point in the flow, the addition of several front lenses and a pinhole are required. The alignment of a pDv system is slightly less complicated than DGV since exact image overlapping is not necessary. It is necessary, however, to focus each measurement component onto the same point where measurements are required. This becomes difficult when each component views the point from a different direction, since slight "image" distortions prevent an exact alignment from channel to channel. This method is an attractive alternative to LDV, since it is non-intrusive as well as being capable of the same high, continuous signal data rates demonstrated by hot-wire anemometry. This also allows the calculation of spectra as well as correlation coefficients. PDv is also easier than LDV to align, since only one beam is needed. Also, pDv uses a higher signal (seeding) level than LDV, which produces a more continuous signal.

This research dealt with the improvement of an existing Point Doppler Velocimeter, by replacing the standard PIN photodetectors with high-gain, high signal-to-noise ratio avalanche photodetectors. In addition, spatial resolution was 
improved by focusing the incident laser beam and signal resolution was improved through the use of a higher resolution A/D board with a higher sampling rate capability. In order to document the improvements to the system, measurements were made on standard round, swirling, and annular free jet flows. These measurements were compared to pDv data obtained in Collins (2000), as well as hot wire data. 


\section{Chapter 2 - Literature Review}

\subsection{Doppler Global Velocimetry}

Komine, et al., (1991) developed the original concept of a Doppler Global Velocimetry (DGV) technique. Although significant improvements to this concept have been made over the past decade, DGV was, and still is a relatively new non-intrusive, optical measurement technique, which can be used to obtain instantaneous, threedimensional flow velocities in a planar region.

In the original DGV system of Komine, Doppler-shifted scattered light was collected by an optical imaging system. The heart of the system was the image analyzer, which transformed light frequency variations (due to Doppler frequency shifts) into light intensity variations, which then allowed a quantitative visualization of the flow velocity patterns. The most important part of the analyzer was a cylindrical glass cell containing Iodine molecules, which have the ability to absorb light frequencies near that of the laser used.

Two modes of operation were feasible, where the particular mode used was determined by the type of laser used for illumination of the flow. For slowly varying flows, time averaged data was obtained using a CW laser. The light was scattered and collected over an entire CCD camera frame exposure time. The second mode utilized a pulsed laser (pulse length $\sim 1$ microsecond) to illuminate the flow. This technique effectively froze the flow, allowing a quantitative visualization of unsteady or turbulent flow phenomena.

The light was scattered by small oil droplets seeded into the flow, with a diameter on the order of a micron. The scattered light was collected by a camera through an Iodine 
vapor absorption line filter, and in order to correct for light intensity and oil droplet size variations across the field of view, the image acquired through the filter was normalized by an image acquired at the same time by a second camera not viewing through the filter. The velocity was calibrated by using a rotating disk with a known size and rotational speed.

Meyers and Komine (1991) later described a prototype one-component velocimeter along with the associated signal processing electronics. This velocimeter was evaluated by using it to measure the velocity of a rotating wheel as well as a subsonic jet flow. A wind tunnel test was also used to determine the applicability of the technique to the flow above a delta wing. The DGV technique described used the edge of an absorption line of the molecular Iodine within the absorption line filter (ALF) to serve as a frequency-to-intensity converter. This allowed a direct measurement of the Doppler shift of the collected portion of the scattered laser light. An Argon-ion laser was operated in single-wavelength mode $(514.5 \mathrm{~nm})$. The laser frequency was tuned by tilting an intercavity etalon. This was done such that the light frequency corresponded to a point about half way up the edge of the absorption line of the Iodine. In order to correct for variations in particle size distribution and number density, and the laser light sheet intensity, the same portion of the flow was viewed with a second camera without the Iodine cell. This image was then used to normalize the image obtained through the ALF.

The signal processing electronics were used to synchronize the cameras, normalize the signal camera output, and correct for camera pixel sensitivity variations. Typically, the output of a camera was transferred to a computer through the use of a digital frame grabber; however, because two cameras were used, they had to be 
synchronized to align corresponding pixels. Since the data then had to be transferred to the computer to be normalized, real-time operation was not possible with this method. In order to rectify this situation, an analog normalization circuit was used in front of the frame grabber. A proof-of-concept test was also run to determine the vortical velocity field above a 75-degree delta wing.

In Meyers, Lee and Cavone (1991), both digital and analog signal processing schemes were discussed. They stated that the simultaneous image acquisition by two cameras could not be accomplished by using multiplexers, therefore they used an analog divider circuit, which allowed real-time normalized output. The normalized video was then false-colored using a standard frame grabber, and recorded on a U-MATIC video recorder. This method did not allow for adjustments to correct for the added background light. Also, pixel sensitivity corrections had to be made within the computer, which prohibited real-time operation. These capabilities could only be provided by using digital circuitry, therefore, a custom dual frame grabber was designed and built to acquire synchronized images from two cameras. The normalization was achieved by using a lookup table with all possible quotients determined from the fact that there were only $65,536\left(256^{2}\right)$ possible ratio values from the 8-bit A/D converter. Background illumination was removed by acquiring signal and reference images with the flow off and then subtracting those from the data images prior to normalization. The Doppler Global Velocimeter was tested at NASA LaRC; this was done by examining the flow field above a 75-degree delta wing.

Meyers (1992) discovered problems in the previous signal processing schemes, particularly the ability to overlay the signal and reference images exactly. This inability 
was thought to be due to differences in the depth of field of the signal and reference cameras, lens aberrations, imperfections in the beam splitters and mirrors, as well as the Iodine vapor cell faces. These were in addition to the nonuniform pixel distributions from camera to camera. The main problem was the inability to align the system so that each pixel in the signal camera viewed the exact same portion of the flow as the corresponding pixel in the reference camera. Image processing techniques were investigated as a way to correct for this misalignment. The images also had a keystone effect, which distorted the image. This was remedied by taking pictures of a planar calibration grid placed in the light sheet plane. Using a dewarping algorithm, the grids were dewarped so that the original grid could be generated from an image acquired from an oblique viewing direction.

Since the pixels in each CCD camera varied in their sensitivity, adjustments had to be made to correct for this. To do this, a pixel sensitivity correction was used at two light intensities to determine the slope and intercept of a transfer function. These were found for each pixel and stored in arrays. The arrays were used to remove the sensitivity variations before dewarping.

Ainsworth and Thorpe (1994) describe a concept for capturing both signal and reference images using only one CCD camera and frame grabber for each velocity component. This was done using an Argon ion laser. Although this method decreased the system complexity compared to two camera systems, and assured the simultaneous capture of both images, it reduced the possible spatial resolution by $50 \%$. In this method, a primary focusing lens captures the scattered light and directs it to a transfer lens, which outputs the collimated light. This light is incident on a beam splitter which separates the 
signal and reference light paths. The signal light is passed through the Iodine cell and is merged with the reference image at a second beam splitter. The images are side by side when passed to the camera lens. The reference image was manipulated into the right side of the camera frame, while the signal image was directed to the left side. Alignment was performed by viewing test targets for coarse alignment and then point sources of light were used to obtain a precise alignment.

A stable reference Iodine cell was developed and used to continuously monitor laser emission frequency. The shifts in laser output frequency were found to be due to two different sources. The first source was a slow drift due to long-term temperature variations, while the second is due to laser vibrations which cause a rapid change in cavity mirror separation. This frequency drift was accounted for by monitoring the laser frequency by using the reference Iodine cell.

Analytical models of an Iodine absorption line filter and CCD camera noise sources were made by McKenzie (1995). Also described were the criteria for ALF optimization. Measurement uncertainties were evaluated, along with the scattering properties of various seed materials. The results of the study showed that single-pulse Planar Doppler Velocimetry (another term for DGV) measurements with uncertainties as small as $2 \mathrm{~m} / \mathrm{s}$ are possible in large test facilities. The size of the flow that can be measured is limited primarily by the performance of pulsed lasers and noise characteristics of CCD cameras. Also, a new arrangement was used in which the signal and reference cameras were replaced by one camera, which was used to image a split view of the filtered and unfiltered data images. The study showed that $2 \%$ uncertainties 
were possible by using 16-bit CCD cameras. It also showed that opaque particles are the least sensitive to changes in particle size distributions and observer direction.

In Meyers (1995), a summary was given of the development of DGV, to that date. Suggestions were given for improving measurement results in the laboratory. First, the cylindrical lens used to form the light sheet was replaced with a high-speed galvanometer scanner. This was done to create a more uniform light-sheet intensity profile. Second, polarization effects were removed by placing a quarter-wave plate in the laser beam path to circularize the polarization. Third, the even and odd lines in the CCD array were separated and processed separately, improving image quality, since the even and odd lines were acquired separately. Fourth, minor misalignments between the signal and reference cameras were repaired by shifting the signal image to negate the misalignment before normalization, and also by trimming the edges by four pixels.

Thorpe, Ainsworth and Manners (1996), described a series of experiments performed using an axisymmetric free air jet. Measured velocity data was compared with established data from the literature. The free jet was used since it was a well-documented flow, and the image contained large variations in intensity due to large velocity gradients in the shear layer. The purpose of the investigation was to create a powerful, accurate single-shot Doppler Global Velocimeter using one CCD camera per measuring component. A frequency-discriminated Argon-ion laser was used for flow illumination. The laser was tunable via an inter-cavity etalon. Image alignment was performed using software manipulation, which involved image warping and interpolation. The low noise capability of the cooled CCD cameras was also evident. Five major error sources were described: laser emission frequency, Iodine cell calibration and stability, the recording 
system, and finally, image misalignment. DGV was shown to be capable of acquiring quality data from single images.

The advancement of techniques and algorithms for DGV data processing is presented in Meyers (1996). The main cause for image misalignment was shown to be due to minor imperfections in the optical elements. The solution was to remove the small imperfections by using various image processing schemes. The first technique used was a dewarping algorithm found in commercial software. There were problems with this since the commercially available software could only be used to remove linear distortions in the image. Software was developed which used piecewise, bilinear warping to remove the minor optical distortions. The second major phase to processing improvement was noise reduction. The noise was found to be due to CCD camera dark current, pixel sensitivity variations, charge transfer noise, the modulation transfer function (MTF) of the lens-camera system, and field interlacing.

A two-component Planar Doppler Velocimetry system was setup and used to measure the instantaneous velocity in a cross stream plane of a Mach 2, axisymmetric, ideally expanded free jet, in Clancy and Samimy (1997). The goal of this research was to determine a repeatable experimental procedure. This was done as McKenzie (1997) was developing improved PDV performance in low speed flows. The minimum, noiselimited resolved velocities were determined along with the sources of PDV measurement uncertainties.

A DGV system was optimized by Roehle (1997), for three component timeaveraged measurements on a swirl spray nozzle flow, and the wake of a car model in a wind tunnel. As was done in Thorpe, Ainsworth, and Manners (1996), one camera was 
used to obtain both the signal and reference images. The final error introduced by the laser and camera was found to contribute to a velocity uncertainty of $+/-1 \mathrm{~m} / \mathrm{s}$.

Elliott, et al., (1997) used PDV to measure the transverse injection of sonic jets with various cross-sections into a Mach 1.98 flow. The results illustrate the mean and instantaneous flow-field in the separation shock, bow shock and the jet mixing layer. These particular experiments utilized a pressure-broadened Iodine cell, wherein, a buffer gas was added to the Iodine vapor in the cell to increase the transmission profile linewidth. This was done to aid in the measurement of instantaneous velocities in this supersonic flow.

A two-component DGV system was described, and early velocity measurements were made, for a rotating wheel by Naylor and Kuhlman (1998) and Naylor (1998). The two-component DGV system utilized two 8-bit Hitachi KP-M1 CCD cameras per measurement component. Data acquisition was performed via a 4-input Matrox Genesis frame grabber, along with software written in Visual Basic and $\mathrm{C}++$. Image processing software was developed for image warping, and pixel sensitivity corrections, as well as calibration, averaging, and data viewing. RMS noise levels for the rotating wheel data were observed to be on the order of $+/-1 \mathrm{~m} / \mathrm{s}$, with a total velocity range error of $+/-1-2$ $\mathrm{m} / \mathrm{s}$. A zero velocity offset error of up to $-20 \mathrm{~m} / \mathrm{s}$ was also observed, the cause of which was unknown at the time. Non-zero data exhibited percent errors of $1.9 \%-8.1 \%$ for velocity ranges of $31.6 \mathrm{~m} / \mathrm{s}-29.6 \mathrm{~m} / \mathrm{s}$, respectively. The RMS deviation of the DGV data was found to be $+/-1.1 \mathrm{~m} / \mathrm{s}$. This was about $+/-3 \%$ of the $32.2 \mathrm{~m} / \mathrm{s}$ velocity range for the experiments. The dominant error source was found to be the 8 bit camera/frame grabber combination. 
In Naylor (1998), a two component DGV system was built and tested to determine problems involving the accuracy of such a system. Corrections were made to the system to account for optical deformities as well as light intensity variations across the field of view. The DGV system was used to measure the velocity of a 12-inch rotating wheel, as well as a fully-developed, turbulent pipe flow and a jet flow. Errors for the wheel data were $2-4 \%$ out of a maximum velocity of $58 \mathrm{~m} / \mathrm{s}$. Flow measurements were compared to pitot probe data and were found to match well. Although velocity offset errors of $20 \%$ were encountered, RMS errors were 5-10\%. In light of these errors, techniques for acquiring data and calibrating the system were improved.

DGV was used to investigate a vortex-tail interaction flow by Beutner, et al., (1998). In this DGV system, two 16-bit thermoelectrically cooled digital cameras with $105 \mathrm{~mm}$ focal length lenses were used to record data. Flow illumination was performed with an externally water-cooled, frequency doubled Nd:YAG laser. The measurement of a free stream component of $20.2 \mathrm{~m} / \mathrm{s}$ displayed a bias error of $0.55 \mathrm{~m} / \mathrm{s}$ and an RMS error of $1.3 \mathrm{~m} / \mathrm{s}$. These errors appeared to be constant and did not depend on the wind tunnel velocity.

Results for a rotating wheel, fully-developed pipe flow, and a free jet are given in Naylor and Kuhlman (1999). RMS noise levels for the rotating wheel were on the order of $+/-1 \mathrm{~m} / \mathrm{s}$, and total velocity errors were between $+/-1-2 \mathrm{~m} / \mathrm{s}$ out of $59 \mathrm{~m} / \mathrm{s}$. The RMS error was mostly due to the 8-bit camera resolution, while the velocity range errors were due to Iodine cell calibration accuracy. Calibration of the Iodine cells was accomplished using a continuous, manual scan of the Argon-ion laser's mode structure. This was done by tilting an inter-cavity etalon through about 10-20 mode hops, over 20-30 seconds. 
Significant improvement in the calibration accuracy was obtained by averaging several of the individual continuous scans. The effects of laser speckle were investigated for the $\mathrm{cw}$ Argon-ion laser. Major error sources were documented: noise from the 8-bit camera resolution, blower reset accuracy, Iodine cell calibration repeatability, inaccurate flatfield correction methods, and the zero velocity tab used to correct for the zero velocity offset. These error sources resulted in a total uncertainty of $+/-4 \mathrm{~m} / \mathrm{s}$.

In Meyers and Lee (1999), potential error sources in DGV were investigated, and found to include Iodine vapor absorption lines, optical systems, camera characteristics, laser frequency stability, seed particle scattering characteristics, and interference fringes. Other error sources which were investigated include geometric DGV component location uncertainties, as well as laser speckle noise, which is increased in its effect by image normalization.

In Samimy and Wernet (1998), the PDV technique was applied to high-speed flows and was compared with two-component LDV results. The results of the PDV technique show good agreement for both mean and turbulence intensity when a frequency monitoring system was used to monitor laser frequency drift.

In Kuhlman, Burton, and Scarberry (2001), a two-component DGV system was improved through the use of vapor-limited Iodine cells which have temperatureindependent responses, along with non-polarizing beam splitters and lower f-number camera lenses. Measurements were obtained for a one-inch diameter uniform circular jet flow at a nominal exit velocity of $60 \mathrm{~m} / \mathrm{s}$, along with annular and swirling jet flows. These data displayed a total variability from a smooth curve of $+/-2-3 \mathrm{~m} / \mathrm{s}$. Exceptions to this level of accuracy were observed in regions of high secondary scattering from the 
nozzle lip, as well as in regions of low seeding levels (low signal-to-noise ratios). Significant improvements in data accuracy were due to the flat-field correction technique.

\subsection{Point Doppler Velocimetry}

Roehle and Schodl (1994) explored the possibility of using DGV to obtain velocity measurements at a point in a seeded flow. Rather than using CCD cameras, the scattered light was collected by a series of front lenses and two photodetectors. In order to make certain that both detectors were viewing the same probe volume, a pinhole was placed behind the first collecting lens. They were able to document an error of $+/-2 \mathrm{~m} / \mathrm{s}$ due to laser control and calibration curves; +/- $0.8 \mathrm{~m} / \mathrm{s}$ due to optical setup; +/- $1 \mathrm{~m} / \mathrm{s}$ due to light detection and signal processing. Additional errors were incurred from low signalto-noise ratios (low intensities) and reflections of the laser light.

Hoffenberg and Sullivan (1994), developed a related velocity measurement device, termed Filtered Particle Scattering. This technique also used the absorption edge of molecular Iodine to measure the Doppler shift in scattered light frequency in a seeded flow field. This technique was used to make measurements in a turbulent jet. FPS was described as a point measurement technique that provides a continuous velocity signal. Several important observations were made: first, values of turbulence intensities were comparable to those obtained with LDV; second, it was discovered that the laser frequency drift must be monitored to prevent mean velocity errors due to frequency changes in the laser output; third, photodetector alignment was found to be crucial to the signal-to-reference ratio stability, since each detector must be viewing the same probe volume to cancel intensity fluctuations. 
In Kuhlman, Naylor, James, and Ramanath (1997), a two-component point Doppler velocimeter was described and a series of velocity measurements were made to document the accuracy of the pDv system. Measurements were made on a rotating wheel, and turbulent pipe flow. Accuracy of the wheel data was $+/-1 \%$ of full scale (57 $\mathrm{m} / \mathrm{s}$ ). Although there was a radial velocity offset of $5-10 \%$ of the mean axial velocity, consistent turbulence intensity profiles and mean axial velocity profiles were obtained.

In the thesis by Ramanath (1997), a point Doppler velocimetry system was developed and evaluated in which the cameras in DGV were replaced with PIN photodetectors. The system was found to have an error of $5 \mathrm{~m} / \mathrm{s}$, with respect to a rotating wheel. Pipe flow results demonstrated an offset of about $+/-2-4 \mathrm{~m} / \mathrm{s}$.

James (1997) described a two-component point Doppler velocimetry system. Mean velocity measurements were performed on a 12 -inch rotating wheel, and fullydeveloped turbulent pipe flow. Good accuracy was obtained for the wheel results, with an observed linearity of $+/-0.6 \mathrm{~m} / \mathrm{s}$. Errors were introduced through cell calibrations and alignment procedures. Pipe flow turbulence levels were calculated and found to agree with hot-wire measurements. Low signal-to-noise ratios and spatial averaging were believed to cause mean velocity errors in the pipe flow near the pipe walls.

Crafton, Messersmith, and Sullivan (1998) developed a point Doppler velocimeter which used a Distributed Brag Reflector diode laser and a Cesium vapor Faraday cell to determine the Doppler shift in frequency of the scattered light. Measurements were made on a rotating wheel and a jet flow. The RMS of the velocity signal was less than 0.05 $\mathrm{m} / \mathrm{s}$. The velocity signal displayed a noise contribution of about $1 \mathrm{~m} / \mathrm{s}$. Results indicated an accuracy of $0.5 \mathrm{~m} / \mathrm{s}$ for the jet flow. 
Kuhlman and Webb (1999) described a 2-component point Doppler velocimeter (pDv) which was used to measure velocities over a NACA 0012 airfoil, and for the velocity of a rotating wheel. The pDv system displayed accuracies on the order of $+/$ 0.5-1 $\mathrm{m} / \mathrm{s}$ for the rotating wheel. Two-component data for the airfoil flow were presented, which included mean and RMS velocities. RMS velocities agreed with hotwire results to within $+/-0.5 \mathrm{~m} / \mathrm{s}$ and mean velocities agreed to within $+/-3 \mathrm{~m} / \mathrm{s}$.

Webb (1999) also described the 2-component point Doppler velocimetry system. PDv mean velocity data was compared to hot-wire data and was found to agree to within $+/-2 \mathrm{~m} / \mathrm{s}$. The RMS velocities matched to within $+/-0.4 \mathrm{~m} / \mathrm{s}$. The major source of error in the system was found to be the variation in the Iodine cell stem temperatures. Also, during the course of the work, the data acquisition/reduction and optical alignment techniques were developed and improved.

Kuhlman and Collins (2000) continued this development by using vapor-limited Iodine cells that operated independent of stem temperature. Measurements were made on a one-inch diameter circular jet, a swirling jet, and an annular jet flow at a nominal exit velocity of $60 \mathrm{~m} / \mathrm{s}$. PDv mean velocities repeated to within $1-2 \mathrm{~m} / \mathrm{s}$. Exit profiles of the pDv agreed with hot-wire results to within $2 \mathrm{~m} / \mathrm{s}$. The pDv RMS velocities were 30-40\% lower than the hot-wire results everywhere but at the exit, where they were too high.

Kuhlman, Collins and Scarberry (2000) improved the pDv velocity results through the use of vapor limited Iodine cells and a reduced measurement volume. Mean velocity results were repeatable to within $1-2 \mathrm{~m} / \mathrm{s}$, while the RMS velocity results repeated to within $1 \mathrm{~m} / \mathrm{s}$. Exit profiles agreed with hot-wire results to within $2-4 \mathrm{~m} / \mathrm{s}$, however, the RMS results were 20-30\% lower than the hot-wire results beyond the exit. 
Collins (2000) documented axial and circumferential pDv mean velocity uncertainties of $2 \mathrm{~m} / \mathrm{s}$. PDv RMS velocities exhibited a repeatability of $0.5-1.0 \mathrm{~m} / \mathrm{s}$. This was done by replacing the original Iodine cells by vapor limited cells. Standard, swirling and annular jet data were compared to hot-wire results at nine different $\mathrm{x} / \mathrm{D}$ locations. A focused laser beam and smaller pinhole sizes were used by Kuhlman and Scarberry (2001) to improve RMS velocity results. An improved A/D board was also used to reduce the minimum velocity resolution from $1-1.5 \mathrm{~m} / \mathrm{s}$ to $0.3-0.8 \mathrm{~m} / \mathrm{s}$. A simple error model was also developed which predicted this resolution, based on photodetector RMS noise voltages. PDv data indicated a mean exit velocity of $57 \mathrm{~m} / \mathrm{s}$, compared to the pitot probe result of $59 \mathrm{~m} / \mathrm{s}$. Circumferential mean velocities were within $+/-1 \mathrm{~m} / \mathrm{s}$ of zero for the standard jet. The exit RMS velocities were 0.66 and $0.84 \mathrm{~m} / \mathrm{s}$ for the axial and circumferential directions, respectively; these values indicated the $\mathrm{pDv}$ system velocity resolution using the PIN photodetectors. 


\section{Chapter 3 - Apparatus and Experimental Configuration}

The laboratory used for the present research was the same facility used by Collins (2000). This system consisted of a one-inch diameter standard jet, which could be modified to produce a swirling jet. The jet flow facility was located in the center of the laboratory, with the laser and laser frequency monitoring system on one side of the room. A mirror was used to reflect the main portion of the laser beam towards the flow measurement area, downstream of the jet, perpendicular to the jet axis. Two pDv measurement components were located downstream of the jet exit, one on each side of the jet flow. An exhaust cone, which was attached to the building exhaust system, was located between the two pDv components, and was used to collect the seed material. A top view schematic of the laboratory is shown in Figure 3.1.

\subsection{Flow Illumination}

\subsubsection{Laser}

A 5-Watt Coherent Innova 305 continuous wave Argon-ion laser was used for flow illumination. The laser was operated in single-line mode at $514.5 \mathrm{~nm}$. This was done by mechanically tilting a heated inter-cavity etalon to adjust the output frequency of the laser. The etalon resulted in single frequency operation of the laser, but reduced the laser output power to approximately 1 Watt. Had this not been done, the bandwidth of the laser would have far exceeded that of the absorption line of the Iodine cells. With no etalon, the laser had a bandwidth of 6-8 GHz; however, with the etalon in place, this range was narrowed to approximately $10 \mathrm{MHz}$ (Collins, 2000). When beam focusing was desired, the focusing lens was placed in the beam path via a small plastic camera tripod. 


\subsubsection{Flow Seeding}

In order to measure the Doppler shift of the scattered light, the flow was seeded with small smoke particles emitted from a ROSCO model 1500 theatrical fogger. The model 1500 was capable of producing fog particles with an average diameter of approximately $1 \mu \mathrm{m}$. This size of particle and the selected fog generation rate were estimated to produce a mass loading of approximately $0.5 \%$. This mass loading was sufficiently small to allow the assumption that the seed particles accurately track the flow, without significantly altering the flow. The Rosco fogger was attached to a large 32 gallon plenum in order to dampen smoke pulses produced by the fog machine. The fog was produced by vaporizing an ethylene glycol-based fluid. Most particle sizes varied in diameter from 0.5 microns to 5 microns, although there were some residual particles from 5-15 microns in diameter (Meyers, 2000-2001).

\subsubsection{Flow Exhaust}

The smoke-filled flow was evacuated from the laboratory by utilizing the building exhaust system. The exhaust vacuum hoses were attached to a large steel cone which was placed downstream of the jet exit to collect the seeded flow. The drawback of the exhaust system was that it was not possible to evacuate all the fog at jet velocities exceeding $60 \mathrm{~m} / \mathrm{s}$.

\section{2 pDv Measurement Components}

\subsubsection{Photodetectors}

The photodetectors used in this research were model 118-70-74-661 avalanche photodetectors (APD's) manufactured by Advanced Photonix, Inc, as well as Thor Labs 
model PDA55 switchable gain silicone PIN photodetectors. The PIN detectors had 5 discrete gain settings of $0,10,20,30$ and $40 \mathrm{~dB}$ which were selectable via a 5 position click-stop switch. They had an active area of approximately $13 \mathrm{~mm}^{2}$ and a spectral range of 400-1100 nm. APD's were selected to replace the PIN photodiodes that had been used previously in the pDv system, in an effort to improve the system signal-to-noise ratio. These APD's were thermoelectrically cooled for reduced noise (typical output stability of $0.15 \% /{ }^{\circ} \mathrm{C}$ ) and had a spectral enhancement for use with a light wavelength of $500 \mathrm{~nm}$. The active area of the APD's was approximately $7 \mathrm{~mm}^{2}$, with a spectral sensitivity of approximately $10^{6} \mathrm{~V} / \mathrm{W}$ at a wavelength of $500 \mathrm{~nm}$ (at gain of 300). The gain was controlled by applying a bias voltage of 0-5 Volts, which, in turn, controlled a high voltage supply within the module, which supplied the reverse voltage used to change the gain. The bias voltage was varied by turning a potentiometer on the back of the module. The APD modules required a low-voltage supply (+/- 12 Volts, +5 Volts) that was built in-house. The modules operated at a temperature which necessitated the use of heat sinks from PC CPU's to provide cooling. These heat sinks were strapped to the top of each module using a nylon cable tie. A photograph of an APD module with its heat sink installed is shown in Figure 3.2.

\subsection{2 lodine cells}

Iodine was used as the molecular frequency discriminating filter by filling a fiveinch long, three-inch diameter cylindrical Pyrex glass container with vapor phase Iodine. Figure 3.3 is a photograph of an Iodine cell. This was done by evacuating the cell and then filling it with Iodine vapor at a cell temperature of $45^{\circ} \mathrm{C}$. Once full, the cell opening was closed so that only vapor Iodine was present in the optical path when the cells were 
operated at or above the filling temperature. The cells used in these experiments were operated at $80^{\circ} \mathrm{C} \pm 0.1^{\circ} \mathrm{C}$ by controlling the flexible band heater using an Iomega CN9000A temperature controller. It was shown by Webb (1999) that using non-vapor limited Iodine cells can lead to a velocity error of about $7 \mathrm{~m} / \mathrm{s}$ in the forward scatter channel and about $2 \mathrm{~m} / \mathrm{s}$ in the back scatter channel. These errors were caused by a variation in the amount of Iodine vapor in these cells as the cell temperature varied and some of the solid phase Iodine was vaporized.

\subsubsection{General Arrangement of Measurement Components}

In order to measure two components of velocity, two $\mathrm{pDv}$ channels were used to collect light scattered from two directions. Each channel consisted of a series of optics mounted to an $18.5 \times 30.5$ inch optical breadboard. All the optical components were covered by a black cloth to create an optically light tight box. The breadboard for each component was mounted to a separate tripod for easy alignment. A photograph of one pDv component with the Iodine cell and APD's installed is shown in Figure 3.4.

The light scattered from the probe volume first passed through a 2.25-inch diameter opening in the front of the pDv channel. This light then impinged on a two-inch

diameter lens which focused the scattered light to a small point, which is where a variable-size pinhole was located. By varying the diameter of the pinhole opening, it was possible to vary the size of the probe volume which was sampled, in addition to varying the amount of light incident on the photodetectors. Behind the pinhole, the light was allowed to diverge to a two-inch diameter collimating lens, which transformed the diverging light beam into a constant-diameter expanded beam. After the scattered light was collimated, it was passed through a four-inch diameter custom-built Melles Griot 
non-polarization sensitive beam splitter, which was mounted on a Newport 605-4 gimbaled mount. The reflected portion of this beam was focused directly onto the reference photodetector via a four-inch diameter Newport 40D10BD.1 front surface mirror mounted on an Aerotech A0M110-4 gimbaled mount and a two-inch diameter focusing lens. The transmitted portion of the expanded beam was passed through the Iodine cell and was then focused onto the signal photodetector using another two-inch focusing lens. The components were mounted on two Melles Griot optical rails which were attached to the optical breadboard. Also included as part of each pDv component was an Iodine cell temperature controller.

\subsection{Flow Facility}

\subsubsection{Flow types considered}

This research concentrated on measuring a standard round jet flow. The round jet (Figure 3.5) was produced by attaching a plenum and nozzle to the end of the Clements National Blower Cadillac 9 amp Quick-Vac blower via a 20.5 inch long 1:2 diameter ratio steel diffuser, with a diameter of 4 inches at the outlet end. A flow straightening element was attached to the inside of the downstream end of the diffuser. Also attached to this end was a clear cylindrical Plexiglas channel which was five inches long by 4 inches in diameter. The plenum/nozzle combination was mounted to the end of this Plexiglas channel, as shown in Figure 3.6. The plenum was constructed with a five inch radius circular converging contour arc, and the nozzle continued this arc and reversed the curvature at a tangency point to complete the contraction (Cavage, 1992). 


\subsubsection{Seed Particle Feed System}

As mentioned previously, the seed particles were injected into a 32 gallon plenum in order to damp out pulsations in the smoke output. This was accomplished by attaching plastic dryer vent hose between the outlet end of the fogger and a hole cut in the plenum. Another 10 foot length of dryer hose was used to connect the plenum outlet to the inlet side of the blower.

\subsubsection{Traverse}

Since the pDv system velocity measurement components were held in fixed locations due to their complexity, a traverse was designed and built (Ramanath, 1997), to allow movement of the jet flow facility. The accuracy of this traverse has been observed to be $+/-0.001$ inches. It was electrically driven via stepper motors with a traverse range of 24 inches by 18 inches in the horizontal plane, and 12 inches vertically. A full description of the traverse is given by Ramanath (1997). A schematic of the 3-D traverse is shown in Figure 3.7.

\subsection{Laser Frequency Monitoring System (LFMS)}

Since the laser frequency varied as a function of the laboratory environment, it was necessary to monitor its output frequency as calibrations and data were taken. This was done by using the Laser Frequency Monitoring System (LFMS) shown in Figure 3.8. This consisted of a large light tight box next to the laser under which several instruments were used to monitor the laser performance. In order to monitor the laser behavior, approximately $10 \%$ of the main laser beam was picked off using a two-inch diameter circular piece of Pyrex glass just past the laser exit. This beam was directed into the box through a small quarter-inch hole on its side. Once inside the box, the laser beam was 
separated into three parts, each part going to an instrument for evaluation. First, the beam was passed through another piece of Pyrex glass (beamsplitter). The reflected portion of this beam was then passed through a neutral density filter, and was directed onto the sensing area of the Burleigh Instruments model SA-200 Plus spectrum analyzer. This spectrum analyzer was used in conjunction with a Burleigh Instruments DA-100 detector amplifier and an oscilloscope to detect the occurrence of laser mode hops. The part of the original beam that was transmitted through the first piece of Pyrex was passed through another neutral density filter and a pinhole to remove any secondary beams created by the Pyrex. After leaving the pinhole, the beam was directed through a gimbaled beamsplitter provided by Melles Griot. This beam splitter was specified to be insensitive to beam polarization to within $\pm 3 \%$. The reflected part of the laser beam was then passed through a CVI Instruments beam expander in order to prevent local saturation within the Iodine cell. This beam expander was set at 10:1, although it was adjustable from 4.5:1 to 10:1. After the beam was expanded, it was then passed through the LFMS Iodine cell and then through a two-inch focusing lens onto the Thor Labs PDA 150 fixed gain signal photodetector. The remaining third portion of the original beam was focused onto the reference PDA 150 photodetector via a two-inch focusing lens.

The entire LFMS and laser were mounted to an optical breadboard, which was placed on a vibration damping table, which consisted of a three inch high wooden box open on the top and filled half way with sand. On top of the sand four eight-inch diameter inner tubes were placed such that they could be inflated/deflated through twelve-inch extension valves to level the breadboard. 


\subsection{Computer Equipment}

\subsubsection{Computers}

The computers used for data acquisition were a Windows NT 4.0-based PC, as well as a Windows 95-based PC. The NT computer used an Intel $266 \mathrm{MHz}$ Pentium II processor, 393 megabytes of RAM, and 5 hard drives with 11.52 gigabytes of storage, while the Windows 95 computer used an Intel $400 \mathrm{MHz}$ Pentium II processor, 64 megabytes of RAM and over 13 gigabytes of hard disk storage. The Windows 95 computer was used to acquire the data through the lower resolution $\mathrm{A} / \mathrm{D}$ board as in Collins (2000) and Webb (1999) as well as for all data reduction. The NT computer was used to acquire data through the new, higher resolution A/D board. The computer used to control the traverse was a Windows 95-based PC. This computer used an Intel 486 series processor operating at $80 \mathrm{MHz}$.

\subsubsection{Data Acquisition Boards}

The A/D boards used for this research were an IO Tech ADC488/8SA 16 bit variable gain A/D board, as well as an 8-channel National Instruments 6052E multifunction I/O board. The IO Tech board was an external unit that was interfaced to the data acquisition computer via an IEEE 488 cable and a National Instruments ATGPIB/TNT controller card. The 6052E was an internal card capable of sampling up to $333 \mathrm{kHz}$ over eight channels (41.625 kHz/channel), at a voltage scale as small as $+/-50$ mV. This board was used in conjunction with a National Instruments SC2040 eightchannel simultaneous sample-and-hold signal conditioning board. The SC2040 is an eight-channel simultaneously sampling differential amplifier for National Instruments 
A/D boards. Each channel provided a DIP-switch-selectable gain followed by a track and hold amplifier. The track and hold amplifier sampled all inputs simultaneously.

\subsubsection{Software}

Various software packages were used for data acquisition, data reduction, A/D board control, and traverse control. In order to use the new National Instruments boards for data acquisition, software was developed in Visual Basic 4.0, which made use of the National Instruments NI-DAQ driver package. A complete description of the software used to reduce the velocity data is given by Webb (1999). A description of the traverse control software is given by Ramanath (1997). 


\section{Chapter 4 - Experimental Procedure}

\subsection{Alignment}

\subsubsection{Initial Steps}

Before a data run could take place, several initial steps were taken to ensure a good optical alignment of all $\mathrm{pDv}$ components, as well as to prepare the electronic components. First, the laser, and A/D boards were turned on and allowed to warm up for approximately 2 hours. The ROSCO fog machine was turned on approximately 20 minutes prior to a data run.

To verify that both measurement components were in the same plane formed by the laser beam and jet axis, the height from the laboratory floor to the jet centerline was measured and checked against the height of the mirror which directed the laser beam into the flowfield. Once these heights were equal, the heights of the tripods holding $\mathrm{pDv}$ components were changed until they equaled the height to the jet centerline. This was done after leveling both $\mathrm{pDv}$ breadboards on the tripod heads. The next preliminary step was to verify that the laser beam was perpendicular to the jet axis. This was accomplished by measuring the distance from the nozzle lip to the laser beam on both sides of the nozzle. These steps were only usually done once after the lab setup was changed from DGV to $\mathrm{pDv}$.

\subsubsection{Component Alignment}

Before the pDv components could be aligned, they both had to be looking at the same probe volume. In order to produce a probe volume, a $1 \mathrm{~mm}$ wide clear vellum pointer was attached to the nozzle via a piece of aluminum L-channel, as shown in Figure 4.1. The lower $1 \mathrm{~mm}$ of the clear vellum tab was painted white, to increase reflectivity. 
The $1 \mathrm{~mm} \times 1 \mathrm{~mm}$ white tab was placed carefully such that it was in the center of the 2 mm diameter unfocused laser beam. The purpose of this was to ensure that the components were being focused on the maximum intensity portion of the Gaussian laser intensity distribution across the beam diameter. For runs with the beam focused, a focusing lens was attached to a tripod and placed in the beam path. Since the original unfocused beam was already aligned on the pointer, the focused beam was adjusted until it was aligned on the tab.

Once the beam was properly aligned with the reference tab, the pinhole diameter on each component was minimized, so that the interference fringes could be viewed behind the pinhole. The light scattered off the tab was collected by a front lens and focused through the pinhole at its minimum diameter. To ensure that the component was looking at the center of the tab, the interference fringes behind the pinhole were centered with respect to each other. The light passing through each of the optical components was then checked to verify that it was centered on each optic. The light that was focused onto the photodetectors was then checked to make sure that it was centered on the active surface of the detector. Also, it was occasionally necessary to adjust the APD gains to obtain similar voltage levels for both the forward and back scatter components. This was done because it was desirable for each component to saturate at the same smoke level, at the same time, so that both components would have similar signal-to-noise ratios.

\subsection{Data Acquisition}

Data files consisted of 8,192 points sampled at $10 \mathrm{kHz}$, for the IO Tech A/D board, and 4,096 points, acquired at a sampling rate of $320 \mathrm{kHz}$, over 8 channels, equivalent to a $40 \mathrm{kHz}$ sampling rate for each channel on the new National Instruments 
board. The data (newer board) was acquired on a voltage scale of $+/-0.5$ Volts. This voltage scale provided the maximum resolution, and the lowest RMS noise levels when measured with the inputs shorted. The voltage scale was changed by changing the SC2040 board gain simultaneously with the National Instruments Measurement and Automation Explorer control software gain. The gains were set to 10; however, the actual gain remained 1, because the National Instruments board control software canceled the SC2040 gain, while altering the voltage scale. Data points were taken at each jet axial location, starting at the exit and progressing to 12 inches $(\mathrm{x} / \mathrm{D}=0.25,0.5,1,2,3,4$, $5,6,8,10,12)$. These points were taken at a constant $\mathrm{z}$ location, or height of the jet, on the jet centerline. Measurements have also been obtained for lateral traverses across the jet, at various $\mathrm{x} / \mathrm{D}$ locations, where lateral traverse increments have been selected so as to yield approximately 20 data points across the jet. Data was acquired through $50-\mathrm{Ohm}$ terminations on each of the pDv component inputs. This reduced the effect of the noise measured. It also allowed a higher photodetector output while still using the $+/-0.5$ Volt scale.

\section{3 lodine Cell Calibration}

To produce a calibration of the Iodine cells, the flow speed was reduced to about $3 \mathrm{~m} / \mathrm{s}$ and the smoke level was adjusted to get the correct output signal levels from the photodetectors (the highest signal attainable without exceeding the 0.5 Volt saturation point). Calibration files were 2,048 data points long, and were taken at $800 \mathrm{~Hz}$ over 8 channels. In order to be able to predict the transmission through the Iodine cell as a function of laser light frequency, the laser frequency was scanned through the left side of the Iodine absorption profile, by mechanically tilting the etalon. The calibration data 
displayed a stair-step pattern, due to the mode hops of the laser. This can be seen in Figure 4.2. Each of these steps was averaged to arrive at the data point for that particular mode as shown in Figure 4.3. These averaged calibration files were then trimmed (Figure 4.4) to ensure that only the left portion of the calibration file was used. After trimming, the data for each calibration file was slid along the frequency axis using linear interpolation such that all of the individual absorption profiles were overlaid. A nonlinear, least squares curve fit was then performed using the Boltzmann fitting function,

$$
y=\frac{A_{1}-A_{2}}{1+e^{\left[\frac{x-x_{0}}{D_{x}}+A_{2}\right]}}
$$

where $A_{1}$ and $A_{2}$ are the upper and lower ratio bounds, $x_{0}$ represents the frequency shifting factor, and $D_{x}$ is the scaling factor. An addition to this method was to trim the resulting calibration file prior to curve fitting such that it spanned from approximately $200 \mathrm{MHz}$ to $1800 \mathrm{MHz}$. This was done to reduce the influence of the upper and lower points or the curve on the Boltzmann curve fit. An example of a final calibration curve set is shown in Figure 4.5. A more complete description of the Boltzmann fitting function can be found in Naylor (1998). It should be noted that calibration quality was observed to increase somewhat with decreasing calibration flow speed.

As can be seen from Figure 4.6, the normalized instantaneous ratios for all three Iodine cells for an exit data file are almost identical, except for a small amount of noise within each signal. This implies that the calibration accuracy could perhaps be improved if the calibrations were normalized, or scaled to one. This would also eliminate the need to perform a calibration at every data acquisition session, since the current vapor-limited Iodine cell frequency response does not appear to change with time. 


\subsection{Data Reduction}

Data reduction took place following the calibration curve fit. Since the sensitivity of the pDv measurement components was dependent on their viewing angles, several distances were measured and used to calculate the angles between the incident laser direction and the viewing directions of the two pDv components. Distances measured were: mirror to the flow exit; mirror to the forward scatter channel; mirror to the back scatter channel; flow exit to the forward scatter channel; flow exit to the back scatter channel; back scatter channel to the forward scatter channel. These distances were used to find the angles using two different methods. The average of the two angles found was used for data reduction. Agreement between the angles from the two different calculation methods was typically 0.1-0.6 degrees. After opening the raw data files, the low voltage thresholds were selected for both the forward and backscatter channels for the APD runs. Data below this minimum threshold was discarded. Typical threshold values were 0.03, 0.001 or 0.003 Volts, depending on the geometry of the components, since the backscatter channel was almost four times as sensitive to velocity fluctuations as the forward scatter channel.

When data was recorded, the ratios were calculated and written to the data file. This was done for each data point within each file. Using the Boltzmann function from the calibration curve fit, the frequency corresponding to each of the data points were calculated. The frequency shift was then found by subtracting the LFMS-measured laser frequency from that of each pDv component. This frequency shift was used, along with the laser properties, in the Doppler shift equation,

$$
\Delta f=\frac{f_{o}}{c}(\vec{a}-\vec{i}) \bullet \vec{V}
$$


to arrive at the relative velocities for each component, where $\Delta f$ was the Doppler frequency shift, $f_{o}$ was the laser frequency, c was the speed of light, $\vec{a}$ was the unit vector between the flow and receiving optics, $\vec{i}$ was the unit vector along the incident laser direction, and $\vec{V}$ was the particle velocity vector. The velocity vector sensed by the pDv system was in the direction of the bisector of the angle formed by the incident laser direction and the viewing direction, as can be seen in Figure 4.7. The orthogonal velocities were then found by using the geometry of the system. More details of the software code used for data reduction have been given by James (1997) and Webb (1999). 


\section{Chapter 5 - Results}

Data has been acquired for the standard circular jet using PIN and APD photodetectors and a focused laser beam. One APD run is presented with an unfocused laser beam, in order to determine the best performance of the APD's with no focusing to aid in the RMS velocity quality. The results are compared to the earlier pDv data from Collins (2000), as well as hot-wire data acquired for the same jet. Mean and RMS velocity data are presented on separate graphs as well as on composite plots, for easy comparison to hot-wire data. It can be seen from these plots, that when the PIN photodetectors were replaced with the APD's, the RMS velocity results were improved; however, there was generally also some decay in the quality of the mean velocity results along the centerline of the jet. One data set is presented for which the PIN detectors were installed in the backscatter component while the APD's were installed in the forward scatter component. This was done in an effort to determine the source of the mean circumferential velocity offset, which will be discussed later.

\subsection{PIN Photodetector Results}

Two complete runs with the PIN photodetectors are presented in the composite plots in Figures 5.1 - 5.4. Data was acquired at x/D locations of 0, 1, 2, 4, 6, 8, 10, and 12. Table 5.1 summarizes the test conditions. The axial exit velocity for the first run was approximately $62 \mathrm{~m} / \mathrm{s}$, with a variability from a smooth curve of approximately $2 \mathrm{~m} / \mathrm{s}$. Pitot probe results from Collins (2000) exhibited a variability of $1 \mathrm{~m} / \mathrm{s}$. This velocity did not begin to decay until $\mathrm{x} / \mathrm{D}=4$, indicating the existence of a potential core. The centerline axial velocity for the first run decayed to approximately $27.5 \mathrm{~m} / \mathrm{s}$ at $\mathrm{x} / \mathrm{D}=12$. Axial RMS velocity results for this run were approximately $1.5 \mathrm{~m} / \mathrm{s}$ at the exit, increasing 
to approximately $6.6 \mathrm{~m} / \mathrm{s}$ at an $\mathrm{x} / \mathrm{D}=8$, and then reducing to approximately $5.9 \mathrm{~m} / \mathrm{s}$ at $\mathrm{x} / \mathrm{D}=12$. These results are shown in Figure 5.1.

Figure 5.2 shows the circumferential velocity results of the first run. Mean circumferential velocities varied from $-0.75 \mathrm{~m} / \mathrm{s}$ to $0.3 \mathrm{~m} / \mathrm{s}$ at the jet centerline for all $\mathrm{x} / \mathrm{D}$ locations; however, this worsened considerably in the shear layer region, due to the reduced flow seeding levels, and thus low signal, in this portion of the jet, particularly at large $\mathrm{x} / \mathrm{D}$ locations. Circumferential RMS velocities for the first run were very similar to the axial RMS velocities from Figure 5.1 at the exit and 1 diameter downstream, however, beyond this point, for corresponding x/D locations, the axial RMS velocity was larger than the circumferential RMS velocities by approximately $0.5 \mathrm{~m} / \mathrm{s}$.

Figure 5.3 illustrates the mean and RMS velocity results for the second run using the PIN photodetectors and a focused laser beam. This second run was acquired using the IO Tech A/D board (see Table 5.1). For this run, the mean exit axial velocity was approximately $64 \mathrm{~m} / \mathrm{s}$, with a variability from a smooth curve of approximately $1 \mathrm{~m} / \mathrm{s}$. Unlike the first run, this mean axial velocity began to decay at 2 diameters downstream; however, this is not physical. Two possible explanations for this are that the pinhole diameters were increased for the second run, and the focal length of the focusing lenses used in each run were different. The mean axial velocity decayed to approximately 28 $\mathrm{m} / \mathrm{s}$ at $\mathrm{x} / \mathrm{D}=12$. Axial RMS velocities for the second run matched those in the first run to within approximately $0.5 \mathrm{~m} / \mathrm{s}$, overall. Again, the maximum centerline RMS velocity reached a maximum at $\mathrm{x} / \mathrm{D}=8$ of approximately $6.3 \mathrm{~m} / \mathrm{s}$.

Composite plots of the circumferential mean and RMS velocities for the $2^{\text {nd }}$ run are shown in Figure 5.4. For this run, the mean circumferential velocity at the centerline 
was confined to between approximately $0.25-0.75 \mathrm{~m} / \mathrm{s}$. This value remained quite constant laterally, until beyond $\mathrm{r} / \mathrm{D}=+/-1.5$, where the signal level was too low to obtain proper signal levels to maintain a useful signal-to-noise ratio. Circumferential RMS velocities increased from approximately $1.2 \mathrm{~m} / \mathrm{s}$ at the exit to $5 \mathrm{~m} / \mathrm{s}$ at $\mathrm{x} / \mathrm{D}=8$, then decayed to approximately $4.8 \mathrm{~m} / \mathrm{s}$ twelve diameters downstream. These values matched the previous run to within approximately $0.5-1 \mathrm{~m} / \mathrm{s}$, depending on the axial location.

One traverse along the centerline of the jet was done for each of the two runs. This data is plotted in Figures 5.5 and 5.6 for runs 1 and 2, respectively. As shown in Figure 5.5, the centerline mean axial velocity decays from approximately $63 \mathrm{~m} / \mathrm{s}$ at the exit to approximately $27 \mathrm{~m} / \mathrm{s}$ at $\mathrm{x} / \mathrm{D}=12$. This is in good agreement with the results of the lateral traverses shown in Figure 5.1. The circumferential mean velocity is a nearly constant value of $0 \mathrm{~m} / \mathrm{s}$, as expected. The axial and circumferential RMS velocities are approximately equal at the jet exit, with the circumferential slightly higher. These values increase to approximately $7 \mathrm{~m} / \mathrm{s}$ for the axial RMS and $6.1 \mathrm{~m} / \mathrm{s}$ for the circumferential RMS velocity at $\mathrm{x} / \mathrm{D}=8$. Both values decay to approximately $5.8 \mathrm{~m} / \mathrm{s}$ at $\mathrm{x} / \mathrm{D}=12$.

Figure 5.6 shows the centerline velocities for the second run. The axial mean velocity is approximately $63 \mathrm{~m} / \mathrm{s}$ at the exit and drops off to approximately $28 \mathrm{~m} / \mathrm{s}$ at twelve diameters downstream. The mean circumferential velocities are slightly higher than for the first run by approximately $2 \mathrm{~m} / \mathrm{s}$. RMS axial velocities increase from approximately $1 \mathrm{~m} / \mathrm{s}$ at the exit to approximately $6.8 \mathrm{~m} / \mathrm{s}$ for the axial RMS and $5 \mathrm{~m} / \mathrm{s}$ for the circumferential RMS velocity at $\mathrm{x} / \mathrm{D}=8$. 


\subsection{Hot-wire and Previous pDv Comparisons for PIN Data}

Figure 5.7 is a comparison of the lateral exit traverses with earlier hot wire and pDv data by Collins (2000). It can be seen from this figure that the two PIN detector runs with focusing gave mean axial velocity results that were consistently higher than the data from Collins (2000), in which the same PIN photodetectors were used. All three runs were consistently of a higher mean axial velocity than the hot wire results, almost over the entire lateral traverse. The first run exhibited a mean axial exit velocity of approximately $61 \mathrm{~m} / \mathrm{s}$, while run 2 showed an exit velocity of approximately $63 \mathrm{~m} / \mathrm{s}$. Data from Collins (2000) showed a mean exit velocity of approximately $60 \mathrm{~m} / \mathrm{s}$, while the hot wire measured a mean exit axial velocity of approximately $58 \mathrm{~m} / \mathrm{s}$. Run 1 displayed a variability from a smooth curve of approximately 1-2 m/s. Axial RMS velocities at the exit were consistent with Collins' data to within approximately $0.4 \mathrm{~m} / \mathrm{s}$. All three data sets overestimated the exit axial RMS velocity by approximately $1.1 \mathrm{~m} / \mathrm{s}$, over the lateral traverse of $\mathrm{r} / \mathrm{D}=+/-0.4$. RMS velocity results became noisy at the outer edges of the jet, near the shear layer, due to low signal strength, and a correspondingly low signal-to-noise ratio.

The mean axial velocity at $\mathrm{x} / \mathrm{D}=4$ (Figure 5.8) agreed very well with the hot wire results for run 1 . The agreement was estimated to be within $+/-1 \mathrm{~m} / \mathrm{s}$ near the centerline and $+/-3 \mathrm{~m} / \mathrm{s}$ beyond r/D's of $+/-0.4$. Collins (2000) and run 2 both underestimated the hot wire results by approximately $5 \mathrm{~m} / \mathrm{s}$, on average, although run 2 matched Collins' data to within $4 \mathrm{~m} / \mathrm{s}$ at worst and $0.5 \mathrm{~m} / \mathrm{s}$ at best. Axial RMS velocities for runs 1 and 2 , as well as Collins' data underestimated the hot wire results for $\mathrm{x} / \mathrm{D}=4$. Run 1 matched the best, but was low by approximately $0.5 \mathrm{~m} / \mathrm{s}$ on the centerline, and less accurate 
everywhere else. Run 2 was low by about $1 \mathrm{~m} / \mathrm{s}$. Both runs exhibited the same physical trend that the hot wire measured, increasing RMS velocities from the centerline to $\mathrm{r} / \mathrm{D}=$ 0.5 and then decreasing toward the outer edge of the shear layer. Both runs with focusing were better than Collins (2000) by approximately $0.9 \mathrm{~m} / \mathrm{s}$ over the entire lateral traverse for run 2 and about $1.3 \mathrm{~m} / \mathrm{s}$ for run 1 .

As seen in Figure 5.9, mean axial velocities at $\mathrm{x} / \mathrm{D}=6$ agreed well with the hot wire results for both runs. Runs 1 and 2 matched the hot wire results to within $1 \mathrm{~m} / \mathrm{s}$ at the centerline and out to $\mathrm{r} / \mathrm{D}=0.5$. Beyond this radius, both runs underestimated the hot wire results by about $2-5 \mathrm{~m} / \mathrm{s}$, following the trend of Collins' data. This may be due to inaccuracies in the hot wire data near the edges of the jet. RMS velocities at 6 diameters downstream again underestimated the hot wire results. Run 1 was low by approximately $2 \mathrm{~m} / \mathrm{s}$ on the centerline and worsened at larger r/D locations. Run 2 underestimated the hot wire measurements by approximately $3 \mathrm{~m} / \mathrm{s}$ on the centerline and followed the same trend as run 1. Collins' data was lower than both runs 1 and 2, by approximately $0.75 \mathrm{~m} / \mathrm{s}$ at the centerline. The data at the outer edges of the jet were dominated by the system noise, as shown by the stray points beyond $\mathrm{r} / \mathrm{D}=+/-0.75$.

Mean axial data for $\mathrm{x} / \mathrm{D}=8$ (Figure 5.10) matched the hot wire measurements very well. Run 1 was within approximately $2 \mathrm{~m} / \mathrm{s}$ over $\mathrm{r} / \mathrm{D}=+/-1$, while run 2 matched this trend. Run 2 overestimated the mean axial velocity around the centerline by approximately $2-3 \mathrm{~m} / \mathrm{s}$ but quickly converged to the hot wire curve beyond $\mathrm{r} / \mathrm{D}=+/-$ 0.25. Again, noise dominated the data at the edge of the jet, causing both runs to underestimate the hot wire measurement by approximately $5 \mathrm{~m} / \mathrm{s}$ at $\mathrm{r} / \mathrm{D}=+/-1.5$. Both runs continued to show low RMS axial velocities at $\mathrm{x} / \mathrm{D}=8$. Run 1 was approximately 2 
$\mathrm{m} / \mathrm{s}$ too low while run 2 was approximately $2.2 \mathrm{~m} / \mathrm{s}$ too low on the centerline. Both runs were higher than the data by Collins (2000) by approximately $1.3 \mathrm{~m} / \mathrm{s}$ on the entire lateral traverse. Noise effects at the edge of the jet can be seen in the stray points beyond $\mathrm{r} / \mathrm{D}=$ $+/-1.25$.

Comparisons were made between the two centerline traverses, Collins' data and the hot wire results, in Figure 5.11. The mean axial centerline velocities for both runs overestimated the hot wire result by approximately $4 \mathrm{~m} / \mathrm{s}$ at the exit, and by approximately $2 \mathrm{~m} / \mathrm{s}$ at $\mathrm{x} / \mathrm{D}=12$. Collins (2000) underpredicted the hot wire result everywhere except the exit and at $\mathrm{x} / \mathrm{D}=12$. Axial RMS velocities for both runs matched Collins' data well at the exit, to within $0.1 \mathrm{~m} / \mathrm{s}$, and out to $\mathrm{x} / \mathrm{D}=5$. Beyond this, runs 1 and 2 both were higher than Collins by approximately $1.5 \mathrm{~m} / \mathrm{s}$. From the exit to $\mathrm{x} / \mathrm{D}=3$, all the $\mathrm{pDv}$ data overestimated the hot wire measurements, after which the $\mathrm{pDv}$ data was too low, compared to the hot wire. At the exit, runs 1 and 2 were too high by approximately $1 \mathrm{~m} / \mathrm{s}$, while at $\mathrm{x} / \mathrm{D}=8$, the data was too low by approximately $2 \mathrm{~m} / \mathrm{s}$.

\subsection{APD Results}

Figure 5.12 shows the run made with APD's installed and no laser beam focusing. The mean axial centerline velocity is approximately $4 \mathrm{~m} / \mathrm{s}$ too low at $56 \mathrm{~m} / \mathrm{s}$, decaying to approximately $22 \mathrm{~m} / \mathrm{s}$ at $\mathrm{x} / \mathrm{D}=12$. The mean circumferential velocity was between -3 $\mathrm{m} / \mathrm{s}$ and $-1 \mathrm{~m} / \mathrm{s}$. The axial RMS data was much improved over the PIN detector data, as will be discussed shortly. The axial RMS velocity at the exit was approximately $0.5 \mathrm{~m} / \mathrm{s}$ for the axial and $0.6 \mathrm{~m} / \mathrm{s}$ for the circumferential velocity. The maximum RMS velocity was approximately $7.5 \mathrm{~m} / \mathrm{s}$ for the axial and 5.1 for the circumferential velocity at $\mathrm{x} / \mathrm{D}=$

8. Figure 5.13 shows the data run with APD's and a focused laser beam. The mean axial 
velocity at the exit is approximately $60 \mathrm{~m} / \mathrm{s}$ and holds constant until $\mathrm{x} / \mathrm{D}=4$, showing the potential core region of the jet. The axial velocity decays to approximately $20 \mathrm{~m} / \mathrm{s}$ at x/D $=12$. The circumferential mean velocity was a constant $-7 \mathrm{~m} / \mathrm{s}$. This appeared to be a mean velocity offset, which was probably due an alignment error. It should be noted that later runs have been made with PIN detectors in the backscatter component, and this offset was drastically reduced. The RMS values were approximately $1 \mathrm{~m} / \mathrm{s}$ for both the axial and the circumferential velocities at the exit and increased to approximately $10 \mathrm{~m} / \mathrm{s}$ and $7 \mathrm{~m} / \mathrm{s}$ for the axial and circumferential RMS velocities, respectively, at $\mathrm{x} / \mathrm{D}=8$.

Although not presented here, data was also taken at the jet exit for a slow jet flow (approximately $3 \mathrm{~m} / \mathrm{s}$ ). These slow data runs displayed a typical circumferential RMS velocity of approximately $0.2-0.3 \mathrm{~m} / \mathrm{s}$ at the exit, illustrating the measurement resolution of an APD-based point Doppler velocimeter.

\subsection{APD Comparisons with Hot Wire and Previous pDv Data}

Figure 5.14 is a comparison between the two pDv data runs and hot wire data as well as pDv data from Collins (2000). The mean axial velocity for the APD run with focusing was too high relative to the hot wire data from the exit to $x / D=4$, by approximately $2 \mathrm{~m} / \mathrm{s}$, after which, it was too low, by approximately $5 \mathrm{~m} / \mathrm{s}$, on average. The APD run with an unfocused beam was too low over the entire traverse of the jet, by approximately 3-6 m/s. Both APD runs gave mean axial velocity results that were higher than the data from Collins, although the unfocused APD run matched to within $2-4 \mathrm{~m} / \mathrm{s}$ over the entire centerline traverse. The RMS velocities at the exit for the unfocused APD run matched the hot wire to within $0.1 \mathrm{~m} / \mathrm{s}$. This continued up to $\mathrm{x} / \mathrm{D}=3$, after which the APD run was too low, by approximately $2 \mathrm{~m} / \mathrm{s}$. The RMS data for the APD run with 
focusing matched Collins' pDv data at the exit, but was too high relative to the hot wire beyond $\mathrm{x} / \mathrm{D}=2$, by approximately $1-1.5 \mathrm{~m} / \mathrm{s}$ at $\mathrm{x} / \mathrm{D}=8$. In contrast, Collins' data was too low relative to hot wire results by approximately $2-4 \mathrm{~m} / \mathrm{s}$.

\subsection{Combined APD/PIN Data}

Figure 5.15 illustrates the axial results of the data run with the PIN photodetectors in the backscatter component and the APD's in the forward scatter component. The mean axial velocity profiles were very uniform, with a variation from a smooth curve of approximately $+/-1 \mathrm{~m} / \mathrm{s}$ near the exit. The measurements indicate a potential core region extending from the exit to $x / D=4$, where the mean axial velocity begins to decay. The mean exit velocity on the centerline was approximately $56 \mathrm{~m} / \mathrm{s}$. This velocity decayed to approximately $24 \mathrm{~m} / \mathrm{s}$ at $\mathrm{x} / \mathrm{D}=12$. RMS velocities indicated good agreement $(+/-0.2$ $\mathrm{m} / \mathrm{s})$ at the exit, as well as at $\mathrm{x} / \mathrm{D}=8(+/-2 \mathrm{~m} / \mathrm{s})$. Data at the edges of the jet was noisy due to low signal strength.

Figure 5.16 is a composite plot of the mean circumferential velocities. This data indicated a velocity range of approximately $-0.3 \mathrm{~m} / \mathrm{s}$ to $1.5 \mathrm{~m} / \mathrm{s}$ for all $\mathrm{x} / \mathrm{D}$ locations within the radius of the jet nozzle. Outside the nozzle radius, however, the velocities became very noisy, particularly at six and eight diameters downstream. The circumferential RMS velocities are reduced compared to the two runs with the PIN detectors. The exit circumferential RMS velocity was approximately $0.6 \mathrm{~m} / \mathrm{s}$, increasing to approximately $5.2 \mathrm{~m} / \mathrm{s}$ at $\mathrm{x} / \mathrm{D}=8$.

Centerline velocity data is shown in Figure 5.17 for the PIN/APD combination run as well as the hot wire data. Mean exit velocities were approximately $56 \mathrm{~m} / \mathrm{s}(\sim 3 \mathrm{~m} / \mathrm{s}$ less than hot wire), decreasing after the potential core region (x/D $<4)$ to approximately 
$18 \mathrm{~m} / \mathrm{s}$ at $\mathrm{x} / \mathrm{D}=12$, which is approximately $8 \mathrm{~m} / \mathrm{s}$ lower than the hot wire results. Mean circumferential velocities for this run were approximately $0 \mathrm{~m} / \mathrm{s}$, with a maximum variation of no more than $+/-2 \mathrm{~m} / \mathrm{s}$. This result is significantly better than other APD runs with focusing, which often had a mean velocity offset of no more than $-7 \mathrm{~m} / \mathrm{s}$. Centerline axial RMS velocities agreed quite well with hot wire data, to within $0.3 \mathrm{~m} / \mathrm{s}$ at the exit and to within $1 \mathrm{~m} / \mathrm{s}$ at $\mathrm{x} / \mathrm{D}=8$.

\subsection{Combined PIN/APD Data Agreement With Theory}

A comparison between the combined run data presented in Figure 5.15 and the Görtler theoretical prediction as mentioned in White (1991) for the circular jet has been made in Figure 5.18. The pDv data has been normalized to allow an easy composite plot comparison with the theory. Data was presented from $\mathrm{x} / \mathrm{D}=4$ and beyond since the data did not match the theory near the exit. Since the theory was based on a constant eddy viscosity, the decay near the edges of the jet is not as dramatic as in experiments. It should be noted that in White (1991), the theoretical profile was at a minimum $x / D=20$. For $|\mathrm{r} / \mathrm{x}|<0.1$, the data agree reasonably well with the Görtler theory, with some scatter.

As can be seen in Figure 5.19, the jet half-width profile was not a smooth curve from 2 diameters downstream to 12 diameters downstream. This non-uniformity was believed to be due to jet movement in the flow facility, i.e., the nozzle was fixed, but the jet flow wandered as a result of the building pressure drop when the doors were opened and movement of people within the lab area. It is believed that higher quality data could be obtained with a more controlled laboratory setting. Then, the jet width growth results should be linear beyond the jet potential core, and the lateral profiles of mean axial velocity would be expected to collapse to the Görtler theory. 
Figure 5.20 shows the same experimental data from Figure 5.18 plotted using the measured jet half-width to normalize the data, rather than the axial location, as was done in Kuhlman (1986). The resulting profiles were much more self-similar at $\mathrm{x} / \mathrm{D}=4$ and beyond. The data agreed to the Kuhlman theory to within $+/-5-6 \%$ for $x / D \geq 4$.

\subsection{Error Model}

A simple error model was developed which was used to predict the minimum possible velocity resolution for each component. These minimum velocities were based on the noise levels of the A/D board, which were measured with the inputs to the board shorted. The noise levels for the board were added to the reference and subtracted from the signal voltages, which were then used to find an error ratio. This error ratio was then propagated through the Iodine cell calibration curve to obtain an error frequency, which was used, along with the component sensitivities, to determine the velocity error. This was done for each component as well as the LFMS. A typical error model analysis is shown in Table 5.2 for measurements on the centerline at the jet exit at a low velocity $(\sim 3$ $\mathrm{m} / \mathrm{s}$ ). The backscatter RMS velocity was overpredicted by approximately $60 \%$, while the forward scatter RMS velocity was overpredicted by a factor of about 3.5. This case was chosen because it was expected that the lowest RMS velocities would occur when the jet was laminar. 


\section{Chapter 6 - Conclusions and Recommendations}

\subsection{Conclusions}

Improvements have been made to an existing Point Doppler Velocimeter (pDv). Axial RMS velocity results have been improved through the use of large area avalanche photodetectors, as well as focusing of the laser beam to reduce the probe volume size, and also through the use of a new higher resolution A/D board. The use of the APD's at times resulted in a mean circumferential velocity offset of up to $-7 \mathrm{~m} / \mathrm{s}$, the cause of which is still unknown. Focusing while using the standard PIN photodetectors tended to improve the mean axial velocities from the Collins (2000) data. Although reducing the probe volume size in conjunction with the PIN detectors helped somewhat, the use of APD's with an unfocused beam drastically reduced the exit RMS velocities to levels comparable to the hot wire results.

In order to document these improvements, velocity data was acquired for a standard circular 1 inch diameter jet. This flow was selected because it was well documented, and could easily be made more complex through the addition of a swirler, or an annular nozzle.

The APD data with an unfocused beam matched the hot wire RMS axial velocity at the exit of the jet, while the APD data with the reduced probe volume (focused beam) matched the mean axial velocity at the jet exit to within $2 \mathrm{~m} / \mathrm{s}$. Runs with the PIN detectors and a reduced probe volume improved the mean axial velocity results, but did not improve the axial RMS velocities at the jet exit. Focusing while using the PIN detectors did; however, improve the downstream RMS velocities somewhat, although these peak RMS levels were still 20-30\% low relative to hot wire results. Focusing while 
using the APD's yielded RMS levels that were too high relative to hot wire data, beyond $\mathrm{x} / \mathrm{D}=2$, by $1-2 \mathrm{~m} / \mathrm{s}(10-30 \%)$.

Non-dimensional mean exit velocities for the combined PIN/APD data run agreed with the Görtler theory to within $+/-23-25 \%$ for $4<x / D<12$, and to within $+/-5-6 \%$ for a Gaussian profile.

\subsection{Recommendations}

There are various ways to improve the overall accuracy of the modified $\mathrm{pDv}$ system. First, it would be beneficial if linear amplifiers were used to amplify the signals from the APD's, thereby increasing the signal-to-noise ratio significantly. This is currently being done at NASA LaRC, and would be a good "next step" for the WVU pDv/DGV lab. Second, the calibration accuracy could perhaps be improved if the calibrations were scaled to one. This would eliminate the need to perform a calibration at every data acquisition session, since the vapor-limited Iodine cell frequency response does not change with time. Another calibration procedure that was followed in Collins (2000) was to take two calibration sets, one before and one following data acquisition. The better of the two calibrations was then used to reduce the data. This was not done for the current research, and would be a way to improve the chances of acquiring a good calibration. Noise at the edges of the jet could possibly be reduced by utilizing a coflowing jet, which would increase the seeding level and therefore the signal level at the edges of the jet. Finally, a problem that was encountered recently was that the water supply pressure to the laser would become so low, as a result of building water use, that the laser would turn off in the middle of a data run or calibration. When the laser was 
turned back on, there was no way of guaranteeing that the beam was in the same location as before, therefore the alignment could have been wrong for parts of those data runs. 


\section{References}

Ainsworth, R.W., and Thorpe, S.J., "The Development of a Doppler Global Velocimeter for Transonic Turbine Applications," International Gas Turbine and Aeroengine Congress and Exposition, The Hague, Netherlands, June 13-16, 1994.

Ainsworth, R.W., Thorpe, S.J., and Manners, R.J., "A New Approach to Flow-Field Measurement - A View of Doppler Global Velocimetry Techniques," International Journal of Heat and Fluid Flow, Vol. 18, No. 1, pp. 116-30, February 1997.

Beutner, T.J., Elliot, G., Mosedale, A., and Carter, C., "Doppler Global Velocimetry Applications in Large Scale Facilities," AIAA Paper 98-2608, $20^{\text {th }}$ Advanced Measurement and Ground Testing Technology Conference, Albuquerque, NM, June 15-18, 1998.

Clancy, P.S. and Samimy, M., "Multiple-Component Velocimetry in High Speed Flows Using Planar Doppler Velocimetry," AIAA Paper 97-0497, 35 ${ }^{\text {th }}$ Aerospace Sciences Meeting, Reno, NV, Jan. 6-9, 1997.

Clancy, P.S., Samimy, M., and Erskine, W.R., "Planar Doppler Velocimetry: ThreeComponent Velocimetry in Supersonic Jets," AIAA Paper 98-0506, $36^{\text {th }}$ Aerospace Sciences Meeting, Reno, NV, Jan. 12-15, 1998.

Crafton, J., Messersmith, N.M., and Sullivan, J.P., "Filtered Doppler Velocimetry: Development of a Point System," AIAA Paper 98-0509, $36^{\text {th }}$ Aerospace Sciences Meeting \& Exhibit, Reno, NV, Jan. 12-15, 1998.

Cavage, W., "The Ground Vortex Flow Field Associated with a Jet Impinging in a Cross Flow for Uniform and Annular Turbulent Axisymmetric Jets," MS Thesis, Department of Mechanical and Aerospace Engineering, College of Engineering, West Virginia University, 1992.

Collins, P.M., "Point Doppler Velocimetry (PDV) Measurements in Circular Jets," MS Thesis, Department of Mechanical and Aerospace Engineering, College of Engineering and Mineral Resources, West Virginia University, 2000.

Elliott, G.S., Samimy, M., and Arnette, S.A., "Details of a Molecular Filter-Based Velocimetry Technique," AIAA Paper 94-0490, 32 ${ }^{\text {nd }}$ Aerospace Sciences Meeting, Reno, NV, Jan. 10-13, 1994.

Elliott, G.S., Mosedale, A., Gruber, M.R., Nejad, A.S., and Carter, C.D., "The Study of a Transverse Jet in a Supersonic Cross-Flow Using Molecular Filtered Based Diagnostics," AIAA Paper 97-2999, 33 ${ }^{\text {rd }}$ AIAA/ASME/SAE/ASEE Joint Propulsion Conference, Seattle, WA, July 6-9, 1997. 
Elliott, G.S., and Beutner, T.J., "Molecular filter based planar Doppler Velocimetry," Progresses in Aerospace Sciences, Vol. 35. pp. 799-845, 1999.

Forkey, J.N., Finkelstein, N.D., Lempert, W.R., and Miles, R.B., "Control of Experimental Uncertainties in Filtered Rayleigh Scattering Measurements," AIAA Paper 95-0298, 33 ${ }^{\text {rd }}$ Aerospace Sciences Meeting, Reno, NV, Jan. 9-12, 1995.

Forkey, J.N., Finkelstein, N.D., Lempert, W.R., and Miles, R.B., “Demonstration and Characterization of Filtered Rayleigh Scattering for Planar Velocity Measurements," AIAA Journal, Vol. 34, No. 3, March 1996.

Hoffenberg, R., and Sullivan, J.P., "Filtered Particle Scattering: Laser Velocimetry Using an Iodine Filter,” ASME-FED, Vol. 161, pp. 135-138, June 20-24, 1993.

James, K.M., "Determination of the Accuracy of a Two-Component Point Doppler Velocimetry System," MS Thesis, Department of Mechanical and Aerospace Engineering, College of Engineering, West Virginia University, June 1997.

Komine, H., United States patent, Patent No. 4,919,536, pp.1-16, April 24, 1990.

Komine, H. and Brosnan, S.J., "Instantaneous, Three-Component, Doppler Global Velocimetry,” Laser Anemometry - Vol. 1, pp. 273-277, ASME 1991.

Komine, H., Brosnan, S.J., Litton, A.B. and Stappaerts, E.A., "Real-Time Doppler Global Velocimetry," AIAA Paper 91-0337, 29 ${ }^{\text {th }}$ Aerospace Sciences Meeting, Reno, NV, Jan. 7-10, 1991.

Kuhlman, J., "Variation of Entrainment in Annular Jets," paper 86-1111, AIAA/ASME Fourth Fluid Mechanics, Plasma Dynamics and Lasers Conference, Atlanta, GA, May 12-14, 1986.

Kuhlman, J., Naylor, S., James, K, and Ramanath, S., “Accuracy Study of a 2Component Point Doppler Velocimeter (PDV)," AIAA Paper 97-1916, $28^{\text {th }}$ AIAA Fluid Dynamics Conference, Snowmass Village, CO, June 29-July 2, 1997.

Kuhlman, J., and Webb, D.L., "2-Component Point Doppler Velocimetry (PDV) Measurements of Turbulent Flow Over an Airfoil," AIAA Paper 99-3517, 30 ${ }^{\text {th }}$ AIAA Fluid Dynamics Conference, Norfolk, VA, June 28-July1, 1999.

Kuhlman, J., and Collins, P., "Circular Jet 2-Component Point Doppler Velocimetry (PDV) Velocity Data," Paper AIAA-2000-2296, 21 $1^{\text {st }}$ AIAA AMT/GT Conference, Denver, CO, June 19-22, 2000.

Kuhlman, J. and Scarberry, T., "Improved Point Doppler Velocimeter (pDv) Turbulence 
Data in Circular Jets," Paper AIAA-2001-0700, 39 ${ }^{\text {th }}$ AIAA Aerospace Sciences Meeting and Exhibit, Reno, NV, January 8-11, 2001

Kuhlman, J., Collins, P., and Scarberry, T., "Two-component point Doppler velocimetry data in circular jets," Measurement Science and Technology, Vol. 12, No. 4, pp. 395-408, April 2001.

Kuhlman, J., Burton, L., and Scarberry, T., "Doppler Global Velocimetry (DGV) Data in Circular Jets," paper 6.3, $19^{\text {th }}$ International Congress on Instrumentation in Aerospace Simulation Facilities, August 27-30, 2001, Cleveland, OH.

McKenzie, R.L., "Measurement Capabilities of Planar Doppler Velocimetry Using Pulsed Lasers," AIAA Paper 95-0297, 33 ${ }^{\text {rd }}$ Aerospace Sciences Meeting, Reno, NV, Jan. 9-12, 1995.

McKenzie, R.L., "Planar Doppler Velocimetry Performance in Low-Speed Flows," AIAA Paper 97-0498, 35 ${ }^{\text {th }}$ Aerospace Sciences Meeting, Reno, NV, Jan. 6-9, 1997.

McKenzie, R.L., "Planar Doppler Velocimetry for Large-Scale Wind Tunnel Applications," Paper No. 9, AGARD Fluid Dynamics Panel 81 ${ }^{\text {st }}$ Meeting and Symposium on Advanced Aerodynamic Measurement Technology, Seattle, WA, Sep. 22-25, 1997.

Meyers, F.F., and Komine, H., "Doppler Global Velocimetry A New Way to Look at Velocity," ASME $4^{\text {th }}$ International Conference on Laser Anemometry, Cleveland, OH, Aug. 3-9, 1991.

Meyers, J.F., Lee, J.W., and Cavone, A.A., "Signal Processing Schemes for Doppler Global Velocimetry," IEEE $14^{\text {th }}$ International Congress on Instrumentation in Aero Simulation Facilities (ICIASF), Rockville, MD, Oct. 27-31, 1991.

Meyers, J.F., “Doppler Global Velocimetry: The Next Generation?,” AIAA Paper 923897, $17^{\text {th }}$ Aerospace Ground Testing Conference, Nashville, TN, July 6-8, 1992.

Meyers, J.F., "Development of Doppler Global Velocimetry as a Flow Diagnostics Tool," Measurement Science and Technology, Vol. 6, No. 6, pp. 769-783, June 1995.

Meyers, J.F., "Evolution of Doppler Global Velocimetry Data Processing," $8^{\text {th }}$ International Symposium on Applications of Laser Techniques to Fluid Mechanics, Lisbon, Portugal, pp. 1-22, July 8-11, 1996.

Meyers, J.F., Personal Communication, 2000-2001.

Miles, R.B., Forkey, J.N., and Lempert, W.R., "Filtered Rayleigh Scattering 
Measurements in Supersonic/Hypersonic Facilities," AIAA $17^{\text {th }}$ Aerospace Ground Testing Conference, Nashville, TN, July 6-8, 1992.

Naylor, S., "Development and Accuracy Determination of a Two-Component Doppler Global Velocimeter (DGV)," Ph.D. Dissertation, Department of Mechanical and Aerospace Engineering, college of Engineering and Mineral Resources, West Virginia University, July 1998.

Naylor S., and Kuhlman, J., "Accuracy Studies of a Two-Component Doppler Global Velocimeter (DGV)," AIAA Paper 98-0508, 36 ${ }^{\text {th }}$ Aerospace Sciences Meeting and Exhibit, Reno, NV, Jan. 12-15, 1998.

Naylor, S., and Kuhlman, J., "Results for a Two-Component Doppler Global Velocimeter (DGV)," AIAA Paper 99-0268, 37 ${ }^{\text {th }}$ Aerospace Sciences Meeting and Exhibit, Reno, NV, Jan. 11-14, 1999.

Ramanath, S., "Development of a Point Doppler Global Velocimeter (DGV)," MS Thesis, Department of Mechanical and Aerospace Engineering, College of Engineering, West Virginia University, 1997.

Roehle, I. and Schodl, R., "Evaluation of the Accuracy of the Doppler Global Technique," Optical Methods and Data Processing in Heat and Fluid Flow, London, UK, pp. 155-61, Apr. 14-15, 1994.

Roehle, I., "Three-Dimensional Doppler Global Velocimetry in the flow of a fuel spray nozzle and in the wake region of a car," Flow Measurement and Instrumentation, Vol. 7, No. 3/4, pp. 287-94, 1996.

Smith, M.W. and Northam, G.B., "Application of Absorption Filter-Planar Doppler Velocimetry to Sonic and Supersonic Jets," AIAA Paper 95-0299, $33^{\text {rd }}$ Aerospace Sciences Meeting, Reno, NV, Jan. 9-12, 1995.

Samimy, M. and Wernet, M.P., "A Review of Planar Multiple-Component Velocimetry in High Speed Flows," AIAA Paper 98-2509, $20^{\text {th }}$ Advanced Measurement and Ground Testing Technology Conference, Albuquerque, NM, June 15-18, 1998.

Smith, M.W., Northam, G.B., and Drummond, J.P., "Application of Absorption Filter Planar Doppler Velocimetry to Sonic and Supersonic Jets," AIAA Journal, Vol. 34, No. 3, pp. 434-41, March 1996.

Thorpe, S.J., Ainsworth, R.W., and Manners, R.J., "The Development of a Doppler Global Velocimeter and its Application to a Free Jet Flow," FED-Vol. 229, Laser Anemometry, ASME, 1995.

Thorpe, S.J., Ainsworth, R.W., and Manners, R.J., “Time-Averaged Free Jet 
Measurements Using Doppler Global Velocimetry," FED-Vol. 239, Fluids Engineering Division Conference, Vol. 4, ASME 1996.

Webb, D., "Development of and Measurements using a Point Doppler Velocimetry (PDV) System," MS Thesis, Department of Mechanical and Aerospace Engineering, College of Engineering and Mineral Resources, West Virginia University, 1999.

White, Frank M., Viscous Fluid Flow, $2^{\text {nd }}$ Edition, McGraw-Hill, Inc., 1991. 
Table 5.1 Data run setup summary

\begin{tabular}{|c|c|c|c|c|c|}
\hline & Run 1 - PIN's & Run 2 - PIN's & APD Run 1 & APD Run 2 & PIN/APD Run \\
\hline Focused Beam & Yes & Yes & No & Yes & Yes \\
\hline A/D Board Used & IOTech & IOTech & NI - 6052E & NI - 6052E & NI - 6052E \\
\hline Voltage Scale & $+/-5$ Volts & $+/-5$ Volts & $+/-1 / 2$ Volts & $+/-1 / 2$ Volts & $+/$ - 1/2 Volts \\
\hline $\begin{array}{c}\text { Sample } \\
\text { Frequency }\end{array}$ & $\begin{array}{c}10 \mathrm{kHz} \text { per } \\
\text { channel }\end{array}$ & $\begin{array}{c}10 \mathrm{kHz} \text { per } \\
\text { channel }\end{array}$ & $\begin{array}{c}10 \mathrm{kHz} \text { per } \\
\text { channel }\end{array}$ & $\begin{array}{c}40 \mathrm{kHz} \text { per } \\
\text { channel }\end{array}$ & $\begin{array}{c}40 \mathrm{kHz} \text { per } \\
\text { channel }\end{array}$ \\
\hline $\begin{array}{c}\text { Viewing Angles } \\
\text { (degrees) }\end{array}$ & $25.3 / 153.4$ & $24.7 / 152.5$ & $21.5 / 143.7$ & $33.0 / 146.1$ & $26.5 / 145.9$ \\
\hline $\begin{array}{c}\text { Approximate } \\
\text { Reference Ratio }\end{array}$ & 0.7 & 0.67 & 0.68 & 0.72 & 0.69 \\
\hline
\end{tabular}




\section{Table 5.2 Error model predicting resolution for slow centerline exit data}

Back Scatter Channel Velocity Error Calculations

Channel Sensitivity $(\mathrm{MHz} / \mathrm{m} / \mathrm{s})=$

3.814

Boltzmann Parameter Input From Data Reduction Screen

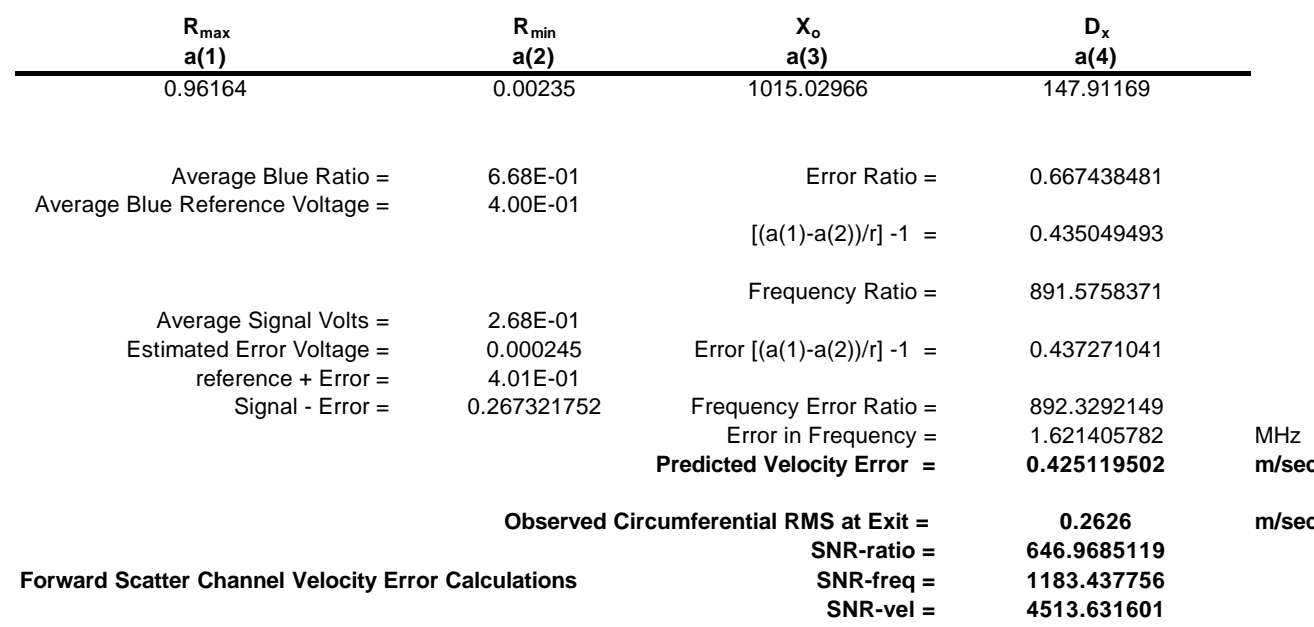

Channel Sensitivity $(\mathrm{MHz} / \mathrm{m} / \mathrm{s})=$

1.204

Boltzmann Parameter Input From Data Reduction Screen

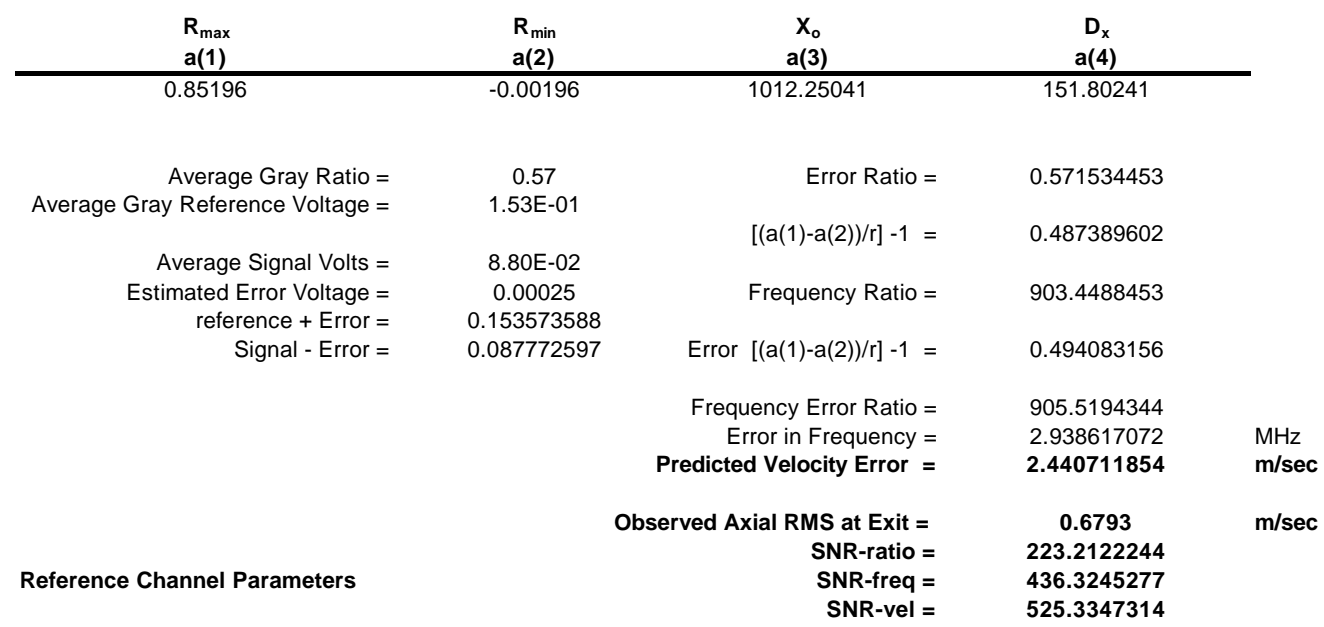

Boltzmann Parameter Input From Data Reduction Screen

\begin{tabular}{|c|c|c|c|}
\hline $\begin{array}{l}R_{\max } \\
\mathbf{a}(1)\end{array}$ & $\begin{array}{l}\mathbf{R}_{\min } \\
\mathbf{a}(2)\end{array}$ & $\begin{array}{c}X_{\circ} \\
a(3) \\
\end{array}$ & $\begin{array}{c}D_{x} \\
a(4)\end{array}$ \\
\hline 1.05762 & 0.00658 & 997.58424 & 152.06434 \\
\hline $\begin{array}{r}\text { Average Red Ratio }= \\
\text { Average Red Reference Voltage }=\end{array}$ & $\begin{array}{c}0.68 \\
4.05 \mathrm{E}-01\end{array}$ & Error Ratio $=$ & 0.679696621 \\
\hline Average Signal Volts $=$ & 2.76E-01 & {$[(\mathrm{a}(1)-\mathrm{a}(2)) / \mathrm{r}]-1=$} & 0.543227182 \\
\hline $\begin{array}{r}\text { Estimated Error Voltage }= \\
\text { reference }+ \text { Error }=\end{array}$ & $\begin{array}{c}0.000268 \\
0.405014192\end{array}$ & Frequency Ratio = & 903.7897898 \\
\hline Signal - Error $=$ & 0.275286778 & Error $[(\mathrm{a}(1)-\mathrm{a}(2)) / \mathrm{r}]-1=$ & 0.54633695 \\
\hline & & Frequency Error Ratio = & 904.6578177 \\
\hline
\end{tabular}




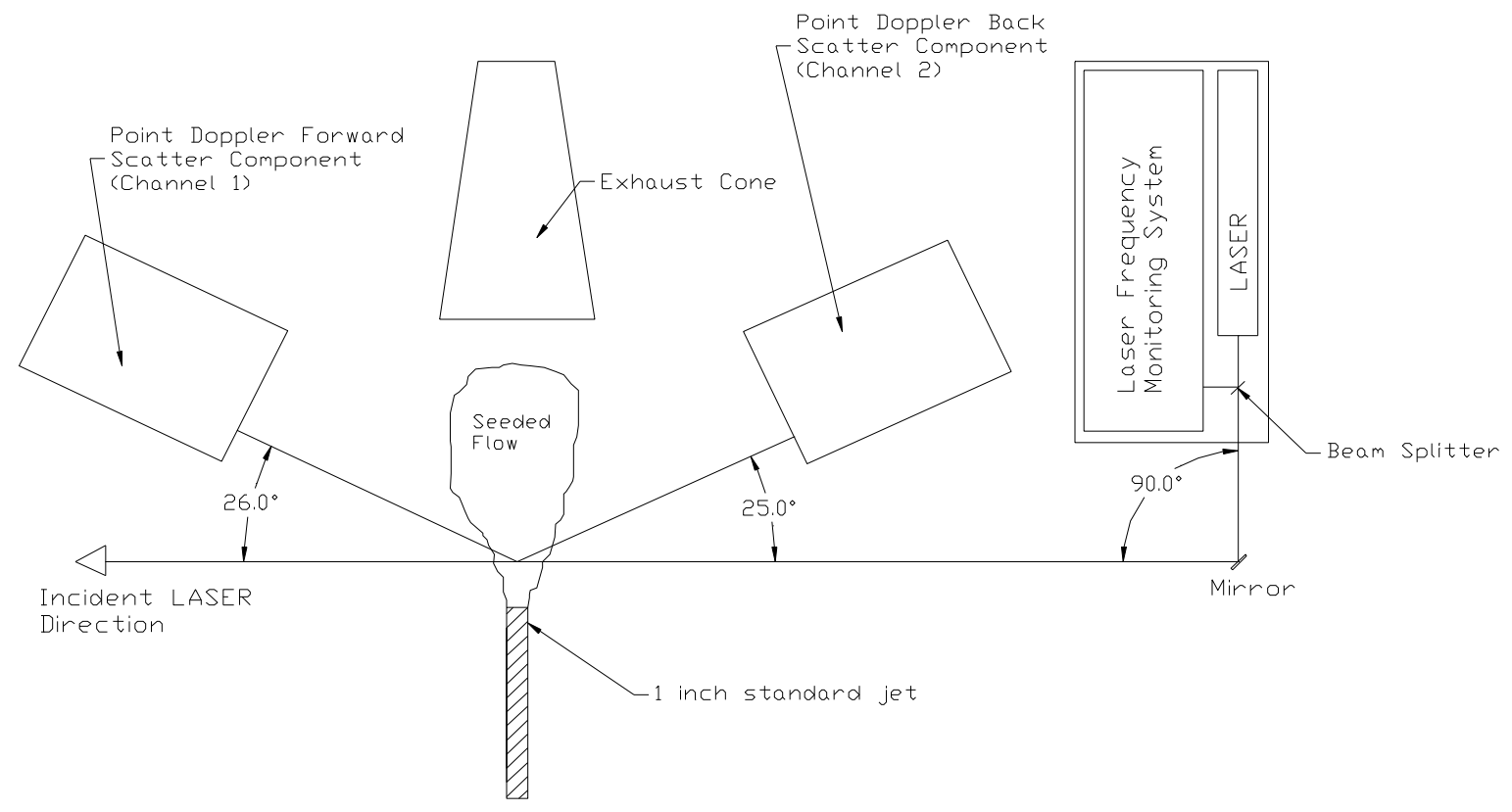

Figure 3.1 Top view schematic of pDv laboratory.

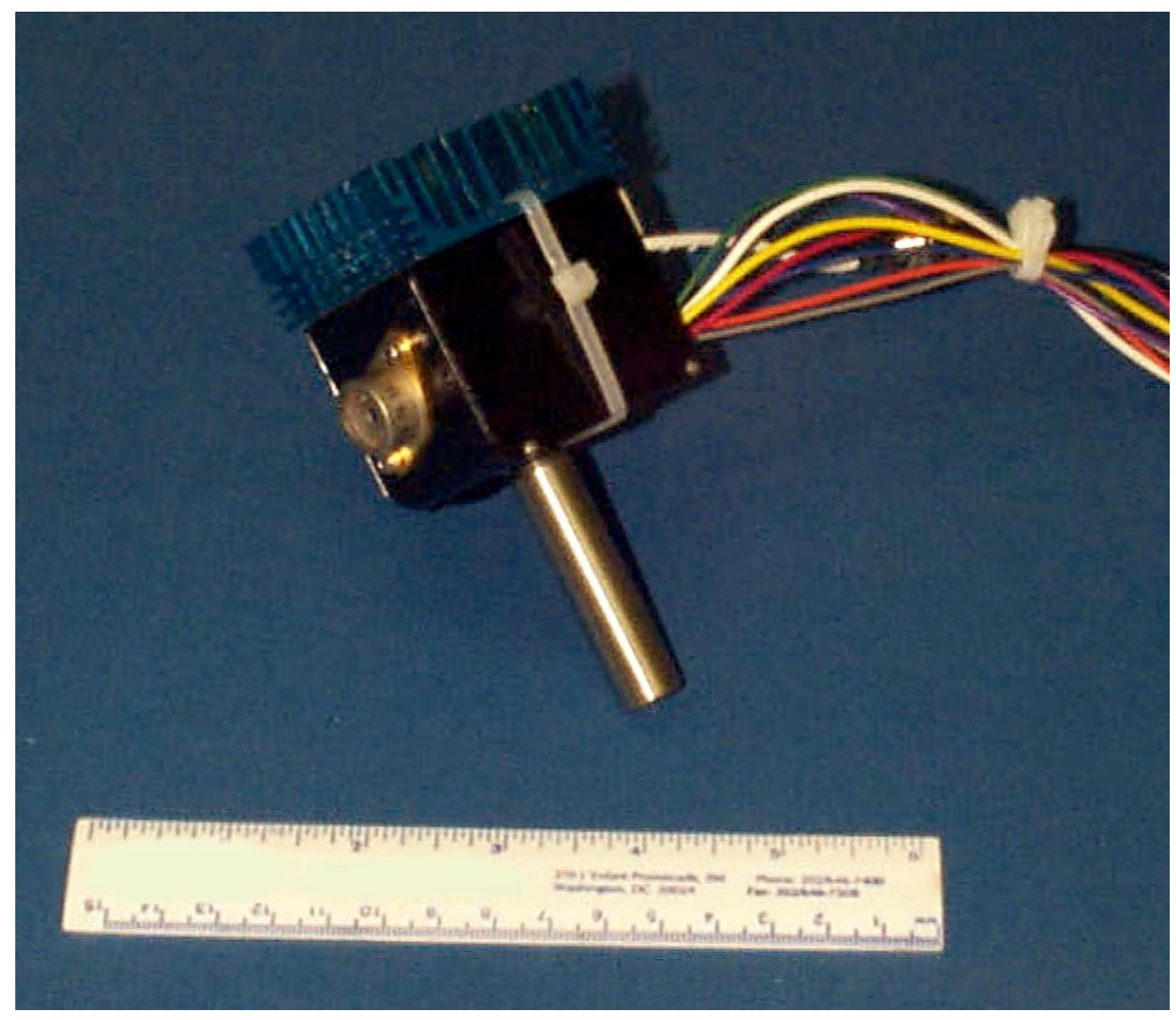

Figure 3.2 Avalanche photodetector module with heat sink attached. 


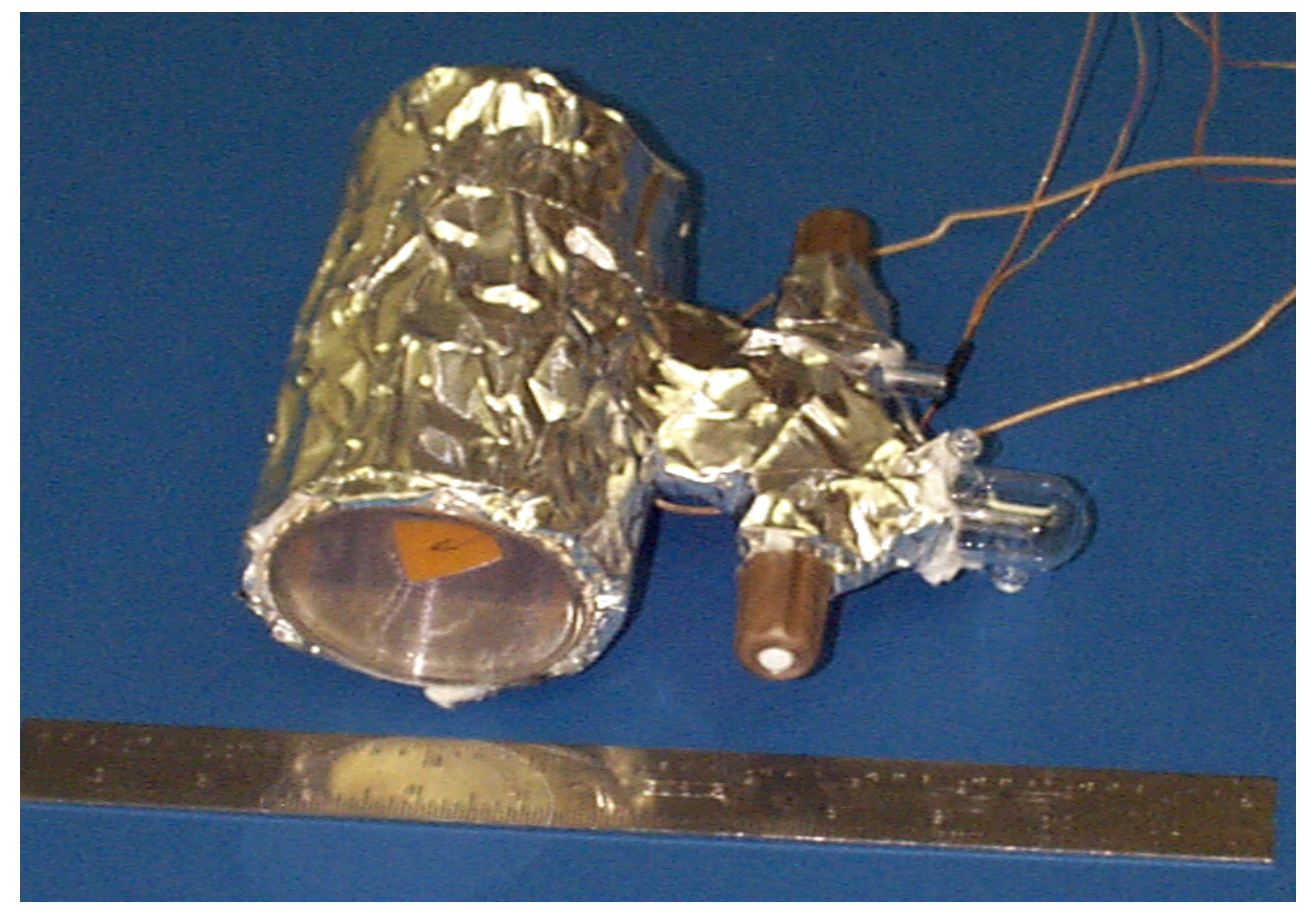

Figure 3.3 Iodine cell wrapped in heater tape and metal foil

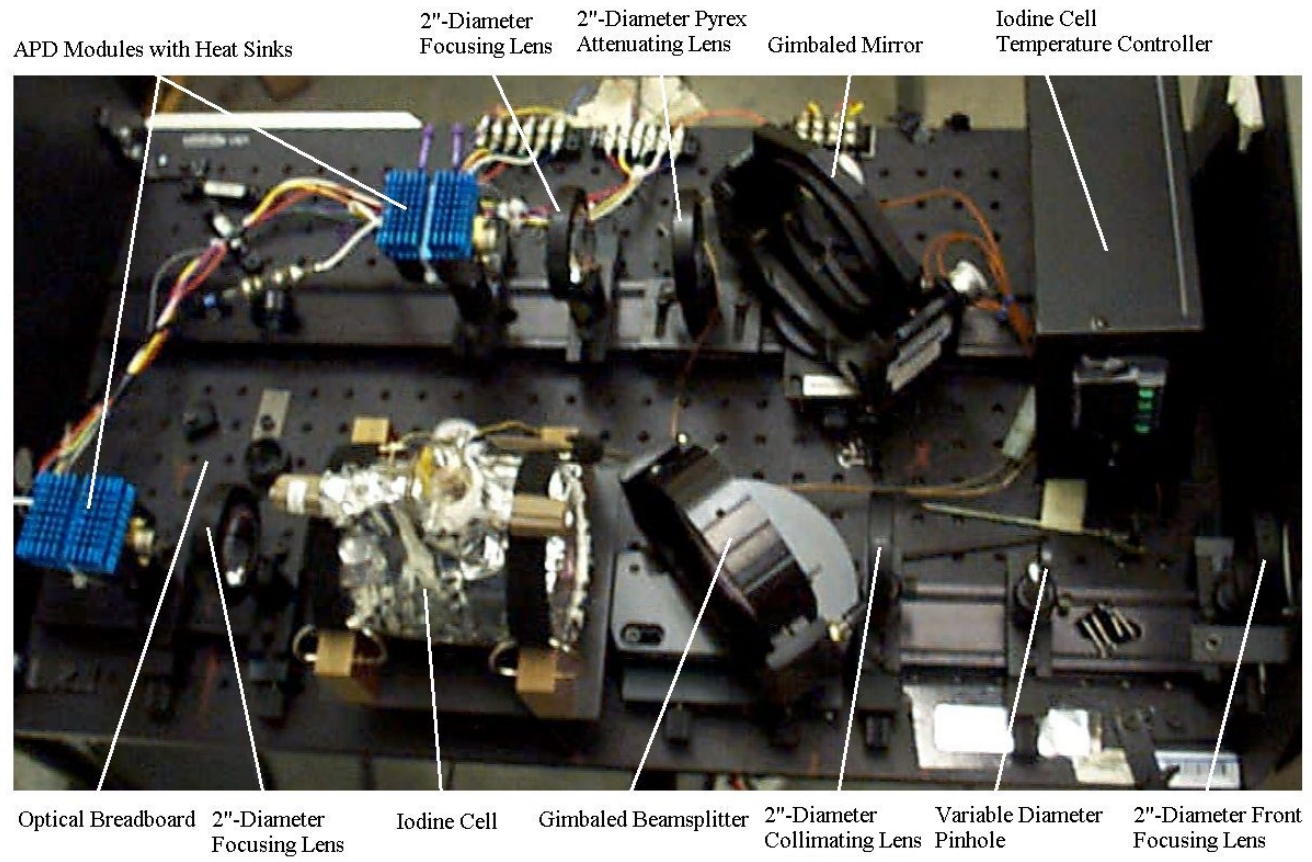

Figure 3.4 Typical point Doppler velocimetry measurement component setup 


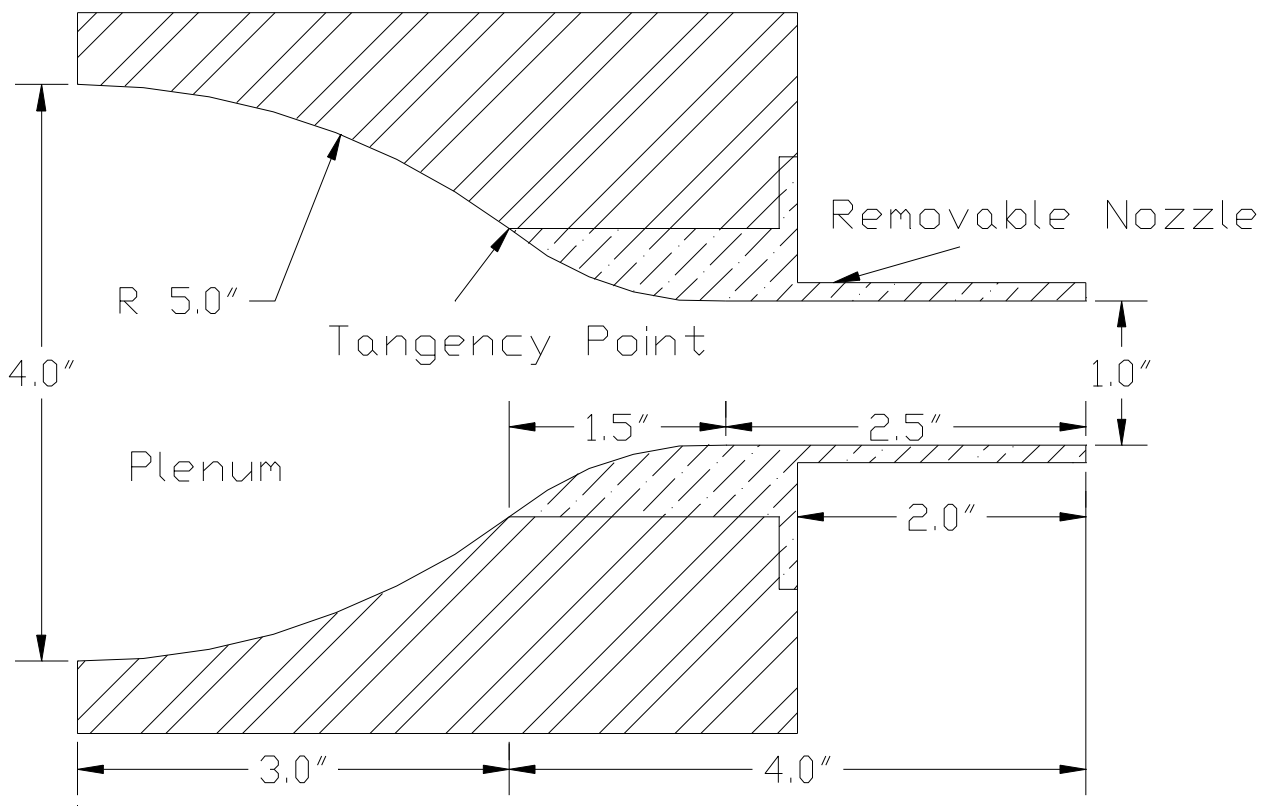

Figure 3.5 Cross section of the circular jet and plenum

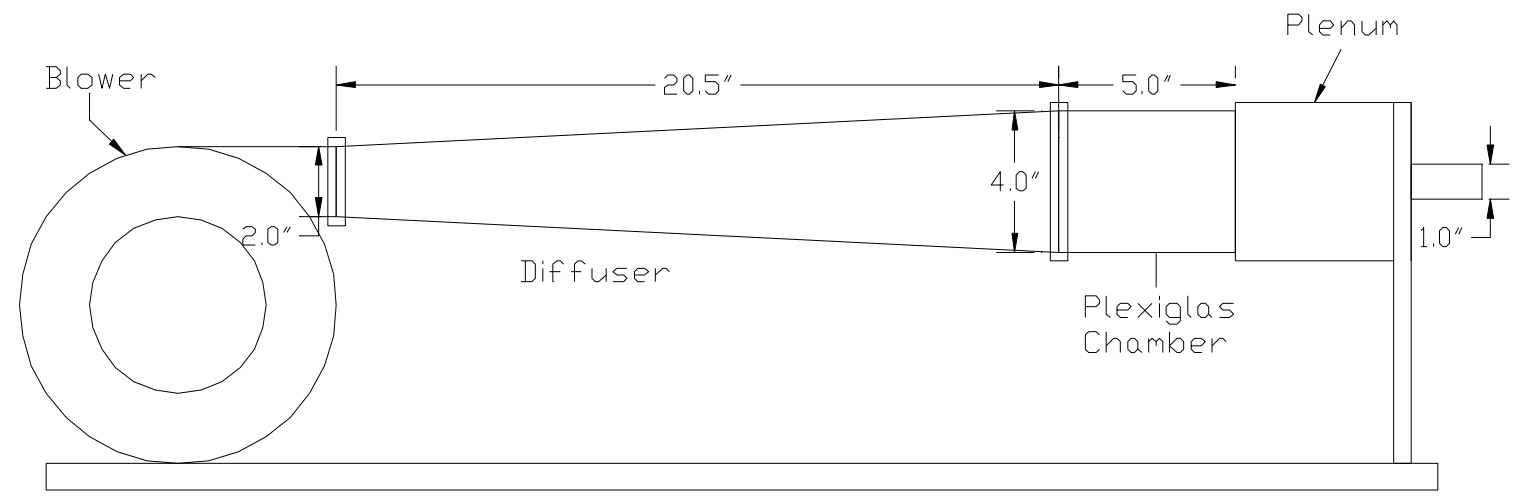

Figure 3.6 Schematic of blower/diffuser/plenum/nozzle combination 


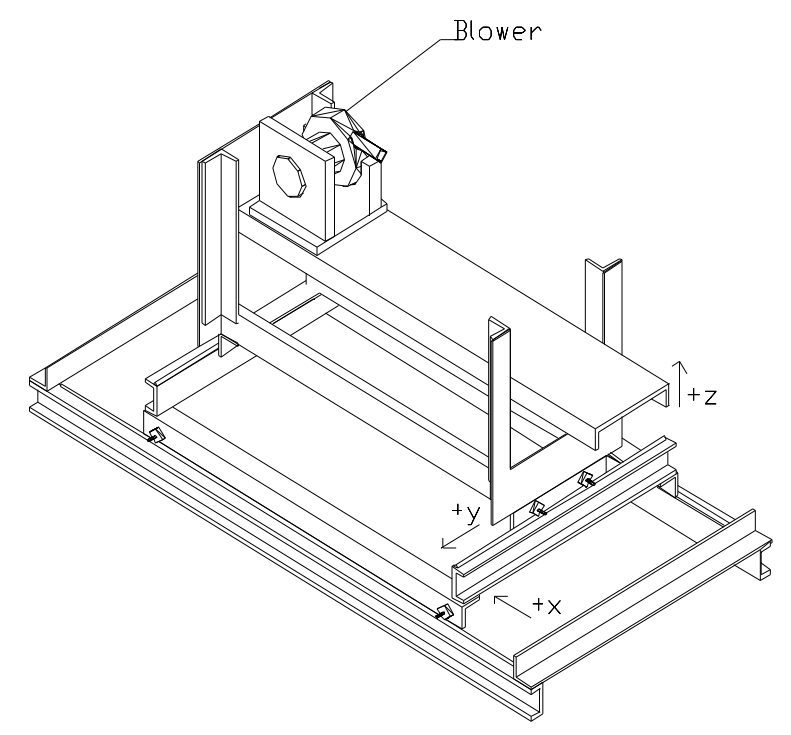

Figure 3.7 Schematic of 3-dimensional traverse

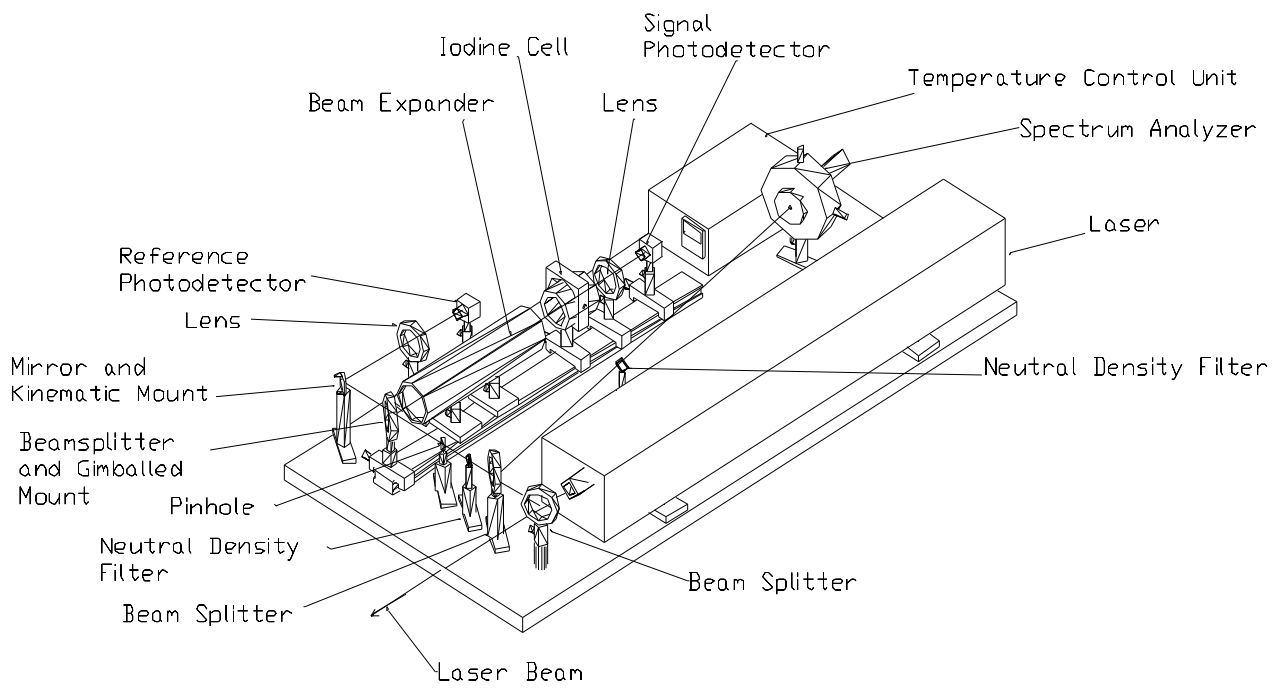

Figure 3.8 Schematic of laser frequency monitoring system (LFMS) 


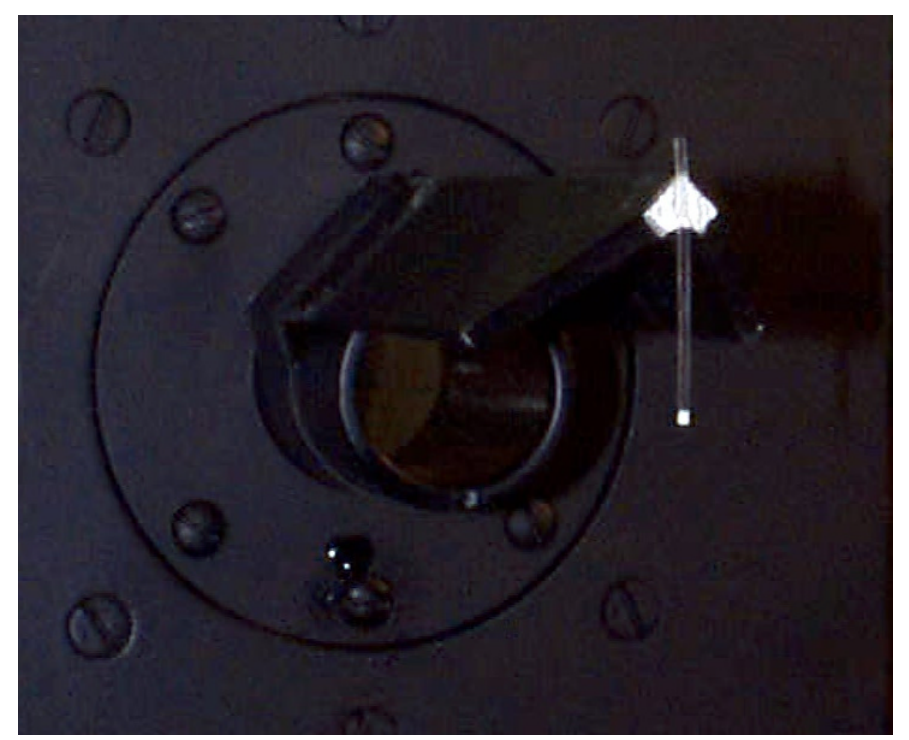

Figure 4.1 Pointer used for pDv component alignment installed on nozzle

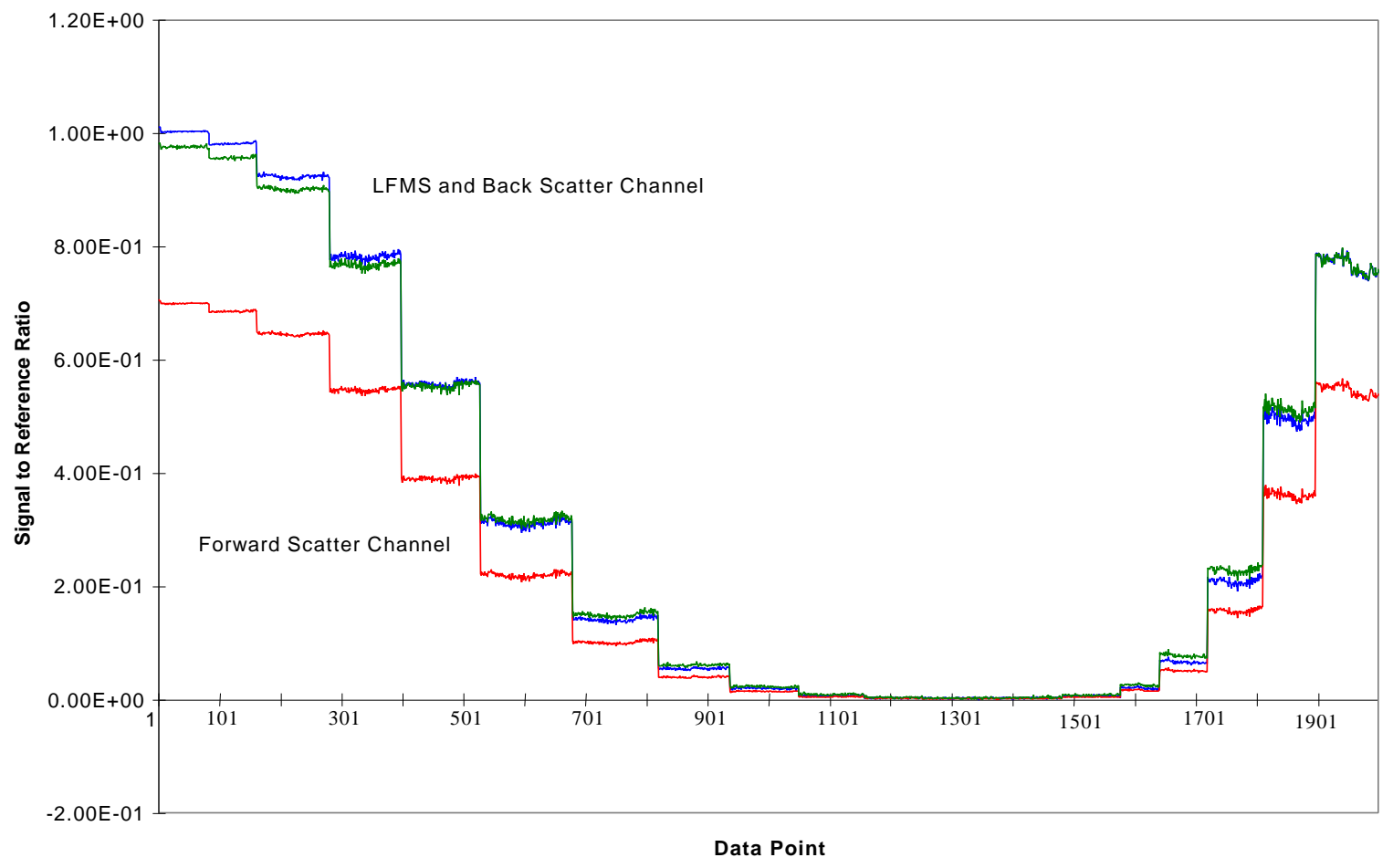

Figure 4.2 Plot of raw calibration ratios 


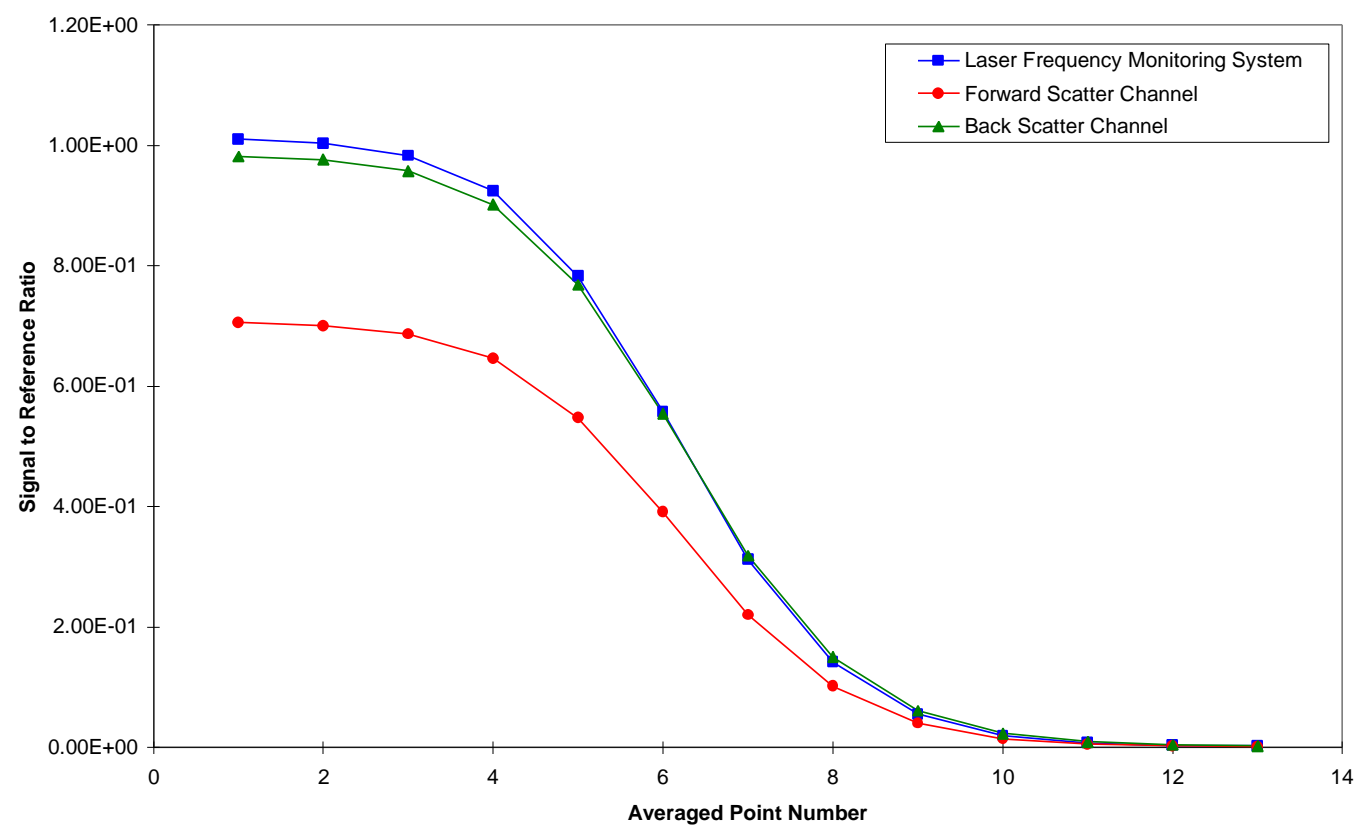

Figure 4.3 Typical averaged calibration curves

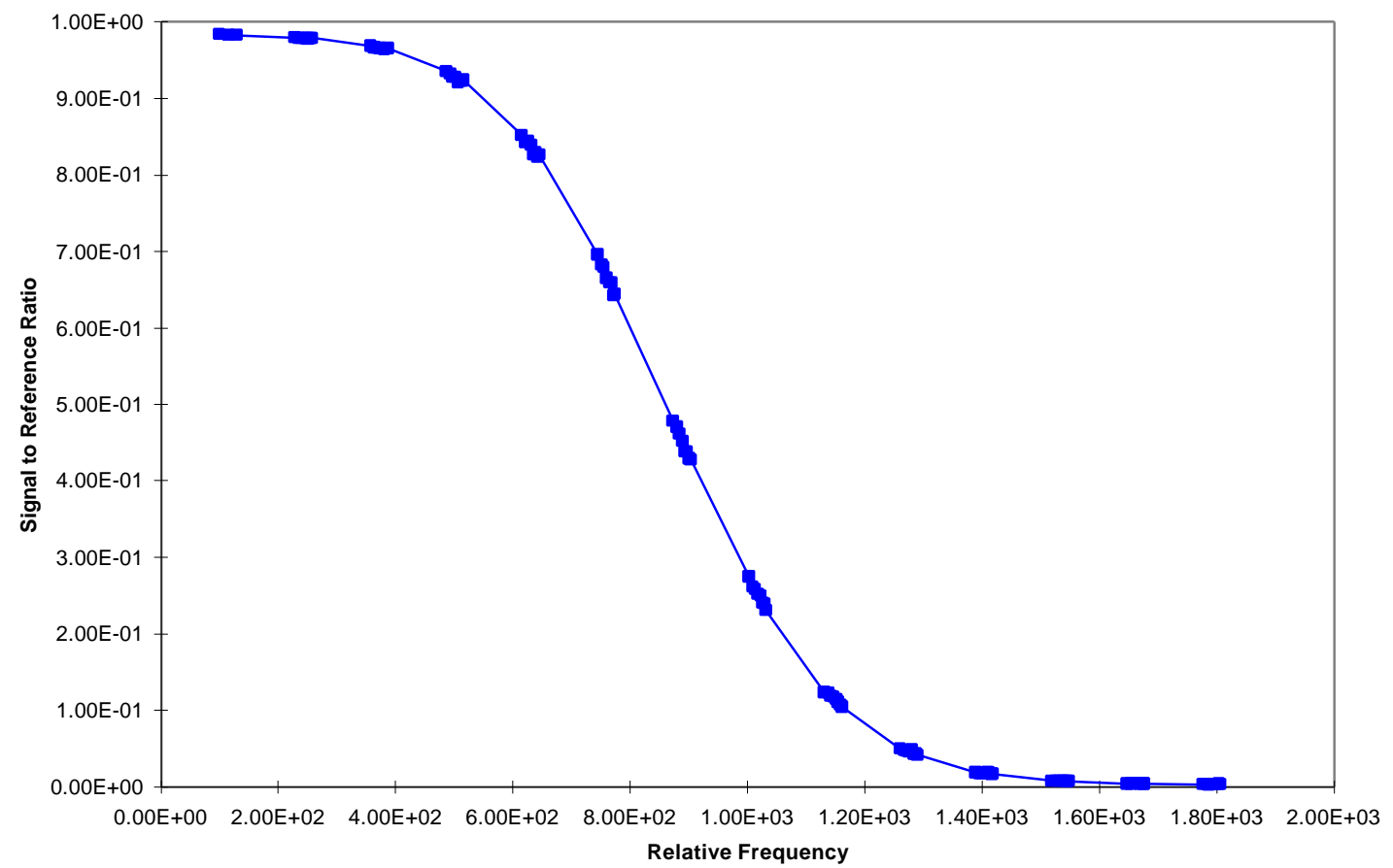

Figure 4.4 Typical calibration file following trimming 


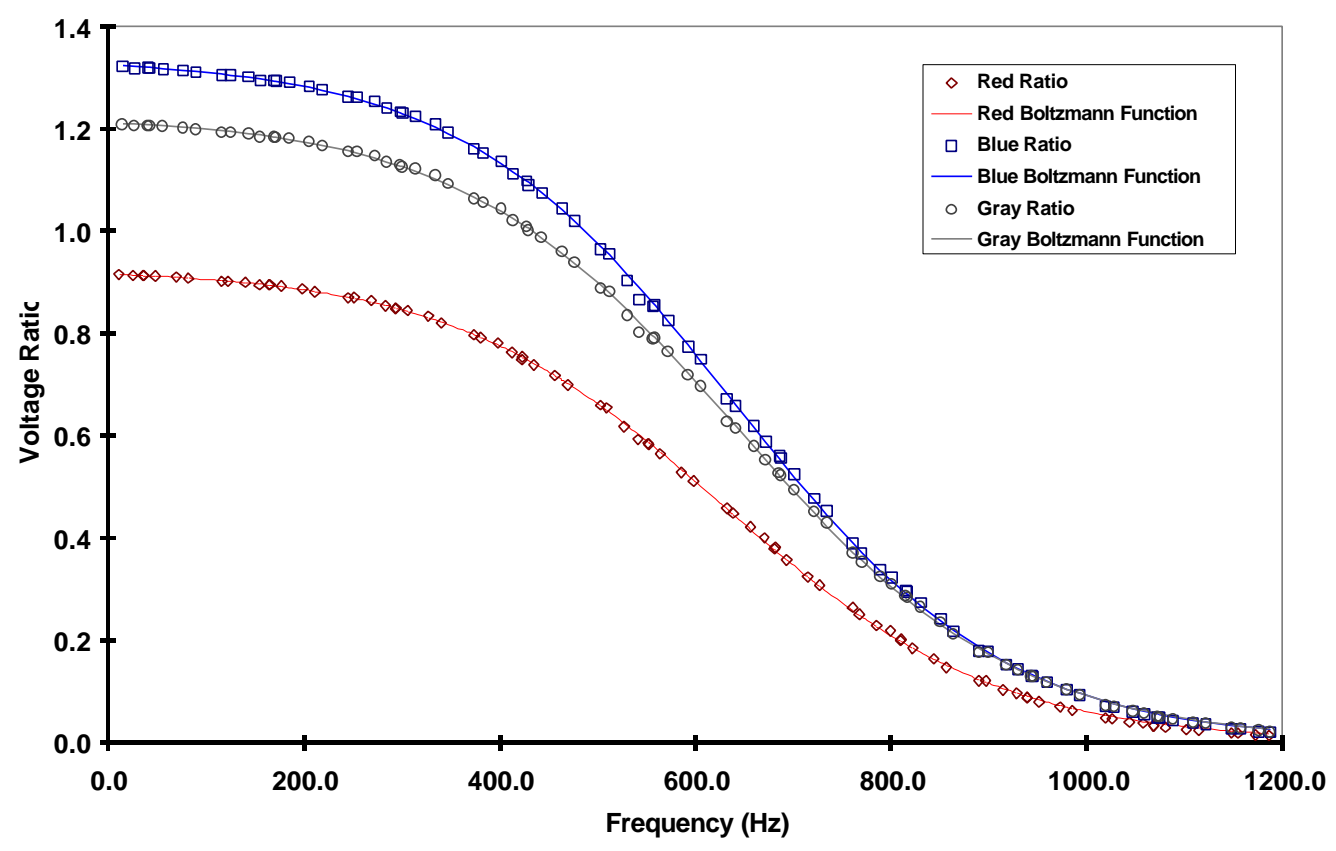

Figure 4.5 Typical final calibration showing Boltzmann fitting function curve fits

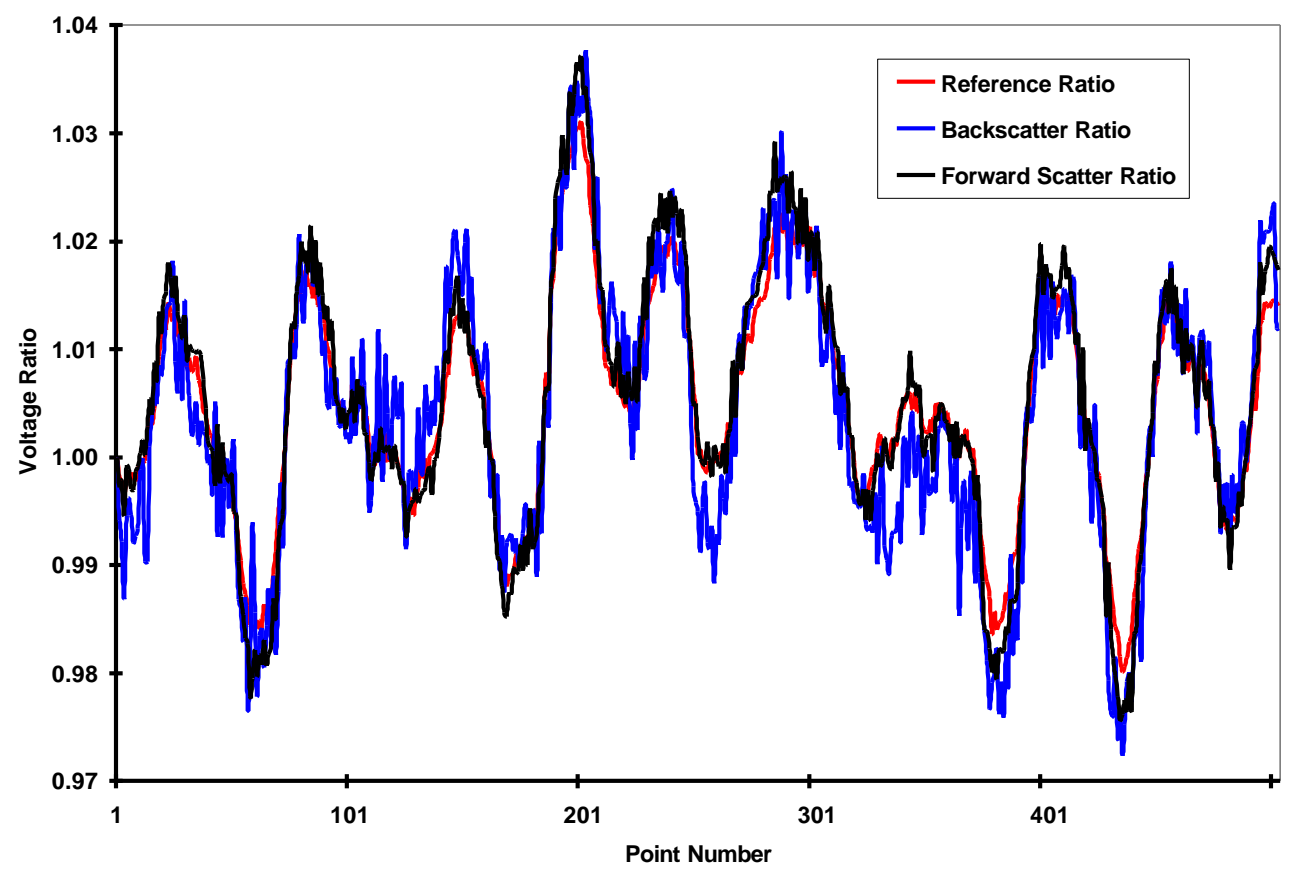

Figure 4.6 Normalized instantaneous voltage ratios for exit file 

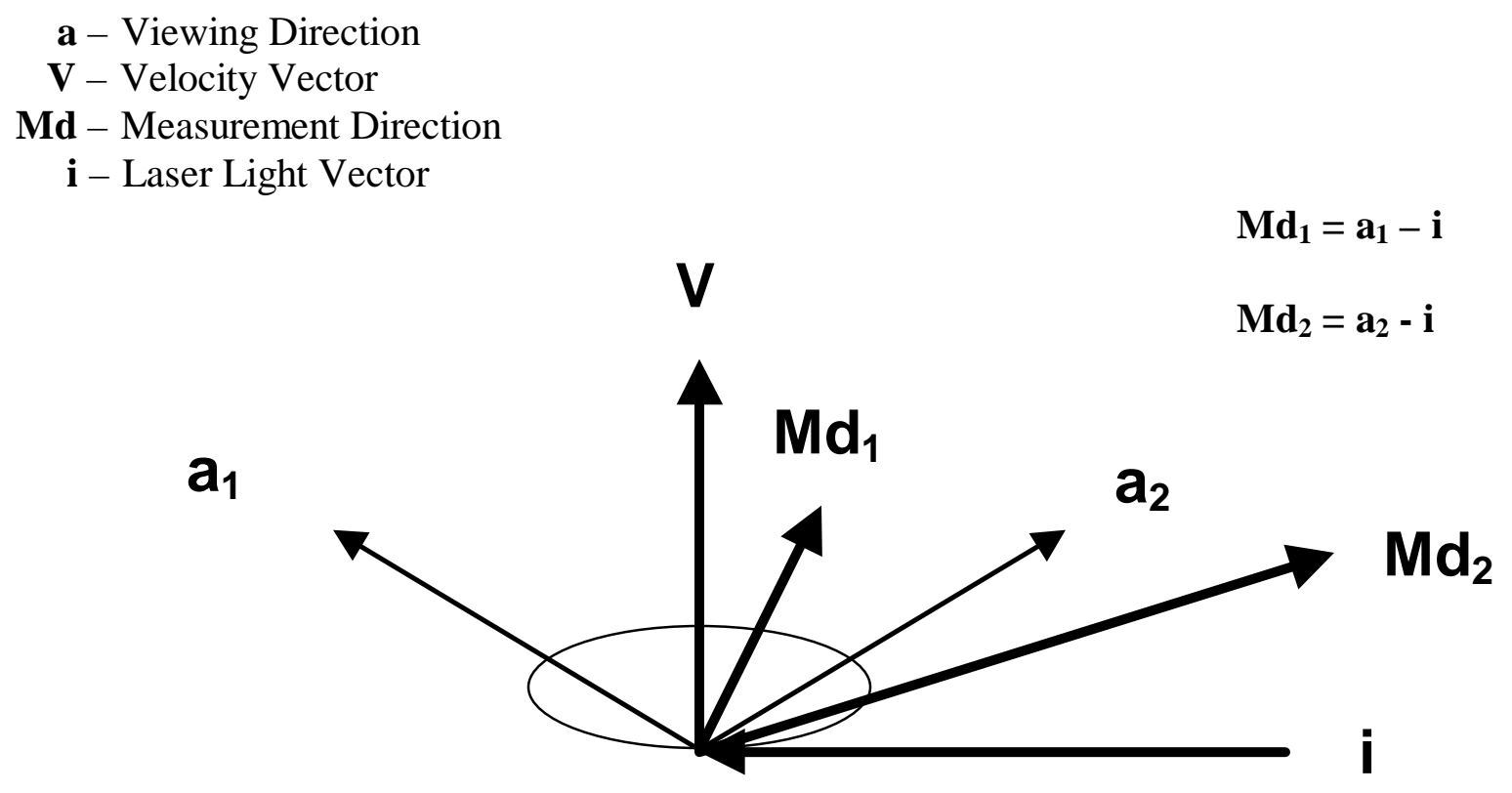

Figure 4.7 Geometry of pDv measurement system 
A:)
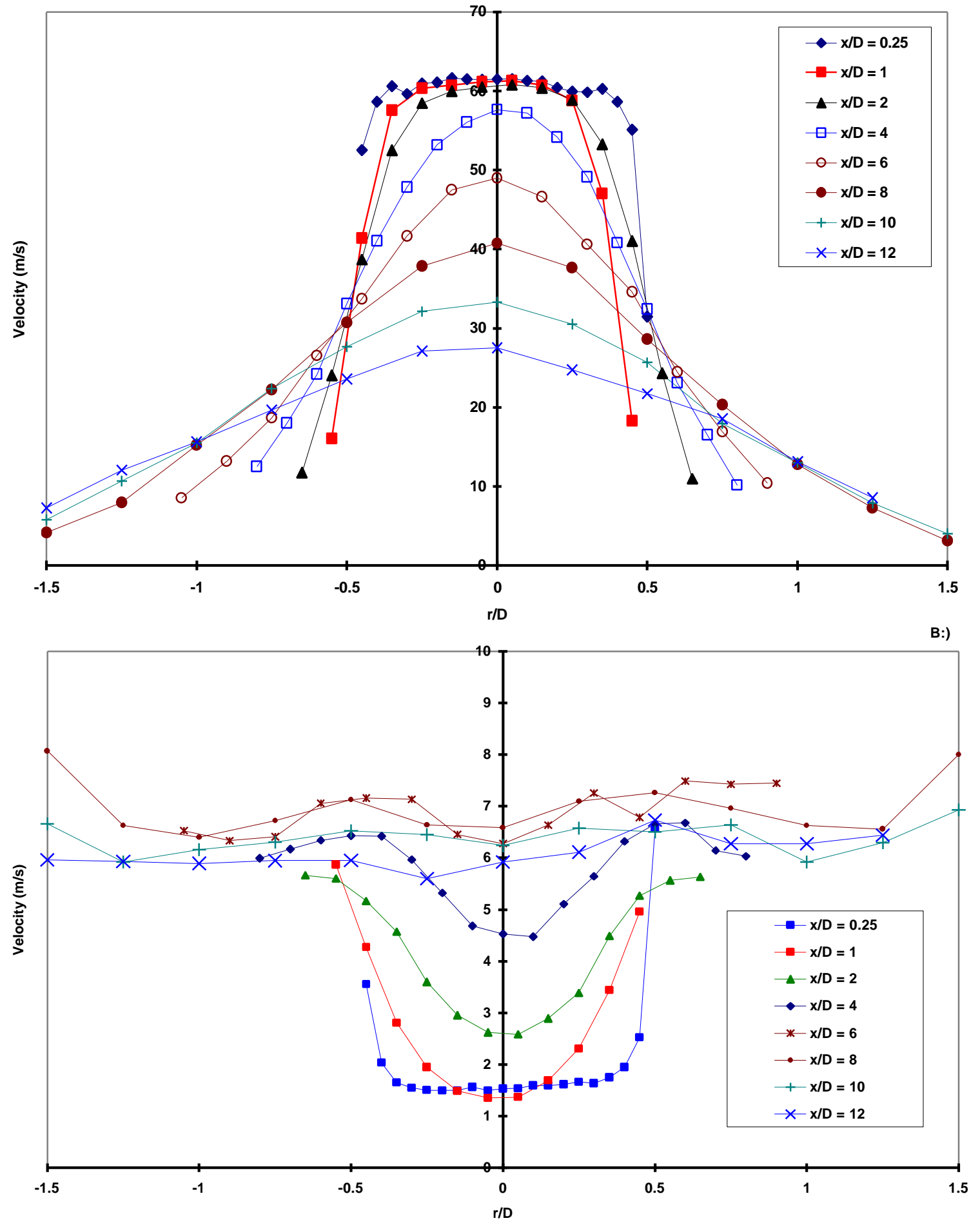

Figure 5.1 Axial velocity results for run 1 (PIN Detectors, focusing)

A:) Mean Velocities

B:) RMS Velocities 

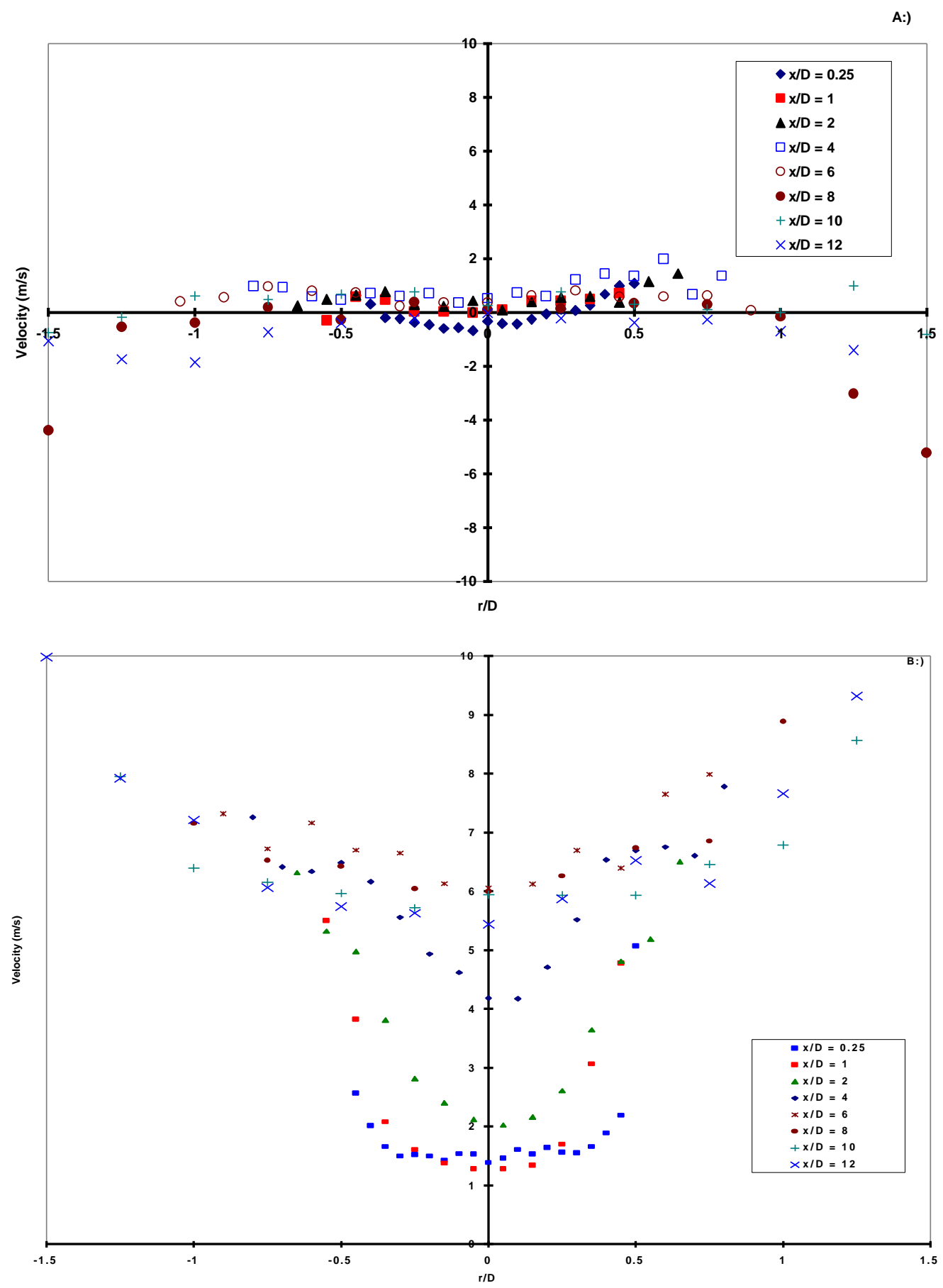

Figure 5.2 Circumferential velocity results for run 1
A:) Mean Velocities
B:) RMS Velocities 


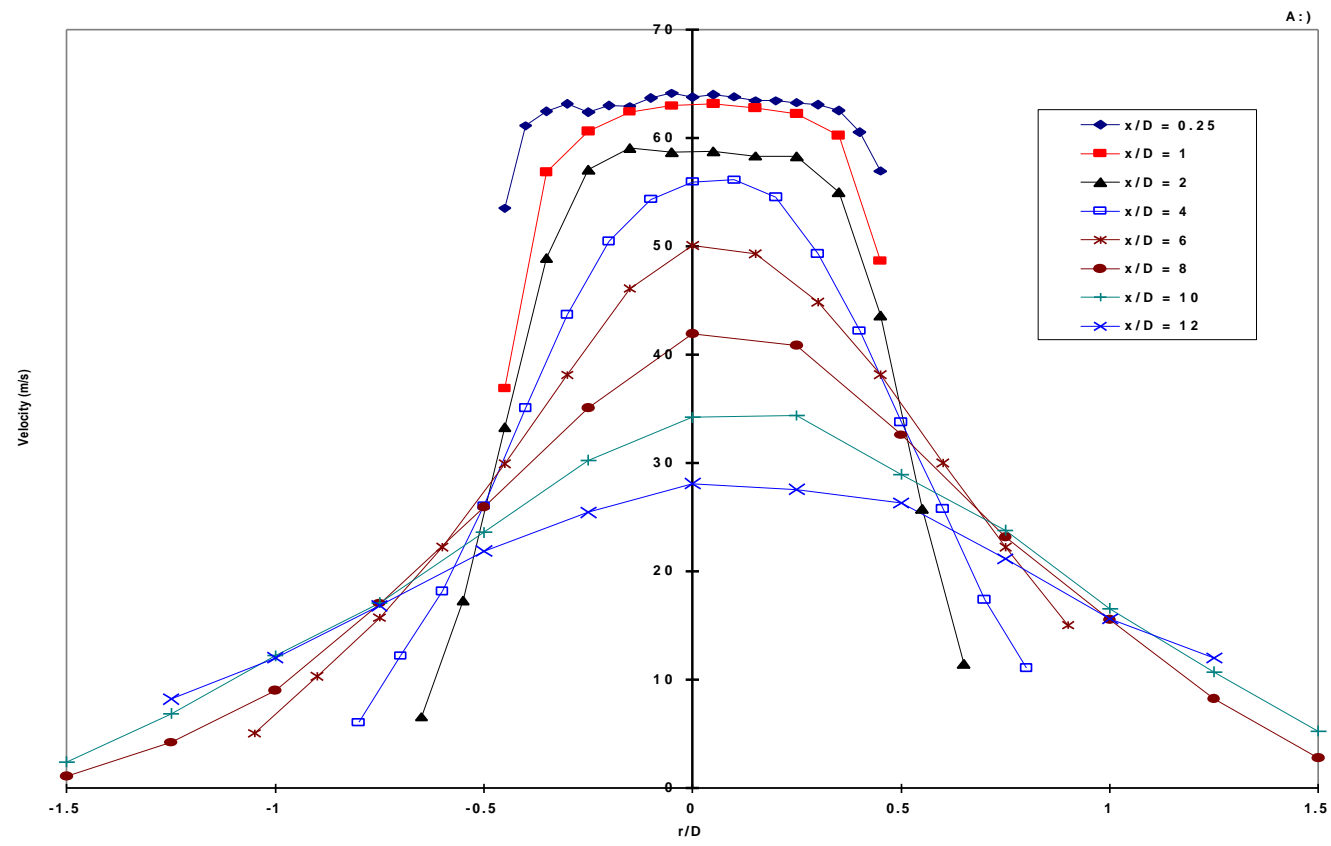

B:)

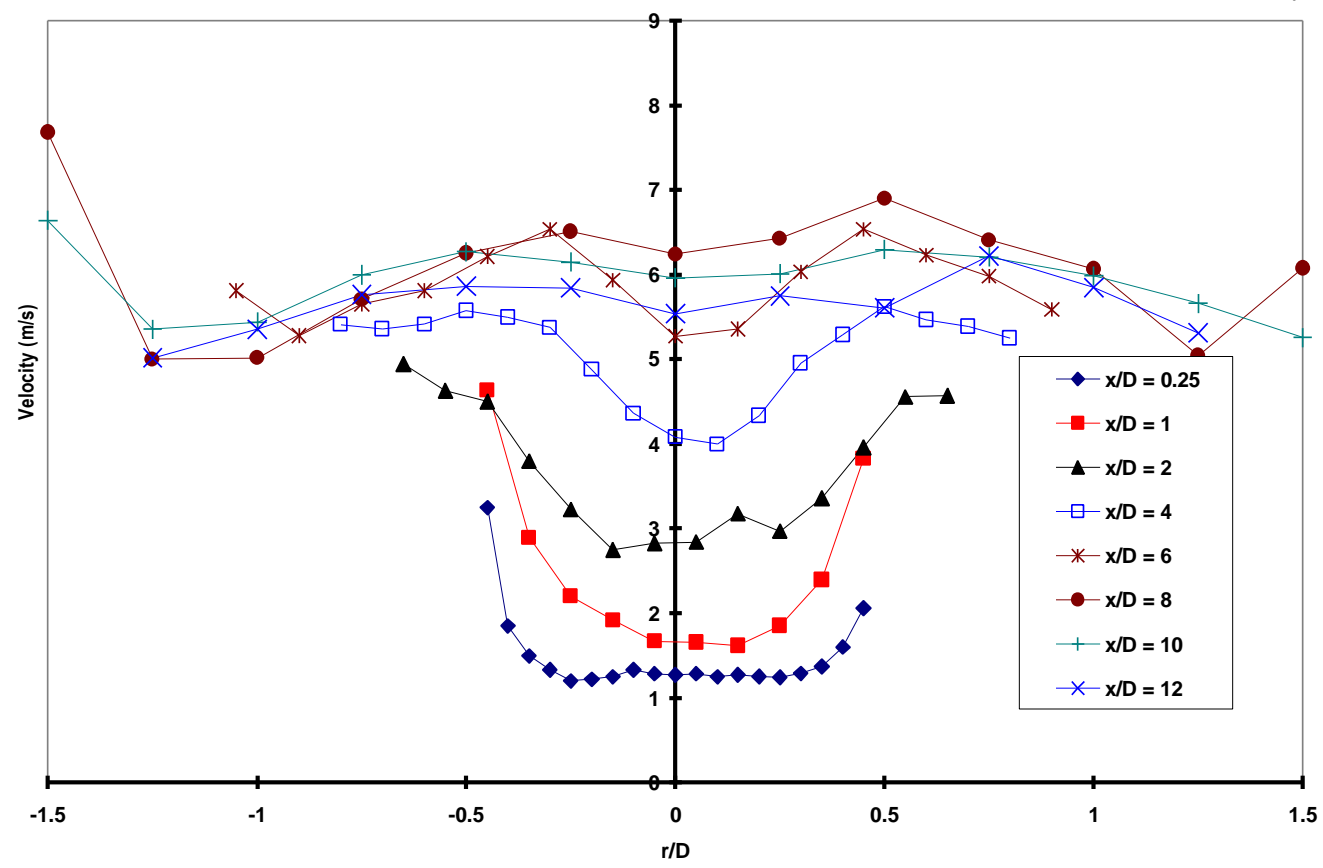

Figure 5.3 Axial velocity results for run 2

A:) Mean Velocities

B:) RMS Velocities 
A:)

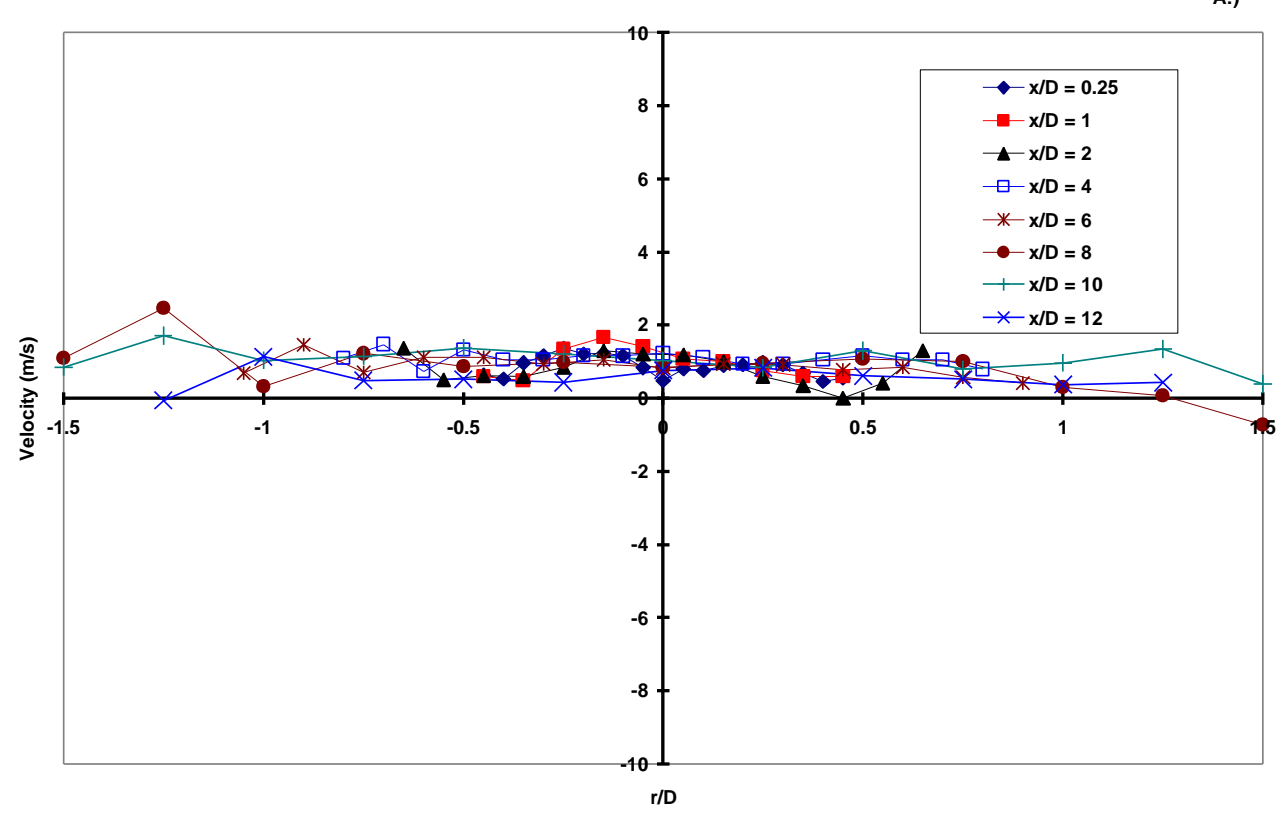

B:)

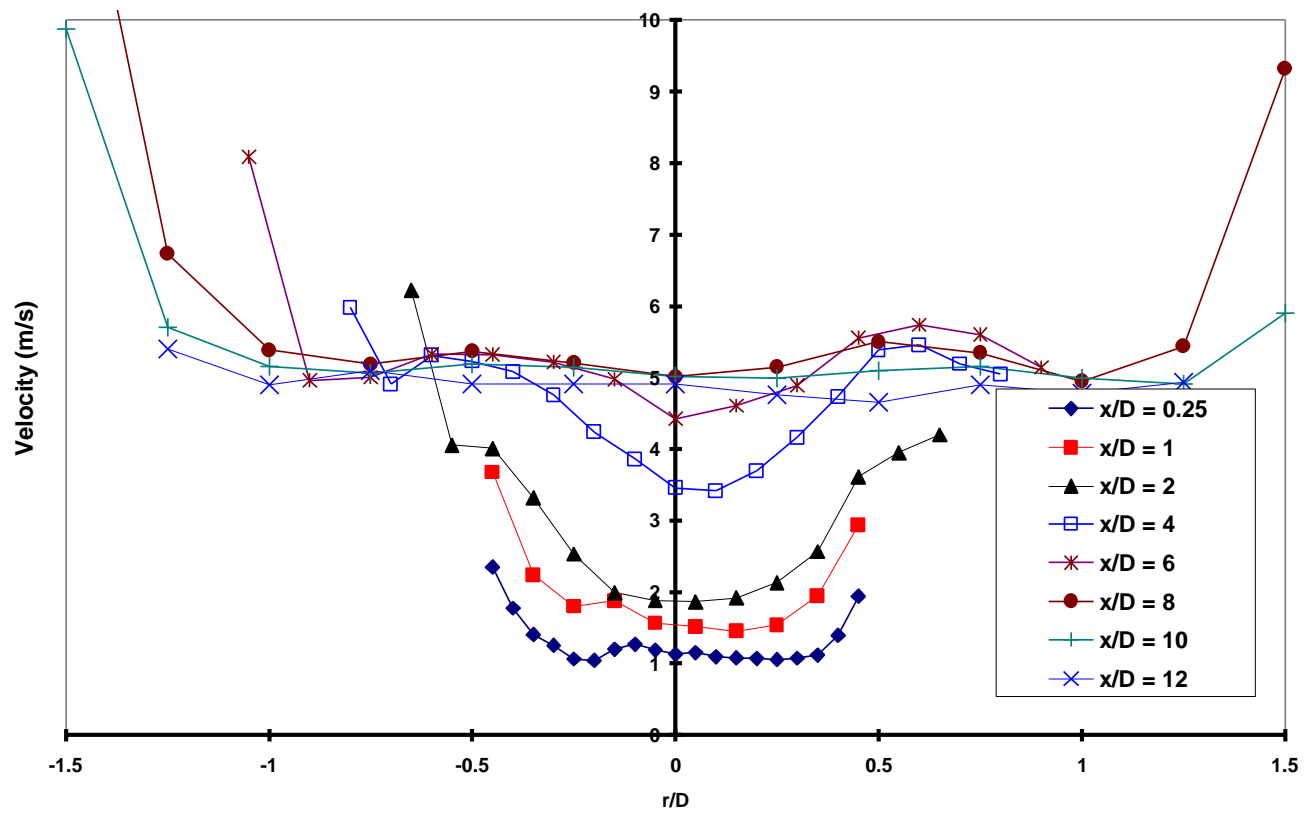

Figure 5.4 Circumferential velocity results for run 2

A:) Mean Velocities

B:) RMS Velocities 

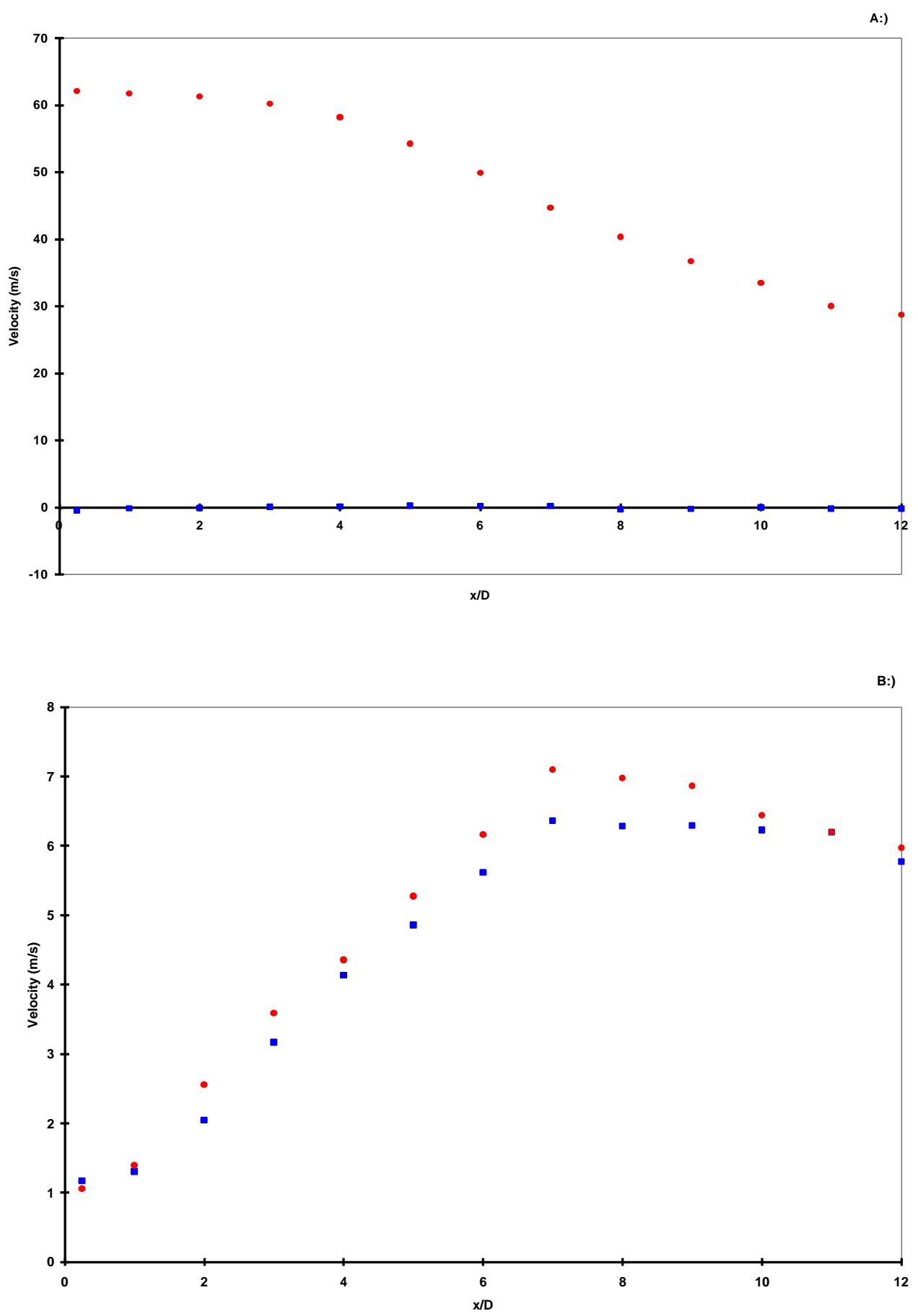

Figure 5.5 Centerline velocity profiles for run 1

Circles - Axial; Squares - Circumferential

A:) Mean Velocities

B:) RMS Velocities 


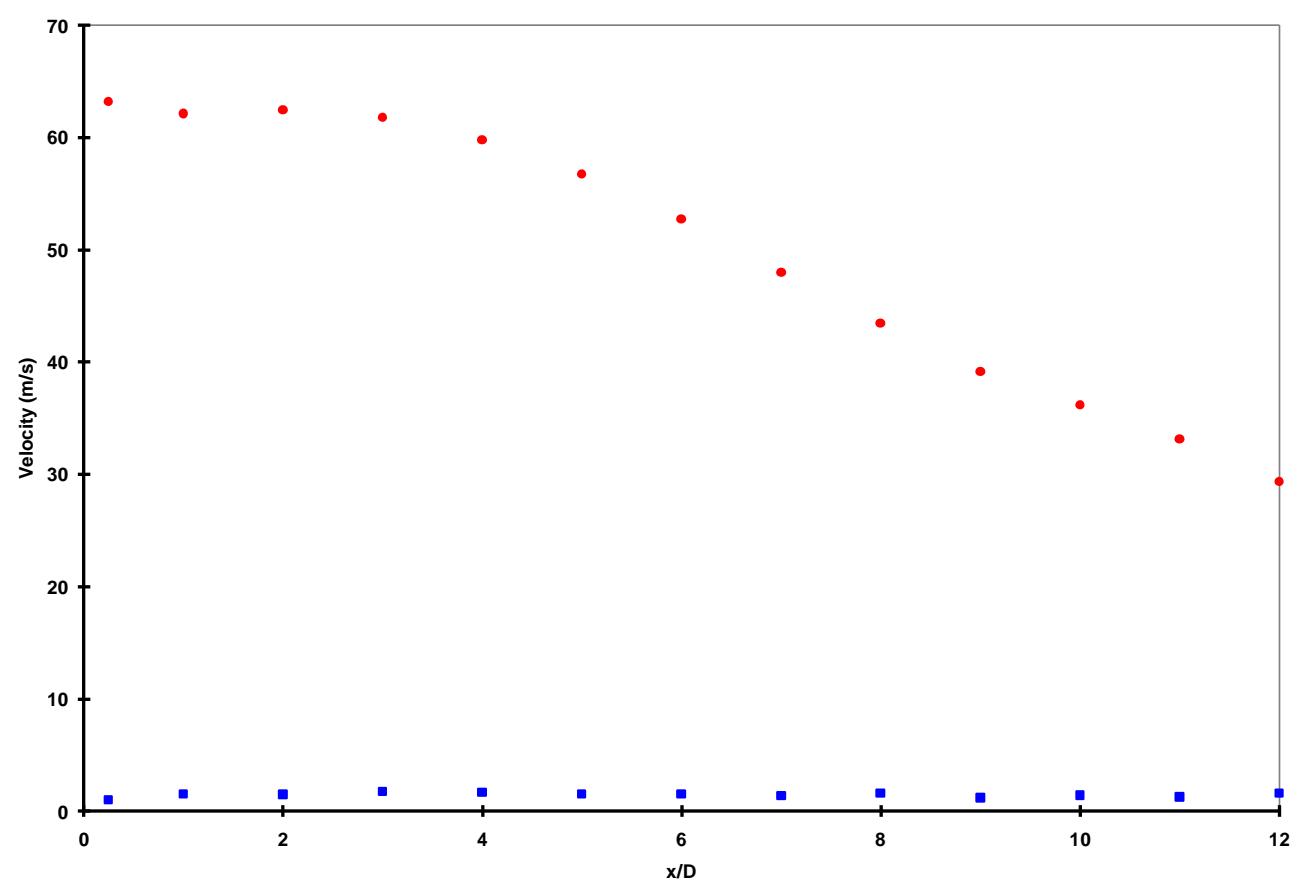

B:)

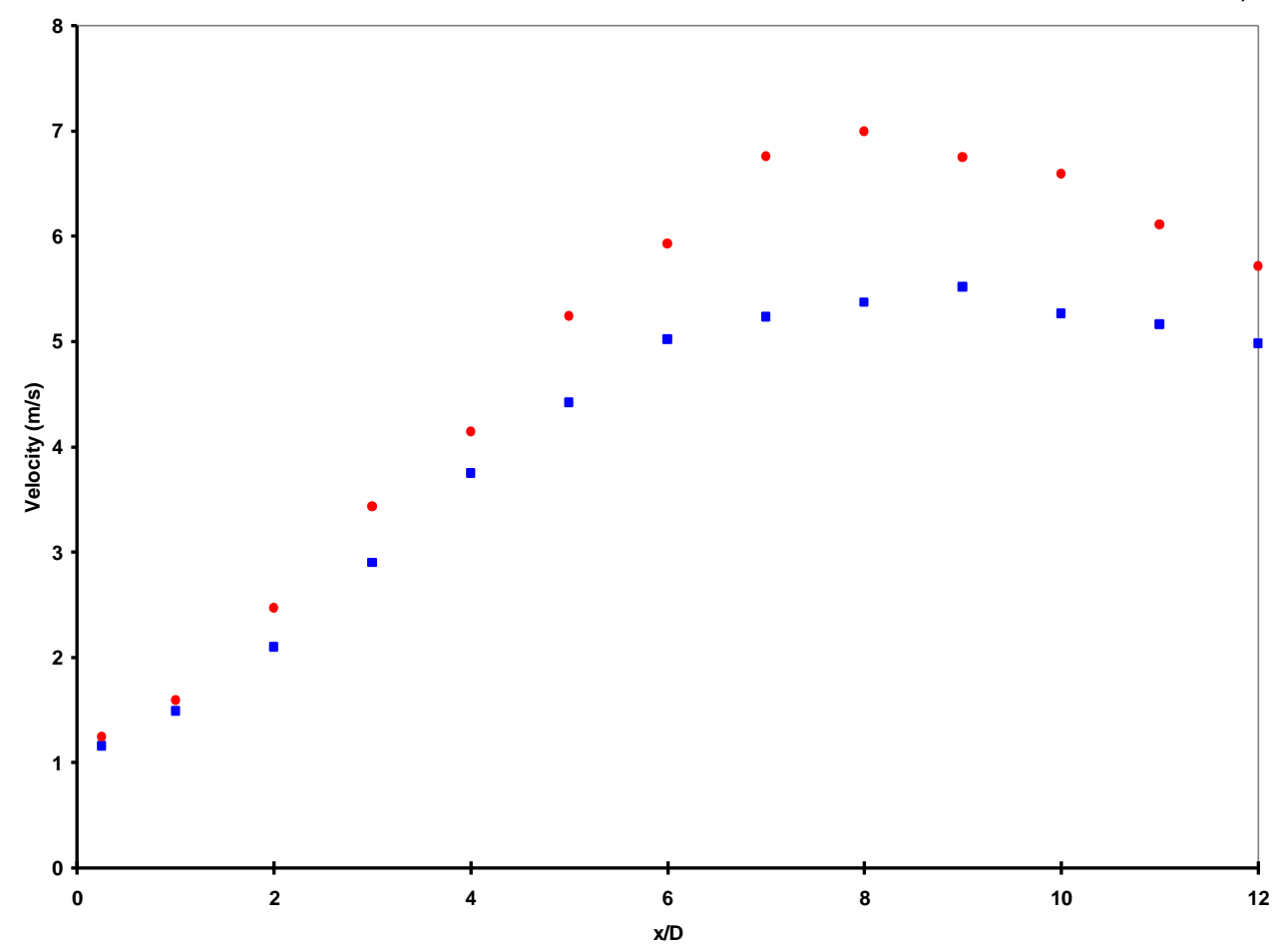

Figure 5.6 Centerline velocity profiles for run 2

Circles - Axial; Squares - Circumferential

A:) Mean Velocities

B:) RMS Velocities 

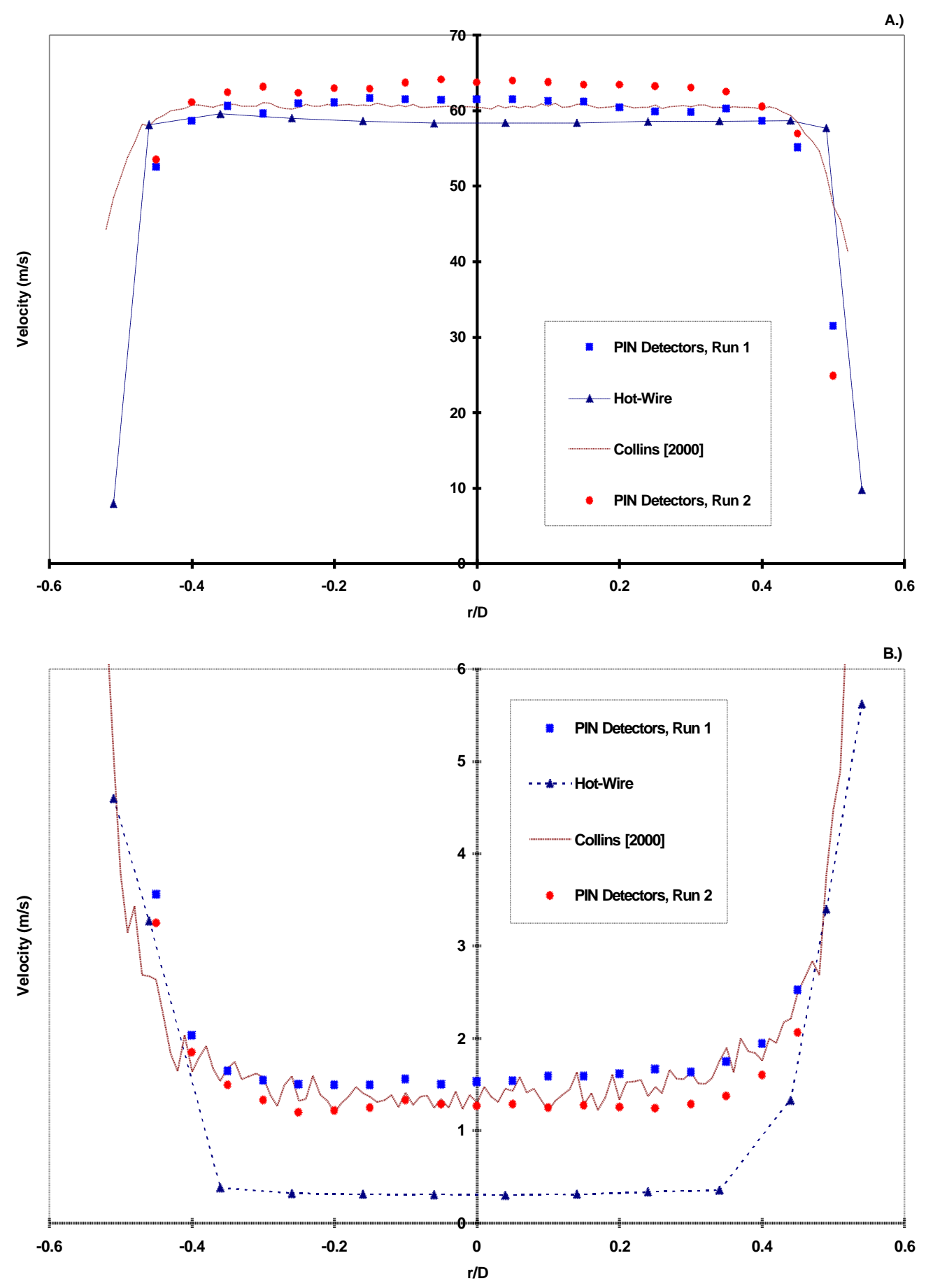

Figure 5.7 Exit comparisons of both runs with Collins and hot wire results

A:) Mean Velocities

B:) RMS Velocities 

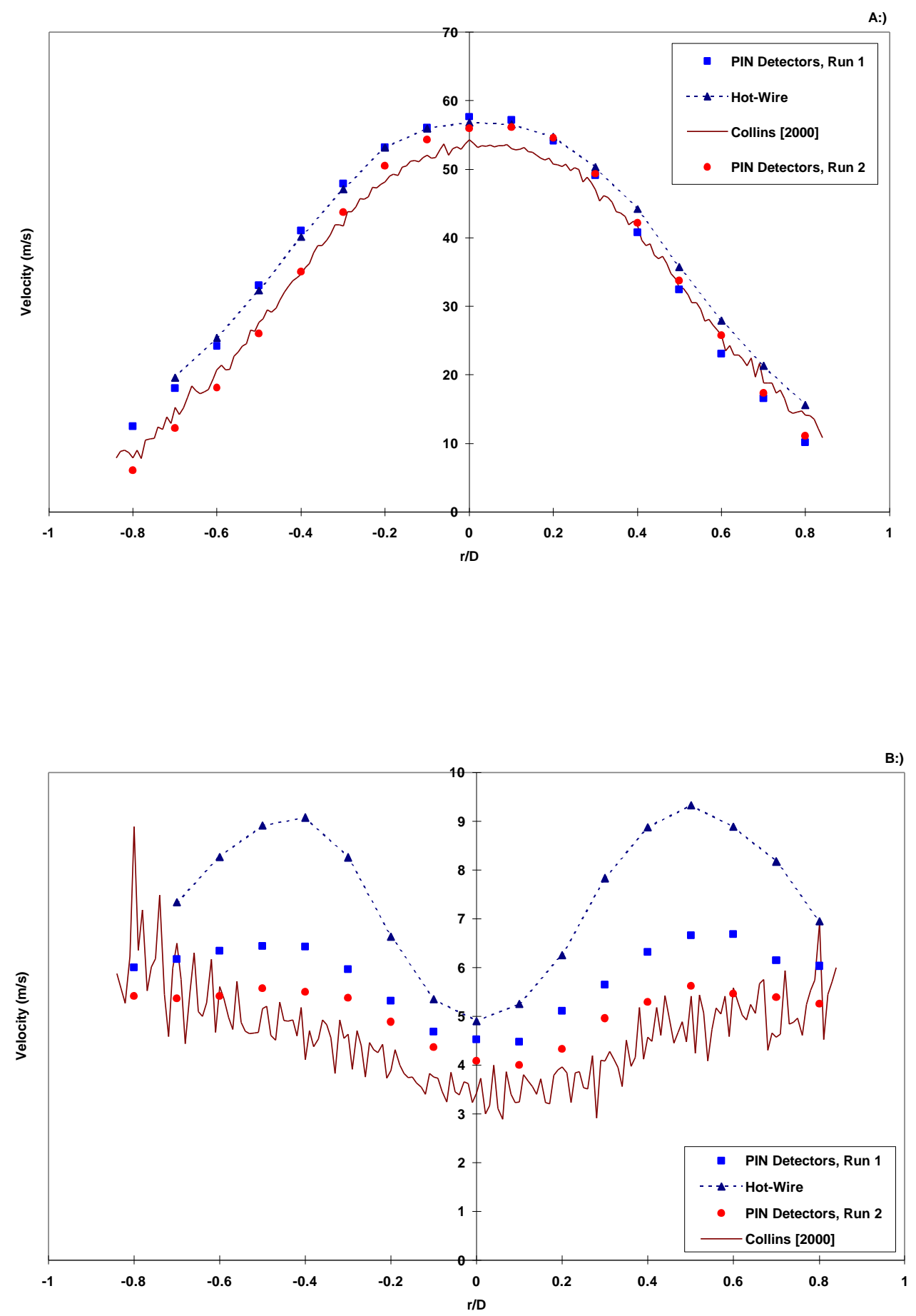

Figure $5.8 \mathrm{x} / \mathrm{D}=4$ comparisons of both runs with Collins and hot wire results
A:) Mean Velocities
B:) RMS Velocities 

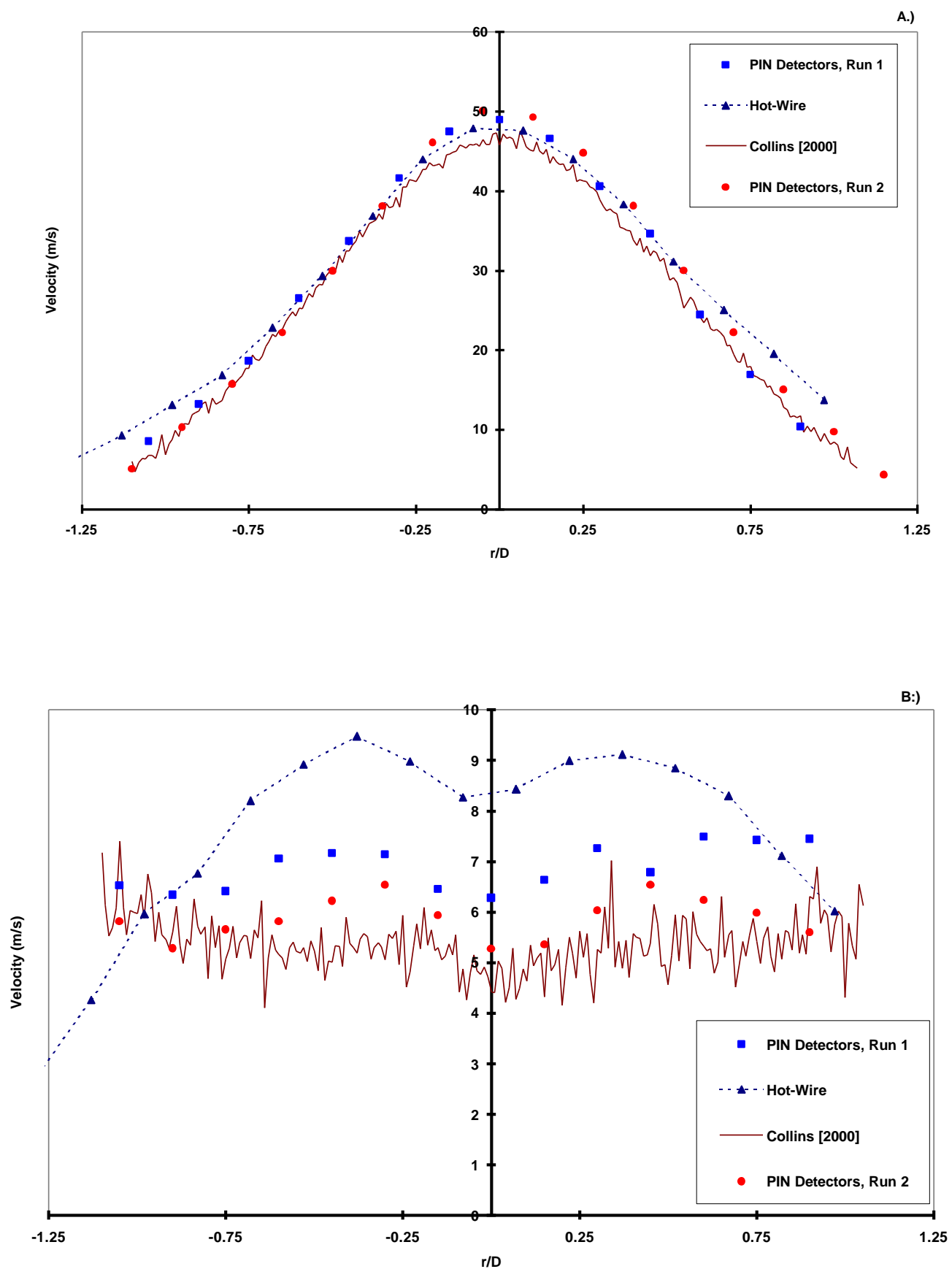

Figure $5.9 x / D=6$ comparisons of both runs with Collins and hot wire results
A:) Mean Velocities
B:) RMS Velocities 

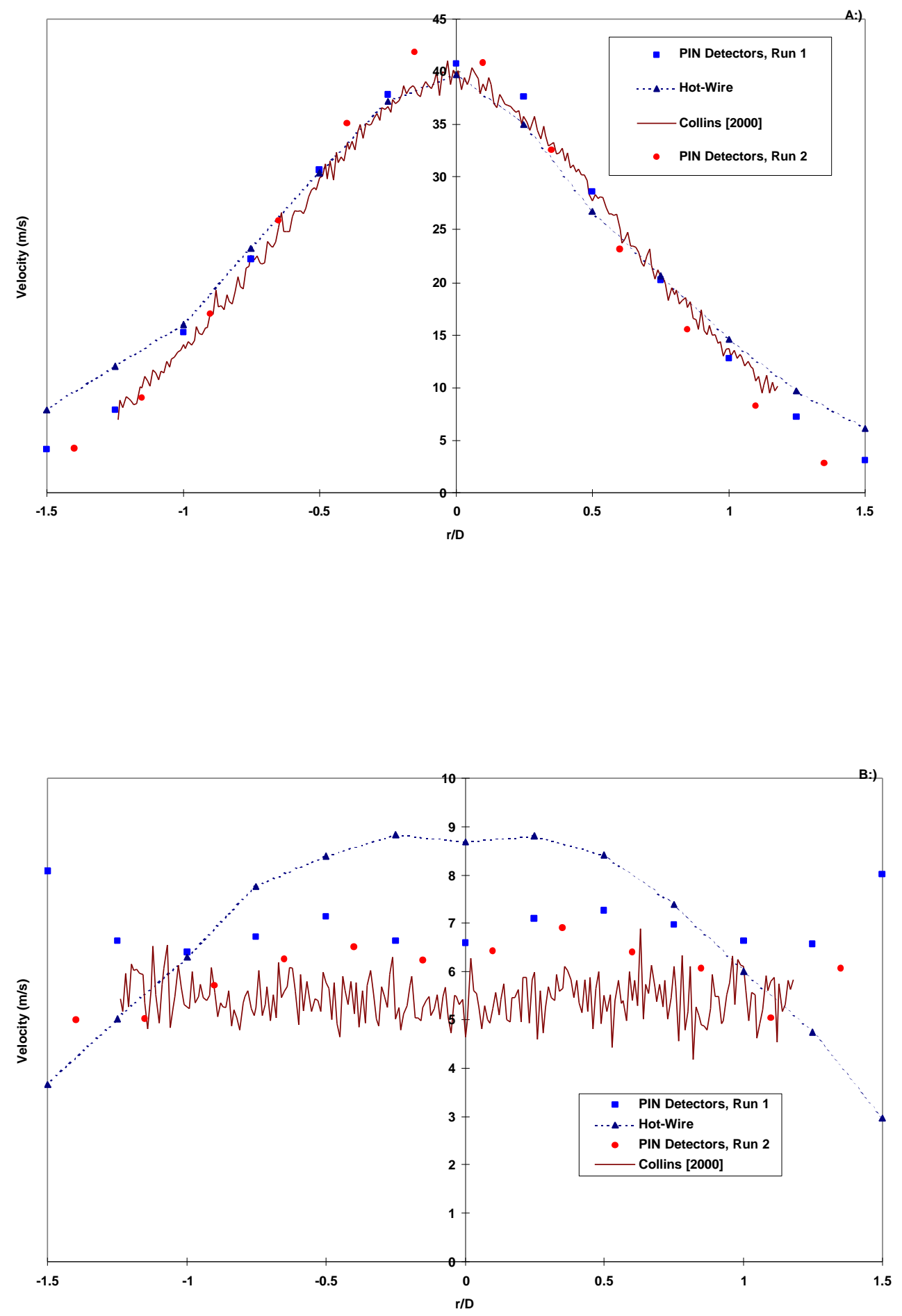

Figure $5.10 \mathrm{x} / \mathrm{D}=8$ comparisons of both runs with Collins and hot wire results

A:) Mean Velocities

B:) RMS Velocities 

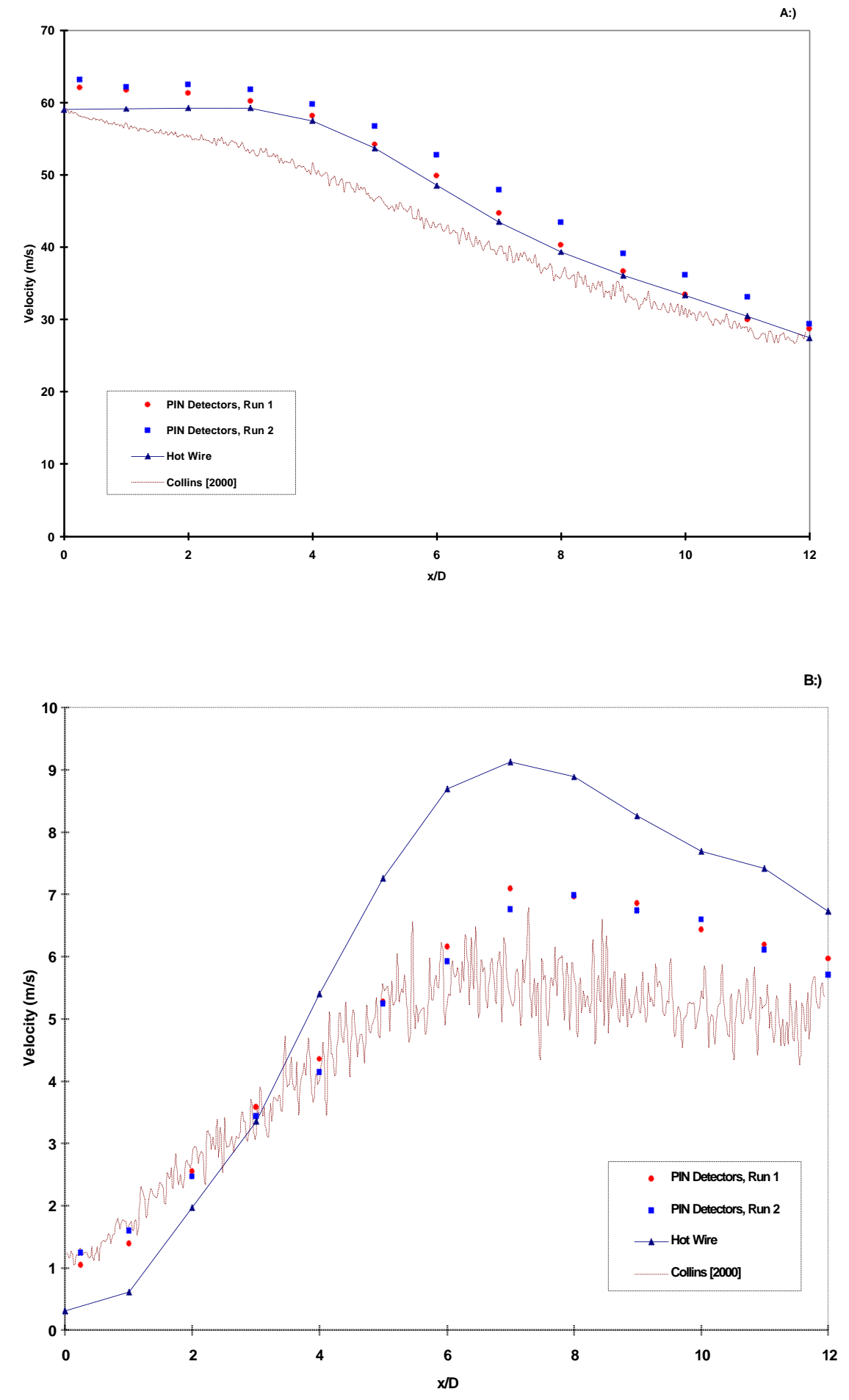

Figure 5.11 Centerline comparisons of both runs with Collins and hot wire results

A:) Mean Velocities

B:) RMS Velocities 


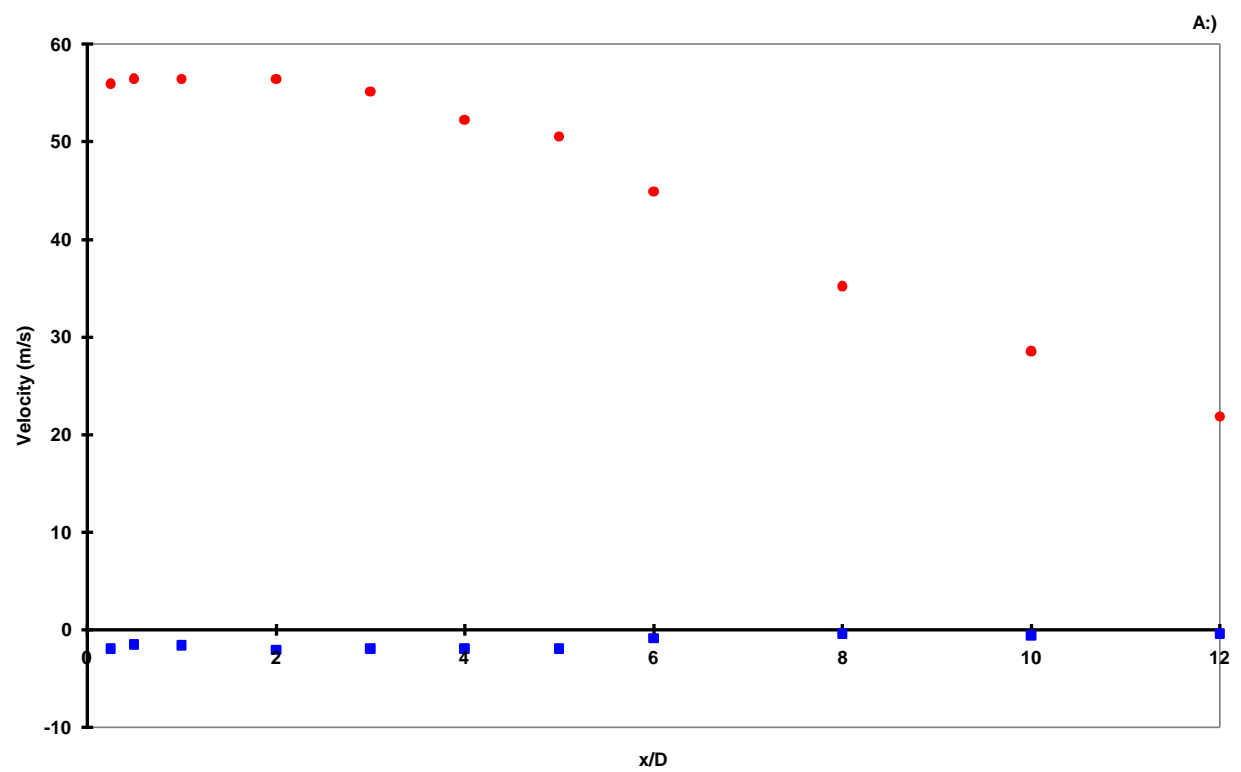

B:)

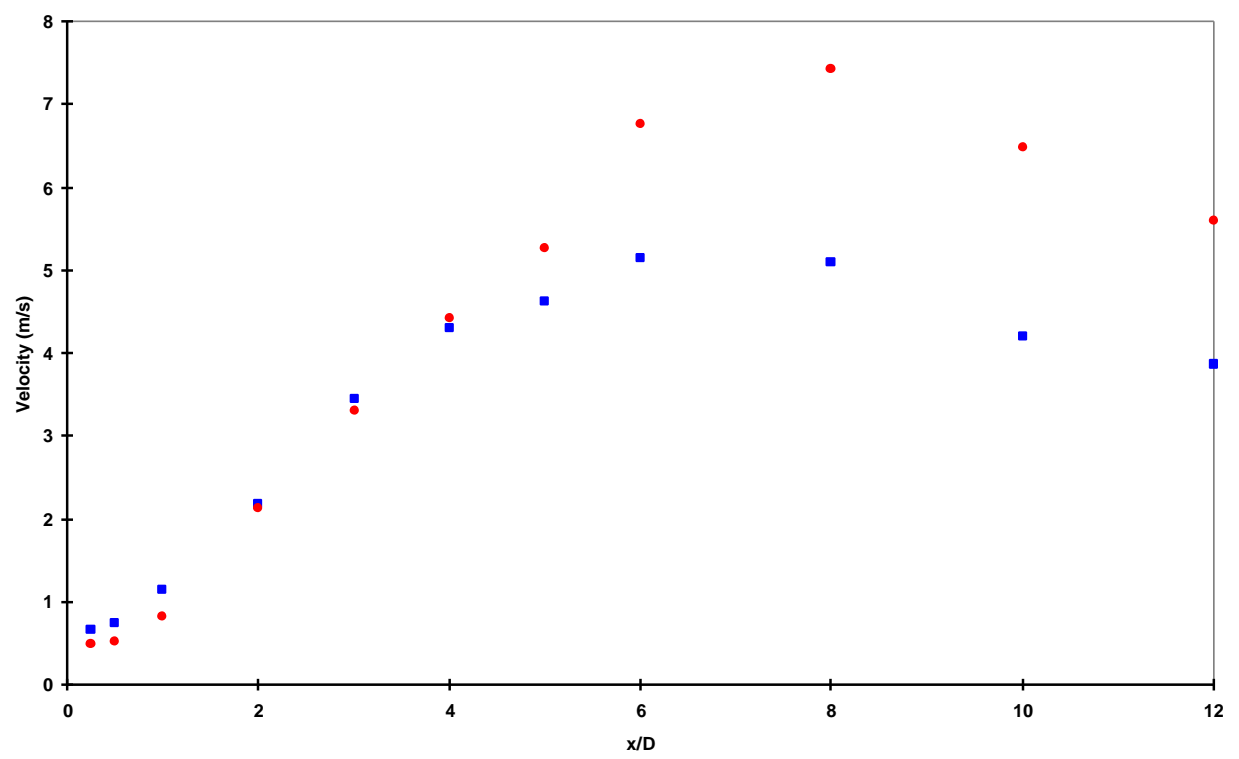

Figure 5.12 Centerline velocity profiles for unfocused APD data run

Circles - Axial; Squares - Circumferential

A:) Mean Velocities

B:) RMS Velocities 

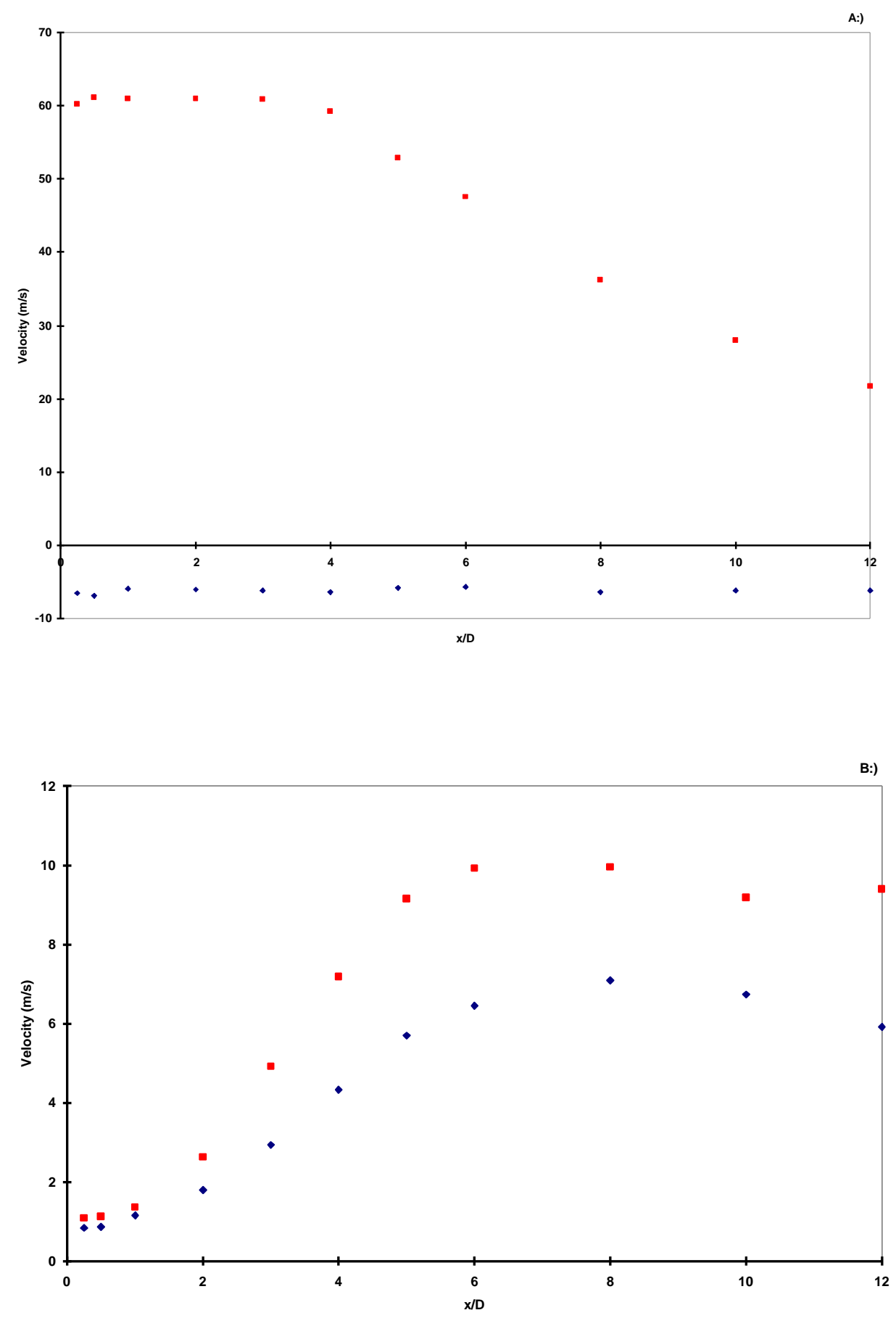

Figure 5.13 Centerline velocity profiles for focused APD run

Circles - Axial; Squares - Circumferential
A:) Mean Velocities
B:) RMS Velocities 

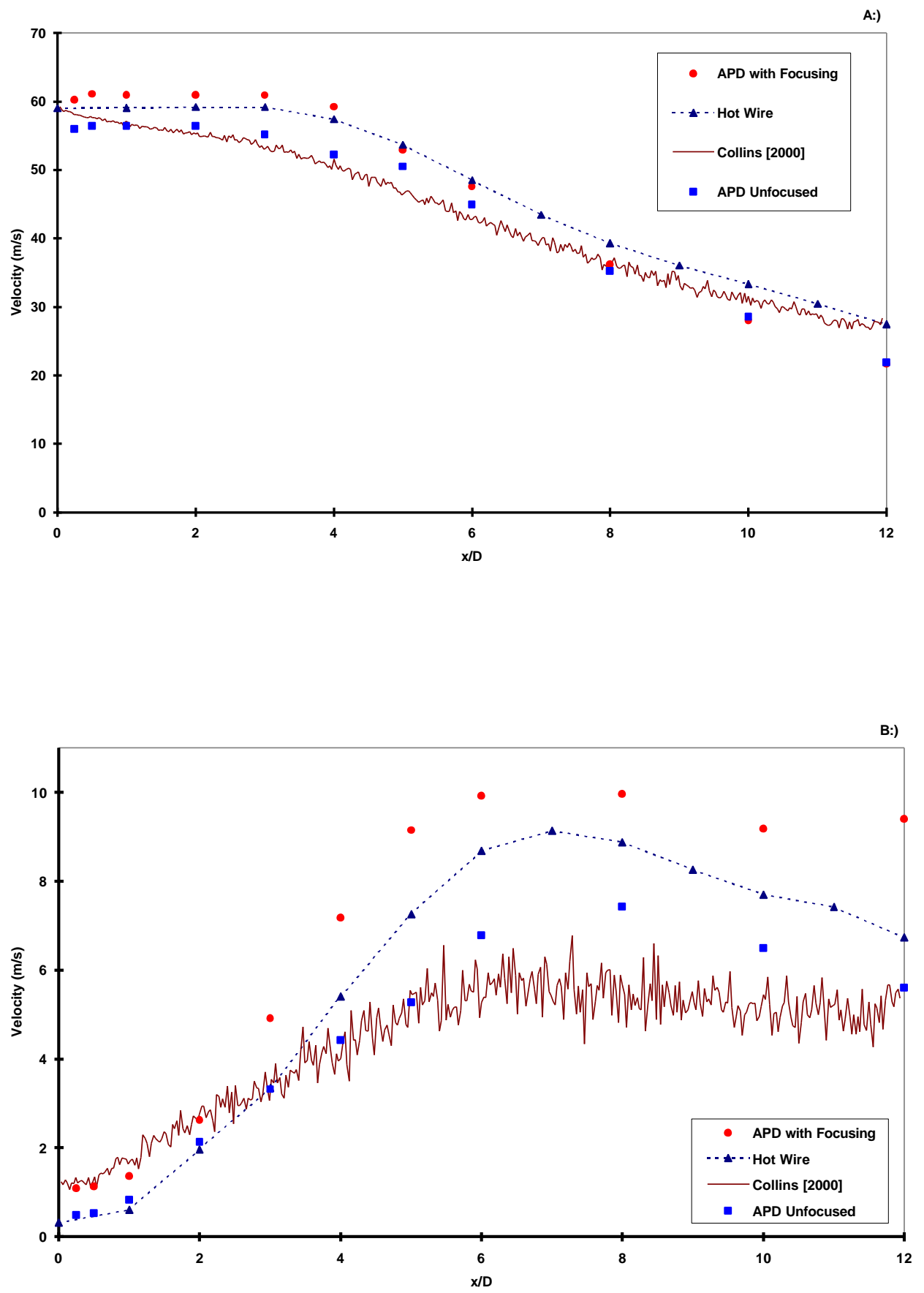

Figure 5.14 Centerline comparisons of axial velocity results for both APD runs with Collins and hot wire data
A:) Mean Velocities
B:) RMS Velocities 


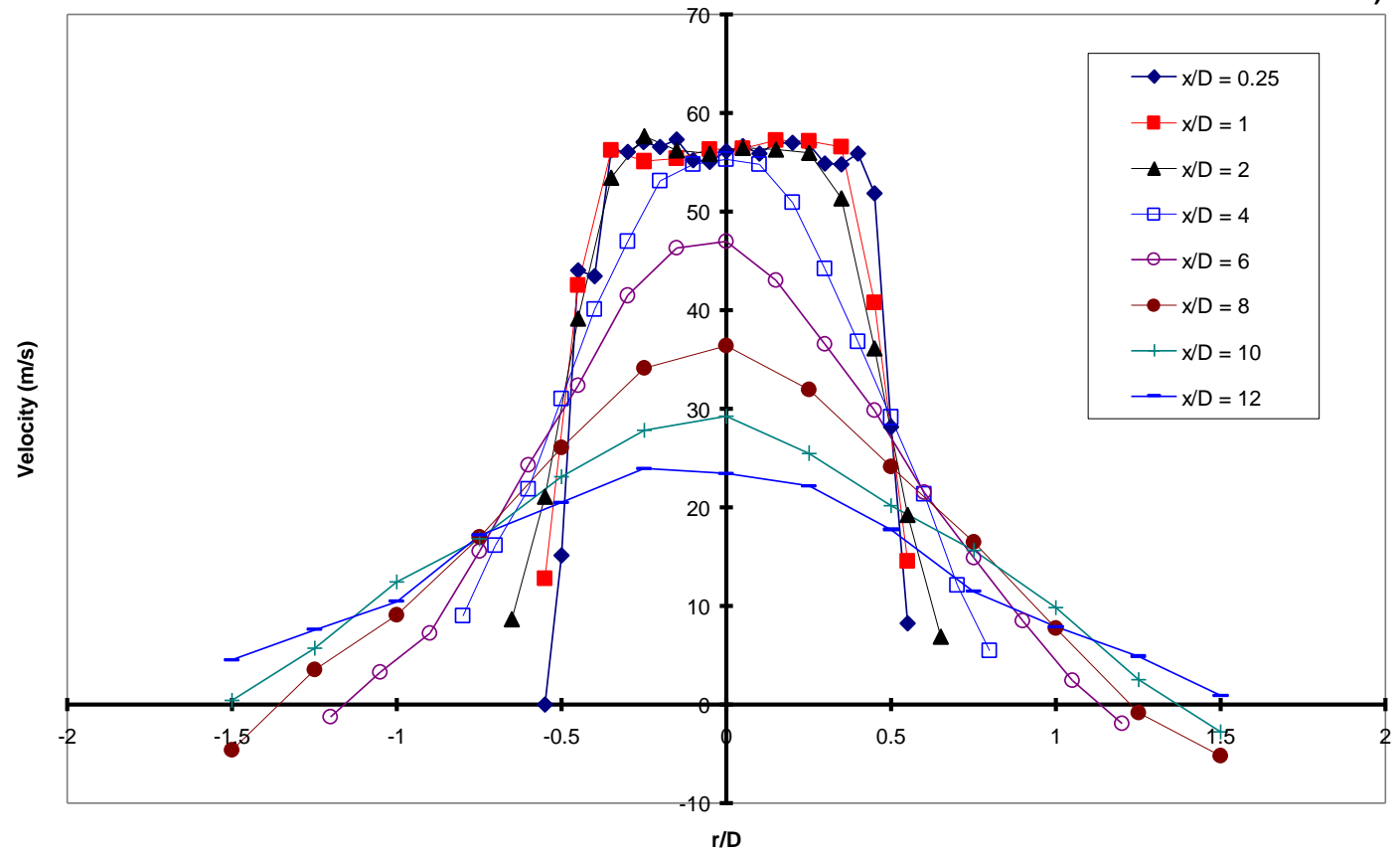

B:)

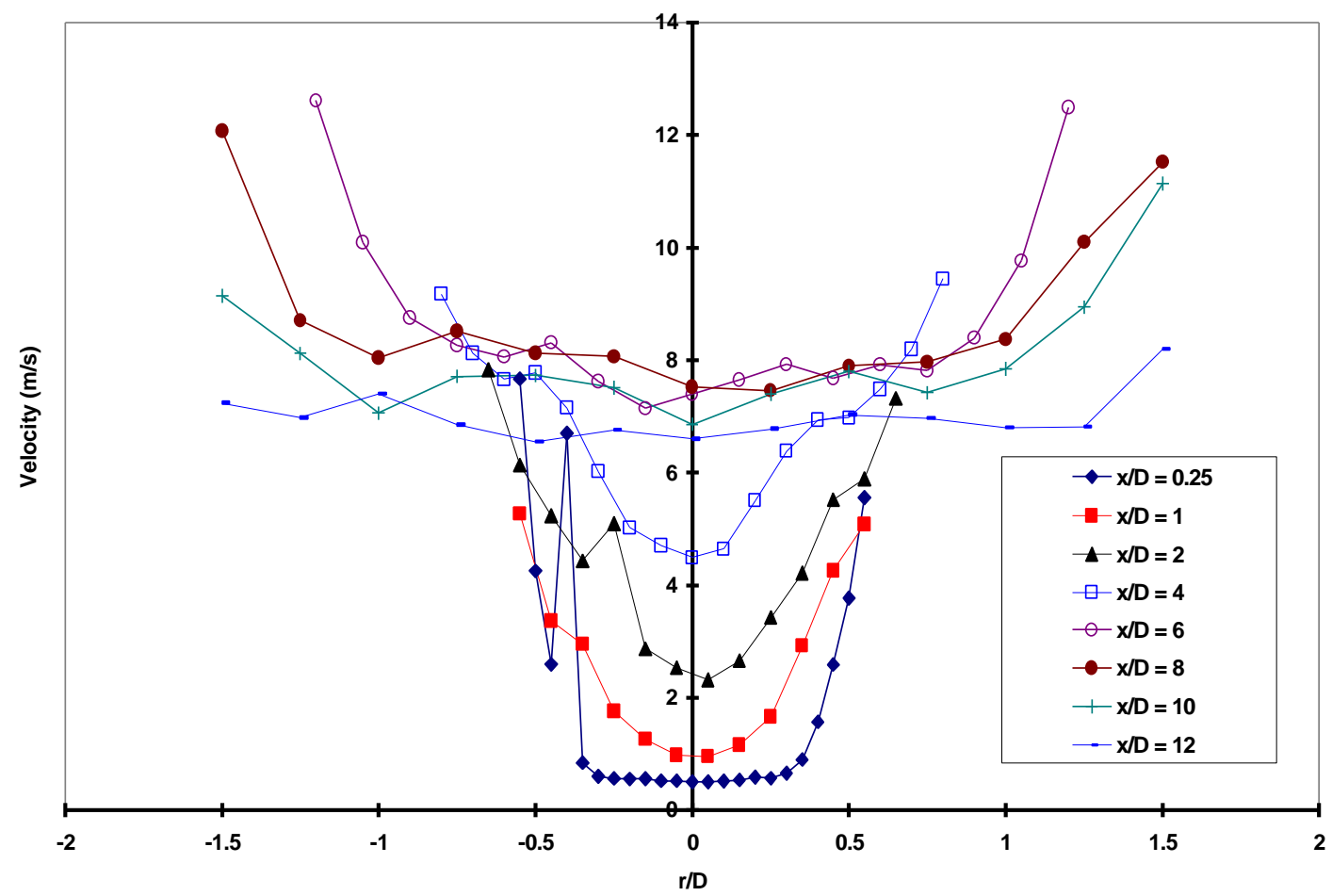

Figure 5.15 Axial velocity results for combined APD/PIN detector data run

A:) Mean Velocities

B:) RMS Velocities 

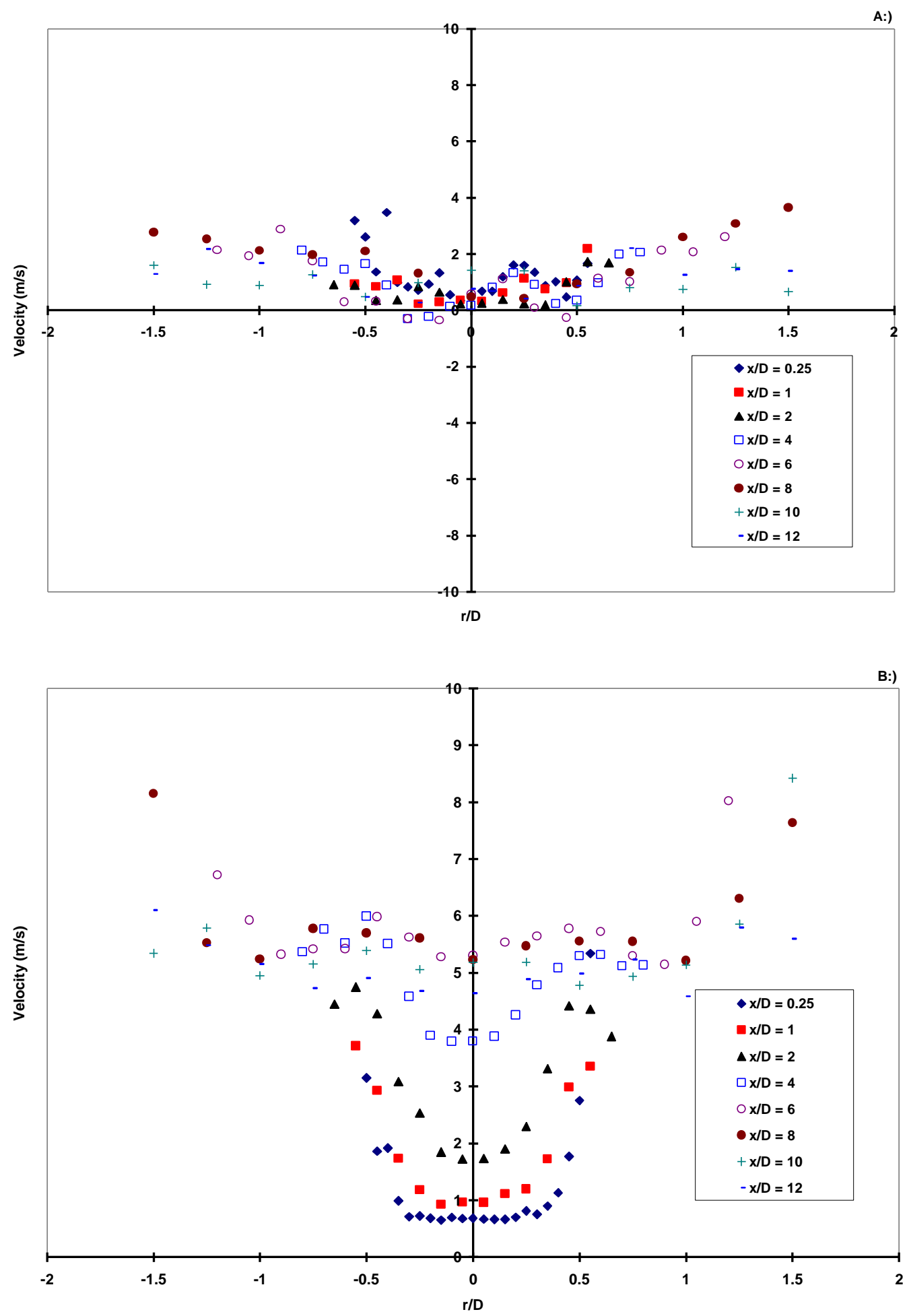

Figure 5.16 Circumferential velocity results for combined APD/PIN detector data A:) Mean Velocities

B:) RMS Velocities 


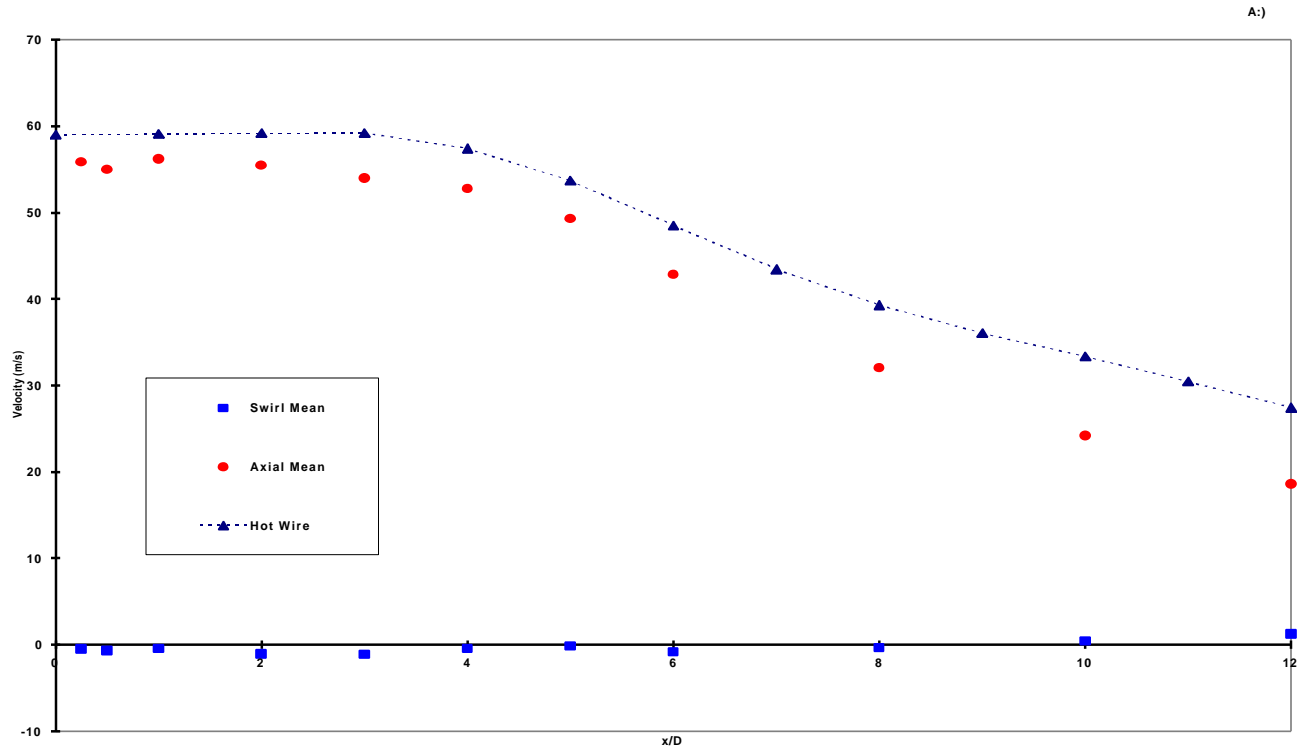

B:)

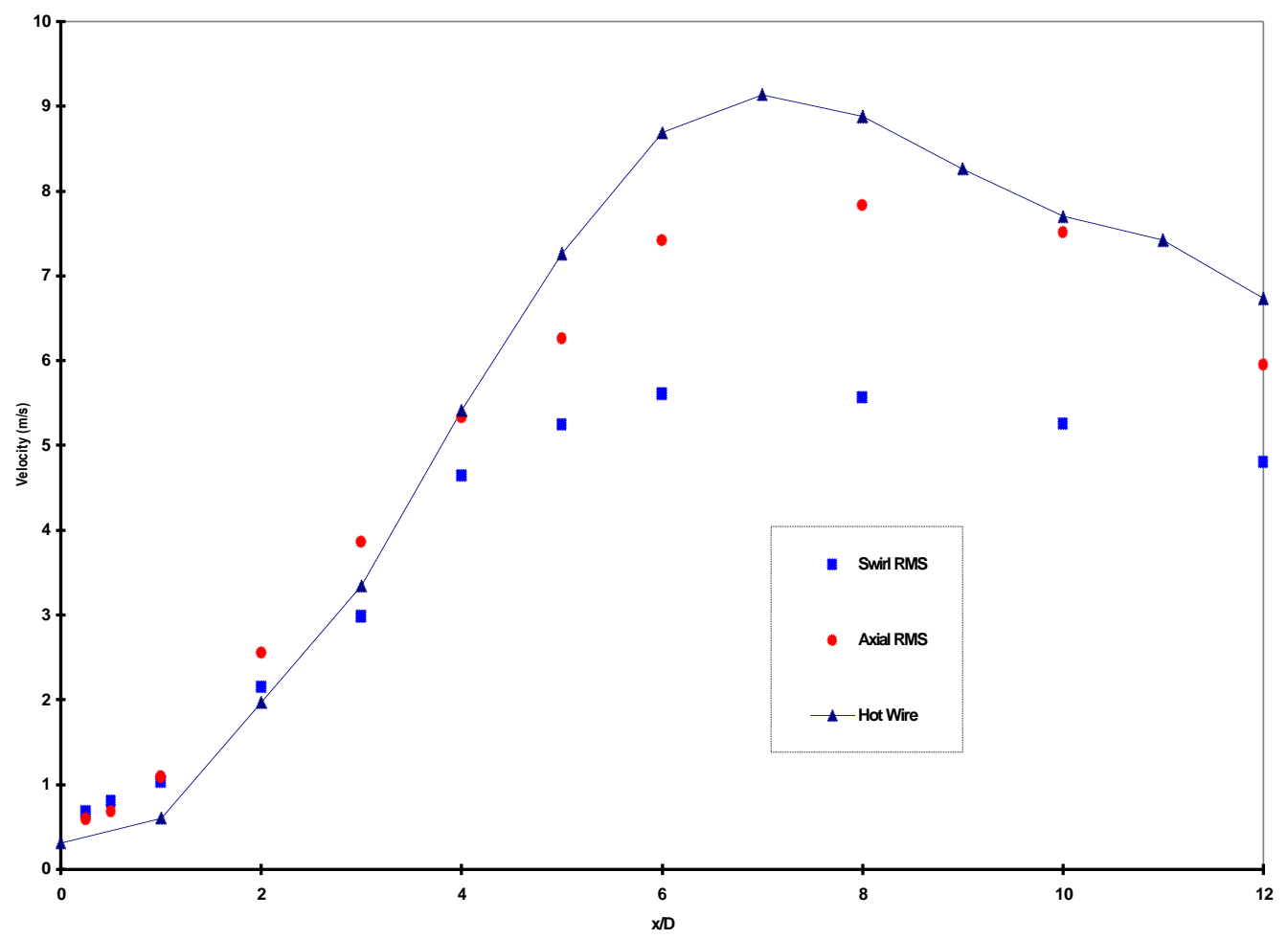

Figure 5.17 Centerline velocity results for combined APD/PIN detector data run

Circles - Axial; Squares - Circumferential

A:) Mean Velocities

B:) RMS Velocities 


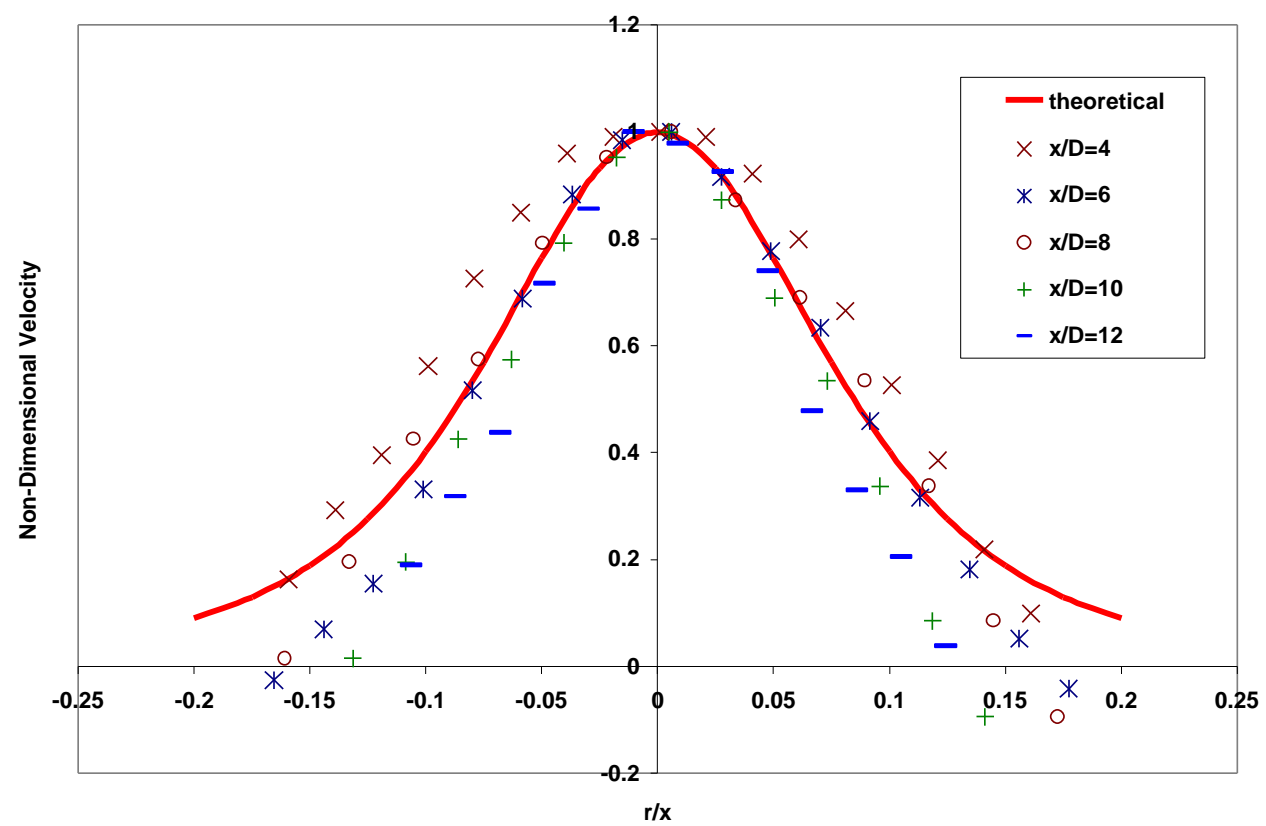

Figure 5.18 Axial velocity comparison to Görtler theory from White (1991)

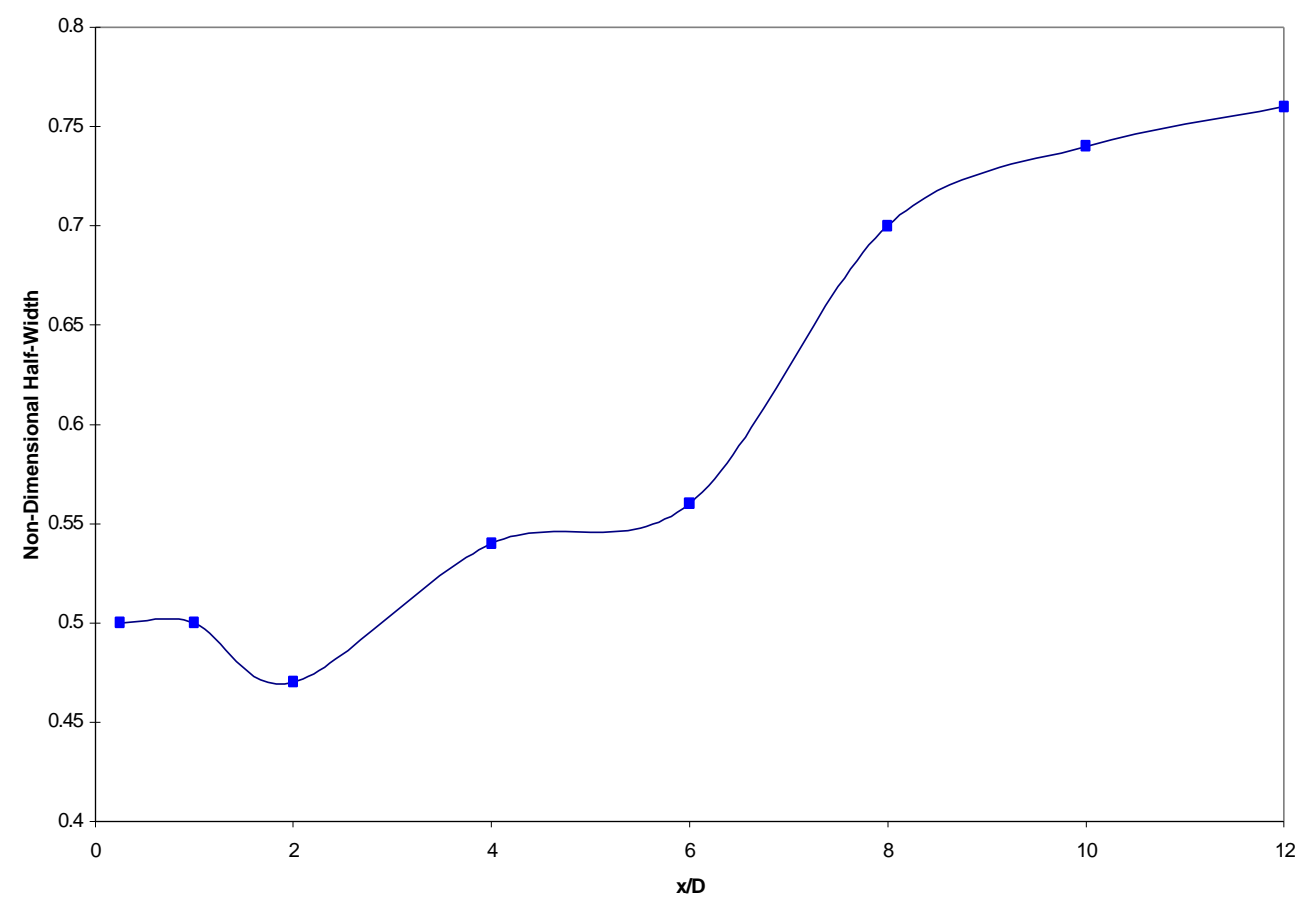

Figure 5.19 Circular jet half-width profile 


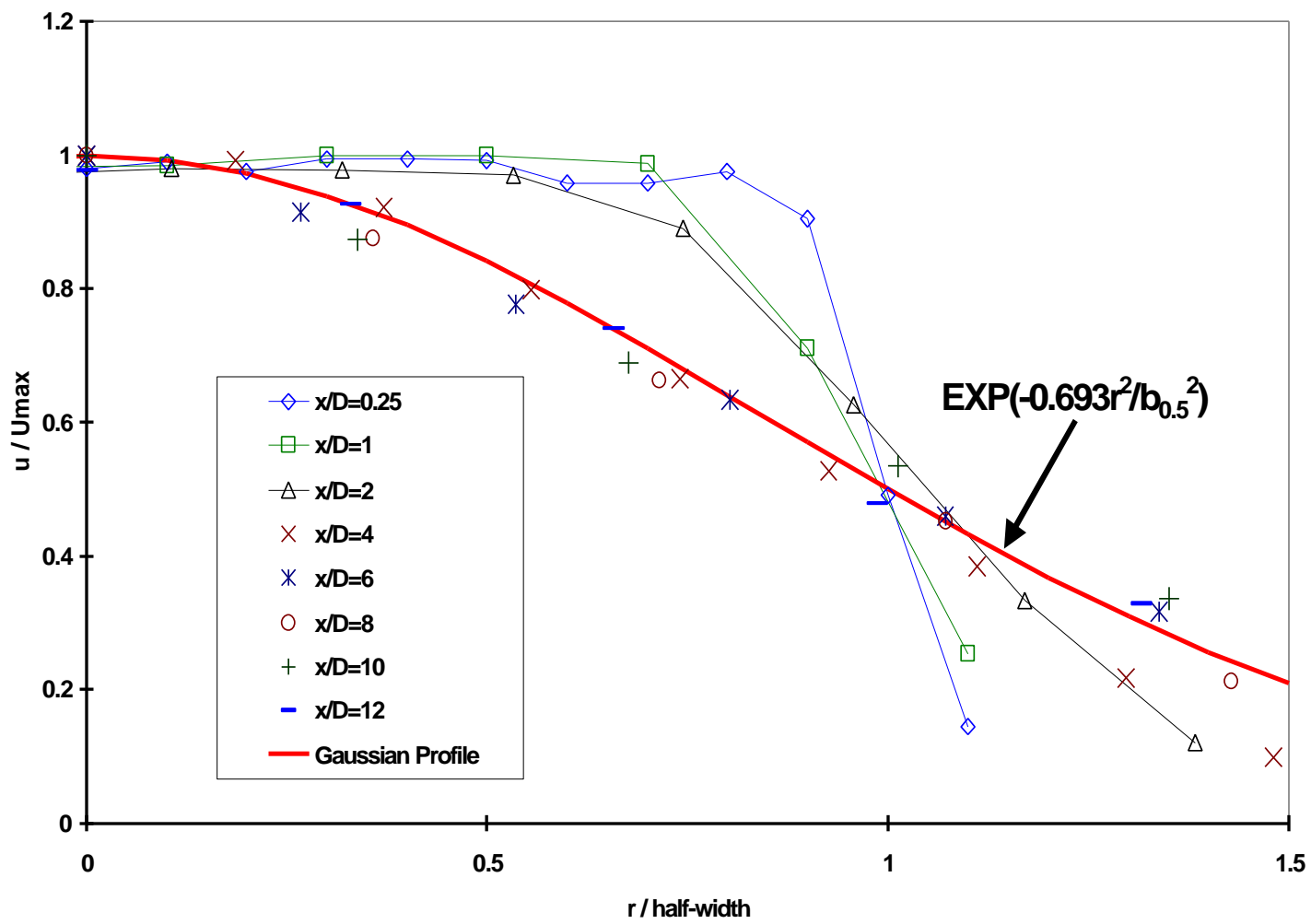

Figure 5.20 Axial velocity comparison to Gaussian profile from Kuhlman (1986) 